\title{
Ethics and Governance of Artificial Intelligence: Evidence from a Survey of Machine Learning Researchers
}

\author{
Baobao Zhang \\ Department of Government, Cornell University \\ Ithaca, NY 14853 USA \\ Markus Anderljung \\ Centre for the Governance of AI \\ Oxford, OX2 ODJ UK \\ Lauren Kahn \\ Perry World House, University of Pennsylvania \\ Philadelphia, PA 19104 USA
}

Noemi Dreksler

Centre for the Governance of AI

Oxford, OX2 0DJ UK

Michael C. Horowitz

Perry World House, University of Pennsylvania

Philadelphia, PA 19104 USA

Allan Dafoe

Centre for the Governance of AI

Oxford, OX2 ODJ UK
BAOBAOZHANGRESEARCH@GMAIL.COM

MARKUS.ANDERLJUNG@GOVERNANCE.AI

LAKAHN@UPENN.EDU

NOEMIDREKSLER.RESEARCH@GMAIL.COM

HOROM@SAS.UPENN.EDU

ALLAN.DAFOE@GOVERNANCE.AI

\begin{abstract}
Machine learning (ML) and artificial intelligence (AI) researchers play an important role in the ethics and governance of AI, including through their work, advocacy, and choice of employment. Nevertheless, this influential group's attitudes are not well understood, undermining our ability to discern consensuses or disagreements between AI/ML researchers. To examine these researchers' views, we conducted a survey of those who published in two top AI/ML conferences $(N=524)$. We compare these results with those from a 2016 survey of AI/ML researchers (Grace et al., 2018) and a 2018 survey of the US public (Zhang \& Dafoe, 2020). We find that AI/ML researchers place high levels of trust in international organizations and scientific organizations to shape the development and use of AI in the public interest; moderate trust in most Western tech companies; and low trust in national militaries, Chinese tech companies, and Facebook. While the respondents were overwhelmingly opposed to AI/ML researchers working on lethal autonomous weapons, they are less opposed to researchers working on other military applications of AI, particularly logistics algorithms. A strong majority of respondents think that AI safety research should be prioritized and that ML institutions should conduct pre-publication review to assess potential harms. Being closer to the technology itself, AI/ML researchers are well placed to highlight new risks and develop technical solutions, so this novel attempt to measure their attitudes has broad relevance. The findings should help to improve how researchers, private sector executives, and policymakers think about regulations, governance frameworks, guiding principles, and national and international governance strategies for AI.
\end{abstract}




\section{Introduction}

Tech companies and governments alike see the potential for artificial intelligence (AI) and have moved to develop machine learning (ML), particularly deep learning, applications across a variety of sectors - from healthcare to national security (Kanaan, 2020; Horowitz, 2018). Civil society groups, governments, and academic researchers have expressed concerns about AI related to safety (Amodei et al., 2016; Russell, 2019), discrimination and racial bias (Noble, 2018; Barocas et al., 2019), and risks associated with uses of AI in a military and government context (Brundage et al., 2018; Horowitz, 2019; Zwetsloot \& Dafoe, 2019).

"Narrow" AI applications (such as self-driving cars, lethal autonomous weapons systems, and surveillance systems) have become an immediate cause for concern for AI/ML researchers, policymakers, and the public (Hoff \& Bashir, 2015). Over the past few years, corporations, governments, civil society groups, and multi-stakeholder organizations have published dozens of high-level AI ethics principles (Fjeld et al., 2020). Some early attempts at international governance include the OECD AI Principles adopted in May 2019 and the G20 Human-centered AI Principles adopted in June 2019 (The OECD Council on Artificial Intelligence, 2019; G20, 2019).

Technical researchers have a crucial role to play in the formation of AI governance, that is the formation of "[t]he global norms, policies, and institutions needed to best ensure the beneficial development and use of ... AI" (Dafoe, 2018). Being close to the technology, AI/ML researchers are well placed to highlight new risks, develop technical solutions, and choose to work for organizations that align with their values. Just as epistemic communities have developed norms to manage technologies that emerged in the 20th century, such as nuclear weapons and chlorofluorocarbons (Adler, 1992; Haas, 1992b, 1992a), we expect $\mathrm{AI} / \mathrm{ML}$ researchers to play a key role in AI governance. For example, the Institute for Electrical and Electronics Engineers (IEEE) established the Global Initiative on Ethics of Autonomous and Intelligent Systems in 2016. Leading tech companies such as IBM, Google, and Microsoft have published frameworks and principles intended to guide how they deploy AI systems, and in several cases, have established research positions and units focused on AI ethics (Butcher \& Beridze, 2019). Individuals working within the AI/ML community have also begun to take an active role in directly shaping the societal and ethical implications of AI, by engaging with employers and governments (Belfield, 2020). For example, in 2018, over 3,000 Google employees signed a petition protesting Google's involvement with Project Maven, a computer vision project run by the US Department of Defense (Wakabayashi \& Shane, 2018).

To better understand the attitudes of this critical community, which will impact future AI governance, we explore technical experts' attitudes about the governance of AI. We surveyed $524 \mathrm{AI} / \mathrm{ML}$ researchers in September and October 2019 who had a paper accepted at one of two leading AI research conferences: the Conference on Neural Information Processing Systems (NeurIPS) and the International Conference on Machine Learning (ICML). Our survey includes direct measures of trust, including attitudes about private and public sector actors. We then compare those results to a 2018 survey of AI attitudes among the US general public. This study allows us to analyze attitudes on the current state of global AI governance: who are the most trusted actors to manage the technology, what AI governance challenges are perceived to be the most important, and which norms have already begun to 
shape AI development and deployment. Though there are limitations to our sample (e.g., not being fully representative of the AI research community), as described below, the scope and expert character of the pool allows us to contribute to the literature.

There is a small but growing literature that surveys the AI/ML community. Most existing surveys focus on eliciting researcher forecasts on AI progress, such as when specific milestones will be reached or when AI will surpass human performance at nearly all tasks (Sandberg \& Bostrom, 2011; Baum et al., 2011; Müller \& Bostrom, 2016; Grace et al., 2018; Walsh, 2018; Gruetzemacher et al., 2020). Others have focused on how computer scientists define AI (Krafft et al., 2020) or the impact of AI on society (Anderson et al., 2018). AI/ML professionals have also been surveyed in regard to their views on working on military-related projects (Aiken et al., 2020b) and their immigration pathways and intentions (Aiken et al., 2020a; Zwetsloot et al., 2021). Several studies have examined public opinion toward AI. Past survey research related to AI tends to focus on specific governance challenges, such as lethal autonomous weapons (Horowitz, 2016), algorithmic fairness (Saxena et al., 2019), or facial recognition technology (Smith, 2019; Ada Lovelace Institute, 2019). A few largescale surveys have taken a more comprehensive approach by asking about a range of AI governance challenges (Eurobarometer, 2017; Smith \& Anderson, 2016; Smith, 2018; West, 2018; Cave et al., 2019; Eurobarometer, 2019; Zhang \& Dafoe, 2020; European Commission, 2020; Balaram et al., 2018). While previous work has compared the public's and AI/ML researchers' forecast of AI development timelines (Walsh, 2018; Zhang \& Dafoe, 2019), little work compares the attitudes of AI/ML researchers and the public toward AI governance.

Key results from our survey include:

- Relative to the American public, AI/ML researchers place high levels of trust in international organizations (e.g., the UN, EU, etc.) to shape the development and use of AI in the public interest. While the American public rated the US military as one of the most trustworthy actors, AI/ML researchers place relatively low levels of trust in the militaries of countries where they do research.

- The majority of AI/ML researchers (68\%) indicate that AI safety, broadly defined, should be prioritized more than it is presently.

- Researchers reveal nuanced views about the appropriate sharing of research. While most researchers believe that "researchers should be encouraged to share" all aspects of research, there is considerable variation among the aspects of research that they feel "must be shared every time": $84 \%$ think that high-level description of the methods must be shared every time while only $22 \%$ think that of the trained model. Further, a majority of AI/ML researchers (59\%) support "pre-publication review" for "work that has some chance of adverse impact."

- The respondents are wary of AI/ML researchers working on certain military applications of AI. Respondents are the most opposed to other researchers working on lethal autonomous weapons ( $58 \%$ strongly oppose) but far fewer are opposed to others working on logistics algorithms (6\% strongly oppose) for the military. $31 \%$ of researchers indicate that they would resign or threaten to resign from their jobs, and $25 \%$ indicate that they would speak out publicly to the media or online, if their organization decided to work on lethal autonomous weapons. 


\section{Methods}

To study attitudes about trust and governance in AI, we conducted a survey of $\mathrm{AI} / \mathrm{ML}$ researchers between September 16 and October 13, 2019. The researchers were selected based on having papers accepted at two top AI research conferences, following the sampling frame of Grace et al. (2018). One group of respondents had papers accepted to the 2018 NeurIPS conference and the other to the 2018 ICML conference. Another group had papers accepted at NeurIPS and ICML in 2015 and participated in a 2016 researcher survey on AI (Grace et al., 2018). We chose the sample to match that of Grace et al. (2018), which chose ICML and NeurIPS as they were the two largest, widely cited, and general conferences (Zhang et al., 2021). The sample may skew toward ML researchers as opposed to AI researchers more broadly and toward those doing theoretical rather than applied research.

Out of the 3,030 researchers who were contacted via email to complete our survey, 524 researchers $(17 \%)$ completed at least some part of the survey. To incentivize participation, we offered one in every ten respondents (via lottery) a gift card of $\$ 250$ USD. The survey took a median 17.4 minutes to complete.

This paper presents the results from the component of the survey focused on AI governance. Other parts of the survey asked the respondents to forecast developments in AI research (manuscript in preparation) and about their preferences regarding country of work (Zwetsloot et al., 2021). The full text of the survey questions reported in this paper can be found in the Appendix. We also collected relevant demographic data about the respondents (e.g., country of their undergraduate degree, workplace type, citation count) using publicly available information. For some questions, we compare responses from this survey with those from the US public. This public opinion data come from a representative national survey of 2,000 US adults conducted in 2018, in which similar questions were asked (Zhang \& Dafoe, 2020). ${ }^{1}$

Our analysis is pre-registered using the Open Science Framework. ${ }^{2}$ Unless otherwise specified, we use multiple linear regression to analyze the associations between variables. For estimates of summary statistics or coefficients, "don't know" or missing responses were re-coded to the weighted overall mean, unconditional on treatment conditions. Almost all questions had a "don't know" option. If more than $10 \%$ of the variable's values were "don't know" or missing, we included a (standardized) dummy variable for "don't know" / missing in the analysis. For survey experiment questions, we compared "don't know" / missing rates across experimental conditions. Our decision was informed by the Standard Operating Procedures for Donald Green's Lab at Columbia University (Lin \& Green, 2016).

Heteroscedasticity-consistent standard errors were used to generate the margins of error at the $95 \%$ confidence level. We report cluster-robust standard errors whenever there is clustering by respondent. In figures, each error bar shows the $95 \%$ confidence intervals.

While our sample is more extensive than previous research, it has clear limits. Our sample strategy focused on those who publish in the top two AI/ML conferences; it thus may underweight the perspective of those subgroups of the AI/ML community who are less likely to publish there, such as product-focused industry researchers. Moreover, these

1. For the public opinion results, we weighted the responses to be representative of the US adult population using weights provided to us by the survey firm YouGov that conducted the survey on our behalf.

2. The project URL is https://osf.io/fqz82/. 
conferences emphasize ML, meaning they may under-represent other approaches to AI. Second, this survey captures the views of the researchers at a particular point in time, while the norms around AI research and publishing continue to evolve, and significant shifts in the psychological, political, and socioeconomic landscape continue to occur, for example, as a result of COVID-19. Future work could expand the sampling frame of respondents (e.g., to include more researchers who work in industry or to develop a more representative sample of the $\mathrm{AI} / \mathrm{ML}$ community) and include panel studies that examine changes in respondents' attitudes over time.

Another limitation might include demographic biases or response bias. Demographic characteristics of the respondents and non-respondents are found in Table $\mathrm{S}^{3}$. A multiple regression that examines the association between demographic characteristics and response finds that respondents have lower h-indexes (a measure of productivity and citation impact of researchers) and are more likely to work in academia compared with non-respondents (see Table S2). Overall, however, we do not see evidence of concerning levels of response bias. Compared with other work of its kind, our survey has more respondents, a higher response rate, and more global coverage than other surveys of AI/ML researchers we reviewed. Separately from response bias, there are other aspects of the population of AI/ML researchers worth keeping in mind, such as gender (91\% of our respondents and $89 \%$ of non-respondents were male, reflecting the low gender diversity of the field itself).

\section{Results}

Our results section proceeds by evaluating AI governance challenges, trust in different actors who develop and use AI, AI safety, AI publication norms, and military applications of AI.

\subsection{Evaluation of AI Governance Challenges}

To gauge their views on AI governance challenges, we asked our respondents: "In the next 10 years, how important is it for tech companies and governments to carefully manage the following issues?" Respondents were presented with a list of five randomly selected items out of a list of 13 , that they then assigned a number value on a four-point slider scale that allowed value input to the tenth decimal place. The scale ranged from 0 "not at all important" to 3 "very important." 4

Figure 1 shows the mean importance of AI governance challenges, along with the corresponding $95 \%$ confidence interval for both AI/ML researchers and the general public (Zhang $\&$ Dafoe, 2020). For the AI/ML researcher group, almost all issues were rated as having a mean importance of around 2.5, between "somewhat important" and "very important," with the top five issues including preventing criminal justice bias, ensuring autonomous vehicles are safe, preventing critical AI system failure, protecting data privacy, and preventing mass surveillance. Hiring bias and technological unemployment are rated slightly (about 0.3 points) lower than other issues. The one outlier is "Reducing risks from US-China competition over AI," rated significantly below the other challenges at 1.8 (just below "somewhat important"); this result may be an artifact of our question phrasing, in that AI/ML re-

3. Supplementary tables and figures labelled with an "S" can be found in the Appendix.

4. All the multiple-choice questions include an "I don't know" answer option. 
Zhang, Anderluung, Kahn, Dreksler, Horowitz \& Dafoe

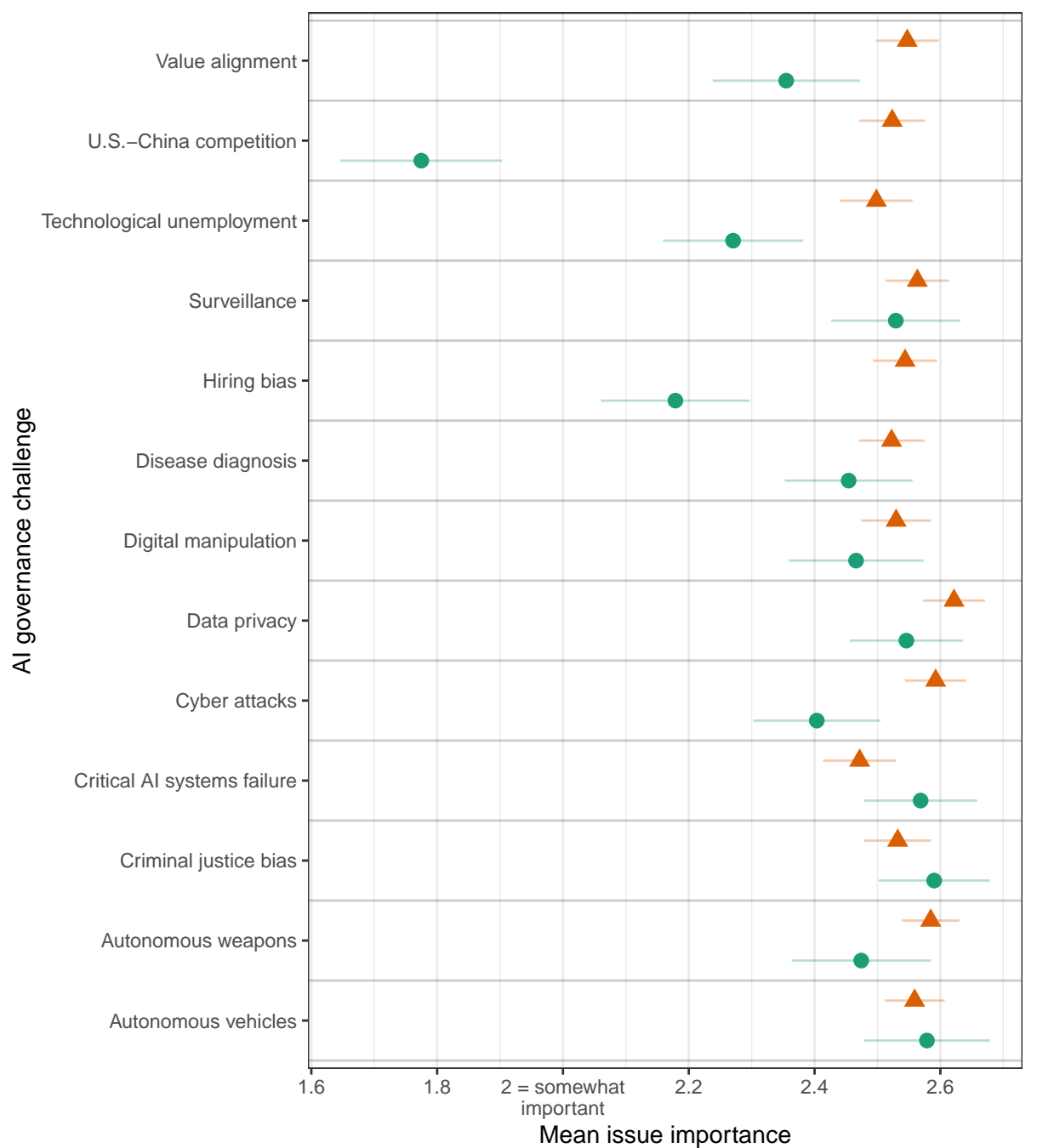

(4-point scale: 0 = not important at all; 3 = very important)

$\mathrm{Al} / \mathrm{ML}$ researchers $A$ US public

Figure 1: Perception of "how important it is for tech companies and governments to carefully manage" AI governance challenges. We compare AI/ML researchers' and the US public's responses. Each respondent was presented with five AI governance challenges randomly selected from a list of 13. Respondents were asked to evaluate the importance of each governance challenge using a fourpoint scale (the slider scale allows respondents to input values to the tenth decimal point): $0=$ not important, 1 = not too important, 2 = somewhat important, $3=$ very important. We present the mean responses for each governance challenge (by respondent type) along with the corresponding 95\% confidence intervals. 
searchers may believe that risks from US-China competition are real, but not one that is helped by "tech companies and governments" trying to "carefully manage" them (see the Appendix for the text of the survey questions). As Table S9 shows, AI/ML researchers who identified as male, compared with those who identify as female or other, gave lower issue importance scores across the board.

There is considerable overlap between the assessment of AI governance challenges by AI/ML researchers and the US public (for details, see Table S3). Both groups rate protecting data privacy, preventing mass surveillance, and ensuring that autonomous vehicles are safe among the five most important governance challenges. AI/ML researchers placed significantly less importance on value alignment ${ }^{5}$, technological unemployment, and hiring bias, and slightly more importance on critical AI systems failure, criminal justice bias, and autonomous vehicles, than the public.

The gap between AI/ML researchers and the US public is particularly large when it comes to preventing the risks from US-China competition in AI. This is an important topic given that the two countries are home to most investment in AI (Savage, 2020). In contrast to AI/ML researchers' relatively low mean rating of 1.77 out of 3 , the US public gave USChina competition a mean rating of 2.52 out of 3 . One might think that breaking down the AI/ML researchers' responses by demographic subgroups (see Figure S2 - S4) would reveal some potential explanations for the response pattern. However, the results are mixed. Respondents who attended undergraduate school in China rated this issue relatively high (mean score of 2.26); in contrast, respondents who attended undergraduate school in Europe gave a mean score of only 1.59. While respondents who attended undergraduate school in the US gave a mean score of 1.90 , the difference is not statistically significantly different from respondents with undergraduate degrees from China.

\subsection{Trust in Actors to Shape the Development and Use of AI in the Public Interest}

Good governance benefits from understanding what institutions and organizations AI/ML researchers (and other stakeholders) trust. To test AI/ML researcher trust in different organizations and institutions, we ask: "Suppose the following organizations were in a position to strongly shape the development and use of advanced AI. How much trust do you have in each of these organizations to do so in the best interests of the public?" ${ }^{6}$ Similar to the structure of the previous question, respondents were shown five randomly selected

5. Defined as "AI systems are safe, trustworthy, and aligned with human values."

6. A large number of multi-dimensional models of the construct of trust exist in the literature (Lankton \& McKnight, 2008; McEvily \& Tortoriello, 2011; PytlikZillig et al., 2016). Some common factors across models of trust have included dimensions along the lines of capability, reliability, and benevolence (Lankton \& McKnight, 2008; Mayer et al., 1995). Much of the technology and AI trust literature has focused on trust in the technology itself. Institutional trust is a commonly measured construct in the political and social sciences that may well be worth probing further when researching AI ethics and governance. Indeed, Knowles and Richards (2021) have called for more focused research on public trust in AI as an institutional ecosystem, rather than trust in discrete technologies. Here we hoped to probe the trust people held in individual institutions and organizations to act benevolently and with integrity (i.e. "in the best interests of the public"). This was conditioned on the institution or organization being assumed to be capable of shaping the development and use of AI. 
actors. For each actor, they then assigned a number value on a four-point scale ranging from 0 "no trust at all" to 3 "a great deal of trust." 7

Figure 2 shows the mean trust value for the actors, along with the corresponding $95 \%$ confidence interval for both AI/ML researchers and the public. For AI/ML researchers, the most trusted actors, with a mean score above 2, were non-governmental scientific associations and intergovernmental research organizations. The Partnership on AI, a consortium of tech companies, academics, and civil society groups, is also rated relatively highly (mean score of 1.89). Among the international actors, the European Union (EU) ${ }^{8}$ is perceived to be more trusted than the United Nations (UN); the former has a mean rating of 1.98 while the latter has a lower mean rating at 1.74 (two-sided $p=0.010$ ). ${ }^{9}$ It is noteworthy that these more neutral, scientific organizations received the highest trust ratings but currently play a relatively small role in AI development and management.

Out of all the private tech companies listed, ${ }^{10}$ OpenAI, ${ }^{11}$ DeepMind, Google, and Microsoft are relatively more trusted. Facebook is ranked the least trustworthy of American tech companies, and the Chinese companies were rated significantly less trustworthy than all listed US tech companies apart from Facebook. State actors, such as the US and Chinese governments or the militaries of the countries where the respondents do research, received relatively low trust scores from $\mathrm{AI} / \mathrm{ML}$ researchers. In general, respondents trust the government of the country where they do research more than the military of that country (two-sided $p<0.001$ ).

As Figure S6 shows, respondents who attended undergraduate school in the US, compared with those who attended undergraduate school in China, are significantly less trustful of the Chinese government and military, as well as the three Chinese tech companies presented to respondents (Tencent, Baidu, and Alibaba). The interaction plot in Figure S10 shows that those who attended undergraduate school in China trust both Chinese tech companies and Western tech companies more than those who attended undergraduate school in the US. The difference in trust in Western versus Chinese tech companies is smaller for those who attended undergraduate school in China than those who attended undergraduate school in the US (two-sided $p<0.001$ ), as shown in Figure S10.

$\mathrm{AI} / \mathrm{ML}$ researchers, like the US public, as Figure 2 shows, distrust Facebook more than any other US tech company. A major difference between AI/ML researchers and the US

7. The US military and the Chinese military were shown only to respondents who reported the US or China as the countries where they spend the most time doing research. These respondents had equal probability of being shown the US military or the Chinese military. Because very few responses came from respondents who do research in China, we dropped their responses in this figure. We break down responses to these two actors by the country where the respondents completed their undergraduate degree (the US and China) in Figure S6.

8. The term European Union (EU) in the survey was designed to refer to the EU government and/or relevant institutions, such as universities, contained within its borders.

9. For comparing trust between actors, we use $F$-tests to test the equality of coefficients from the regression model presented in Table S16.

10. We asked about all the private tech companies included in Zhang and Dafoe (2020). The companies included OpenAI, which was used as an example of a non-profit entity in the 2018 public opinion survey. See the next footnote regarding how OpenAI's status changed. We also added three leading Chinese AI companies in consultation with experts on the Chinese AI industry.

11. OpenAI announced in March 2019 that it would move from being a non-profit organization to being a "capped-profit" company, a for-profit and non-profit hybrid (OpenAI LP, 2019). The survey of the public was conducted before this change, while the survey of AI/ML researchers occurred afterward. 
Ethics and Governance of Artificial Intelligence

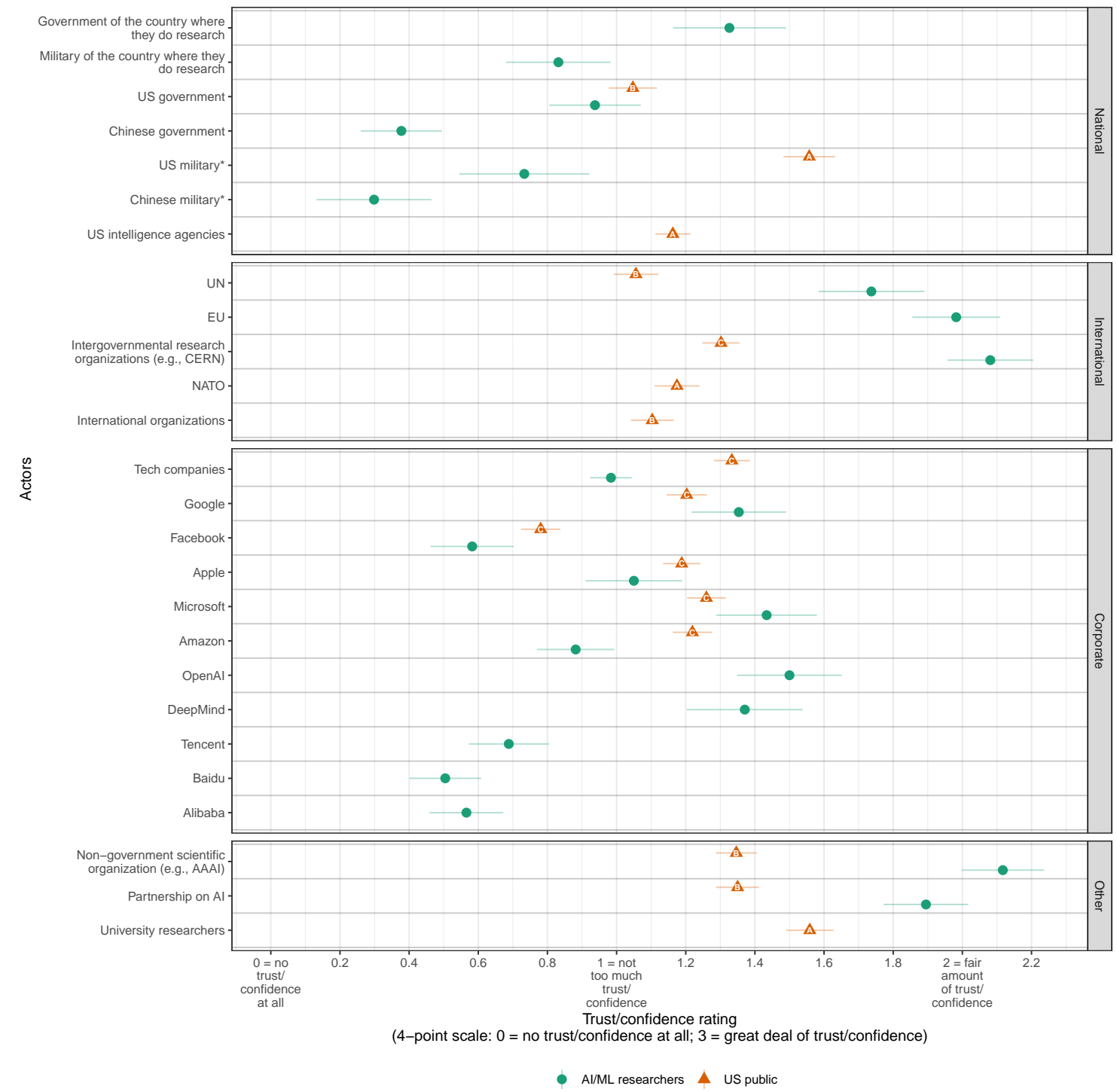

Figure 2: Trust in actors to shape the development and use of AI in the public interest: comparing $A I / M L$ researchers' and the US public's responses. AI/ML researchers were shown five randomly selected actors and asked to evaluate how much they trust the actors using a four-point scale: 0 $=$ no trust at all, 1 = not too much trust, $2=$ a fair amount of trust, $3=$ a great deal of trust. For the AI/ML researchers survey, the "Tech companies" result is the mean response across all corporate actors presented to respondents. *: The US military and the Chinese military responses are only for those who do research in the US. See Figure S6 - S9 for a further breakdown of this question by respondents' background. In the public opinion survey, respondents were asked about their confidence in the actors to develop AI (labeled " $A$ "), or to manage the development and use of AI (labeled "B") in the best interest of the public, using a similar four-point scale. For actors labeled " $C$," both questions were asked; we averaged the responses to these two questions for each of these actors for clarity. For "US intelligence agencies," we averaged across responses to the NSA, the FBI, and the CIA (which were similar). The circle and triangle shapes are the point estimates (mean responses) and the whiskers are the corresponding 95\% confidence intervals. The data for this figure, alongside more detailed breakdowns of the results, can be found in Tables S10 - S15. 
public is their assessment of the military. Whereas surveyed AI/ML researchers, on average, do not have too much trust in the military of the countries where they do research, the US military is among the most trusted of institutions for the US public. There is also a large difference in opinion between AI/ML researchers who do research in the US and the US public. AI/ML researchers who do research in the US gave the US military a mean rating of 0.73 (below 1 "not too much trust"), whereas the US public gave their country's military a mean rating of 1.56 (see Tables S10 - S11 and S15). ${ }^{12}$

In contrast, compared with $\mathrm{AI} / \mathrm{ML}$ researchers, the US public places much less trust in international institutions such as the UN. AI/ML researchers gave the UN a mean rating of 1.74 , while the US public gave a mean rating of 1.06 .

\subsection{AI Safety}

The safety of AI systems may be a critical factor in their development and adoption. We asked respondents about their familiarity with and prioritization of AI safety. We described AI safety in a broad way, as focused on "making AI systems more robust, more trustworthy, and better at behaving in accordance with the operator's intentions," and also provided examples (see the Appendix). We first sought to understand how familiar researchers were with AI safety research. We asked them to make a self-assessment using a five-point scale, ranging from 0 "not familiar at all (first time hearing of the concept)" to 4 "very familiar (worked on the topic)." To evaluate views about the value of AI safety research, we asked respondents, "How much should AI safety be prioritized relative to today?" Respondents selected answers on a five-point Likert scale, ranging from -2 "much less" to 2 "much more" with 0 meaning "about the same."

The AI/ML researchers we surveyed report, on average, moderate familiarity with AI safety as a concept (see Figure S11). The distribution follows an approximately normal distribution, although it is right-skewed. $3 \%$ of respondents say that they are "not familiar at all" with AI safety while $15 \%$ say they are "very familiar."

When asked about prioritizing AI safety, as Figure S13 shows, an overwhelming majority of our respondents $(68 \%)$ say that the field should be prioritized more than at present. These results demonstrate significant growth in the reported prioritization of AI safety in the research community, though different definitions may have caused these differences. In a similar survey of AI/ML researchers conducted in 2016, $49 \%$ of respondents believed that AI safety should be prioritized more than it was at the time (Grace et al., 2018). ${ }^{13}$

12. One potential reason that the US public places so much trust in the US military to manage and develop AI is that the institution is one of the most trusted by US adults. $83 \%$ of US adults indicate that they have "a great deal" or "fair amount" of confidence in the US military to act in the best interest of the public (Rainie et al., 2019).

13. We updated the definition of AI safety research from Grace et al. (2018) after consultation with AI/ML researchers working in AI safety research.

Contrasting with our definition (see the Appendix), the 2016 definition of AI safety was "any AIrelated research that, rather than being primarily aimed at improving the capabilities of AI systems, is instead primarily aimed at minimizing potential risks of AI systems (beyond what is already accomplished for those goals by increasing AI system capabilities)." The examples provided in 2016 included: improving the human-interpretability of machine learning algorithms to improve the safety and robustness of AI systems, not focused on improving AI capabilities; research on long-term existential risks 


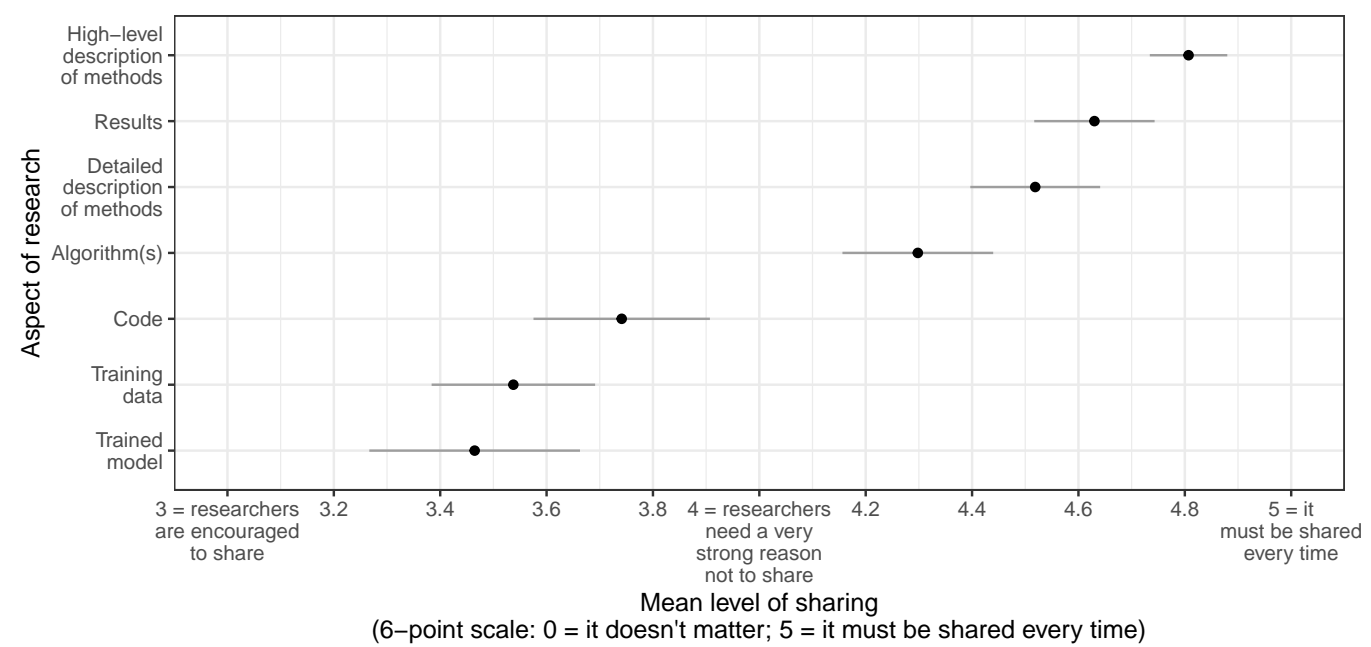

Figure 3: Respondents' perceptions of how openly various aspects of research should be shared. Respondents were presented with three aspects of research, randomly selected from seven. They were asked how openly these aspects of research should be shared using a six-point scale: $0=i t$ doesn't matter, 1 = it's completely up to the researchers to share or not to share, $2=i t$ 's preferred that researchers share but it's not paramount that they do, $3=$ researchers are encouraged to share, $4=$ researchers need a very strong reason not to share, $5=$ it must be shared every time. We show the results (mean response and 95\% confidence intervals) for all respondents.

\subsection{Publication Norms}

The AI/ML research community has recently seen innovation and subsequent controversy regarding publication norms, which also relate to questions of trust. Such norms concern when, how, and where research is published. OpenAI's release strategy for GPT-2, a large language model, is a prime example. Citing concerns the system could be used for "malicious purposes", they employed a staged release strategy; the initial paper was accompanied by a smaller version of GPT-2, the full model only being released eight months later (Solaiman et al., 2019). NeurIPS introduced further innovation, for the first time requiring researchers to submit impact statements along with their papers to the 2020 conference (Lin et al., 2020; Ashurst et al., 2020). The conference also employed a form of pre-publication review, rejecting four papers on ethical grounds after reviews from ethics advisors.

We asked questions to generate insights into $\mathrm{AI} / \mathrm{ML}$ researchers' views on publication norms. First, we assessed how much they agree or disagree that "machine learning research institutions (including firms, governments, and universities) should practice pre-publication review," which involves "a strong norm or policy" to have discussions that are "informed, substantive, and serious" about "the ethical implications of publication" (see the Appendix for the text of the survey).

A majority of respondents agree (20\% strongly agree; $39 \%$ somewhat agree) with the statement (see Table S28). Additionally, as shown in Table S30, both familiarity with AI safety and prioritization of AI safety significantly predict support for pre-publication review.

from AI systems; AI-specific formal verification research; and policy research about how to maximize the public benefits of AI. 
These results speak to interest amongst AI/ML researchers to address the risks of misuse of their work.

Next, we asked respondents about the importance of sharing various aspects of $\mathrm{AI} / \mathrm{ML}$ research. Respondents were shown three aspects of research, randomly selected from a list of seven (e.g., high-level description of methods, code, and training data). For each aspect of research, respondents could select from six levels of sharing, ranging from "it doesn't matter" to "it must be shared every time."

As Figure 3 shows, the respondents think that high-level descriptions of the methods, the results, and a detailed description of the methods should almost always be openly shared. However, support declines for requiring the sharing of other information that would be essential for replication, such as the code, the training data, or the trained model. Researchers felt that sharing these aspects of research should be encouraged but not required. On the high end, $84 \%$ indicated that high-level description of methods must be shared every time; on the low end, only $22 \%$ indicated that the trained model must be shared every time (see Figure S18). We do not find significant differences in responses between researchers who work in academia versus in industry.

\subsection{Attitudes Toward Military Applications of AI}

We also investigated researchers' views toward military applications of AI. Working on military uses of AI requires a great deal of trust in how they might be used, given the central role that some think AI could play in the future of military power (Scharre, 2018). We asked about three areas of military applications of AI that have received public scrutiny: lethal autonomous weapon systems, surveillance technologies for intelligence agencies, and military logistics. Respondents were asked to evaluate two randomly selected military applications out of the three. They were asked whether they would support or oppose researchers working on the application in the country where the respondent currently works or studies. Respondents selected answers on a Likert scale, ranging from -2 "strongly oppose" to 2 "strongly support." Those who answered that they "strongly oppose" or "somewhat oppose" researchers working on the applications were asked what types of collective actions (e.g., signing a petition or protesting) they would take if their organization decided to conduct such research.

Our results show researchers have substantial concerns regarding working on some military applications of AI. Nevertheless, there are nuances to their views. Figure 4 illustrates that researchers, on average, more than somewhat oppose work on lethal autonomous weapon systems $(-1.3)$, very weakly oppose work on surveillance applications (-0.3), and very weakly support work on logistics applications (0.5). Additional detail in Figure S15 demonstrates that $58 \%$ strongly oppose other researchers working on lethal autonomous weapons, $20 \%$ strongly oppose others working on surveillance tools, but only $6 \%$ strongly oppose others working on military logistics. This is consistent with work by Aiken, Kagan, and Page (2020b), which focuses just on US-based AI professionals and finds that US-based AI professionals are more opposed to working on battlefield applications of AI than other applications. 


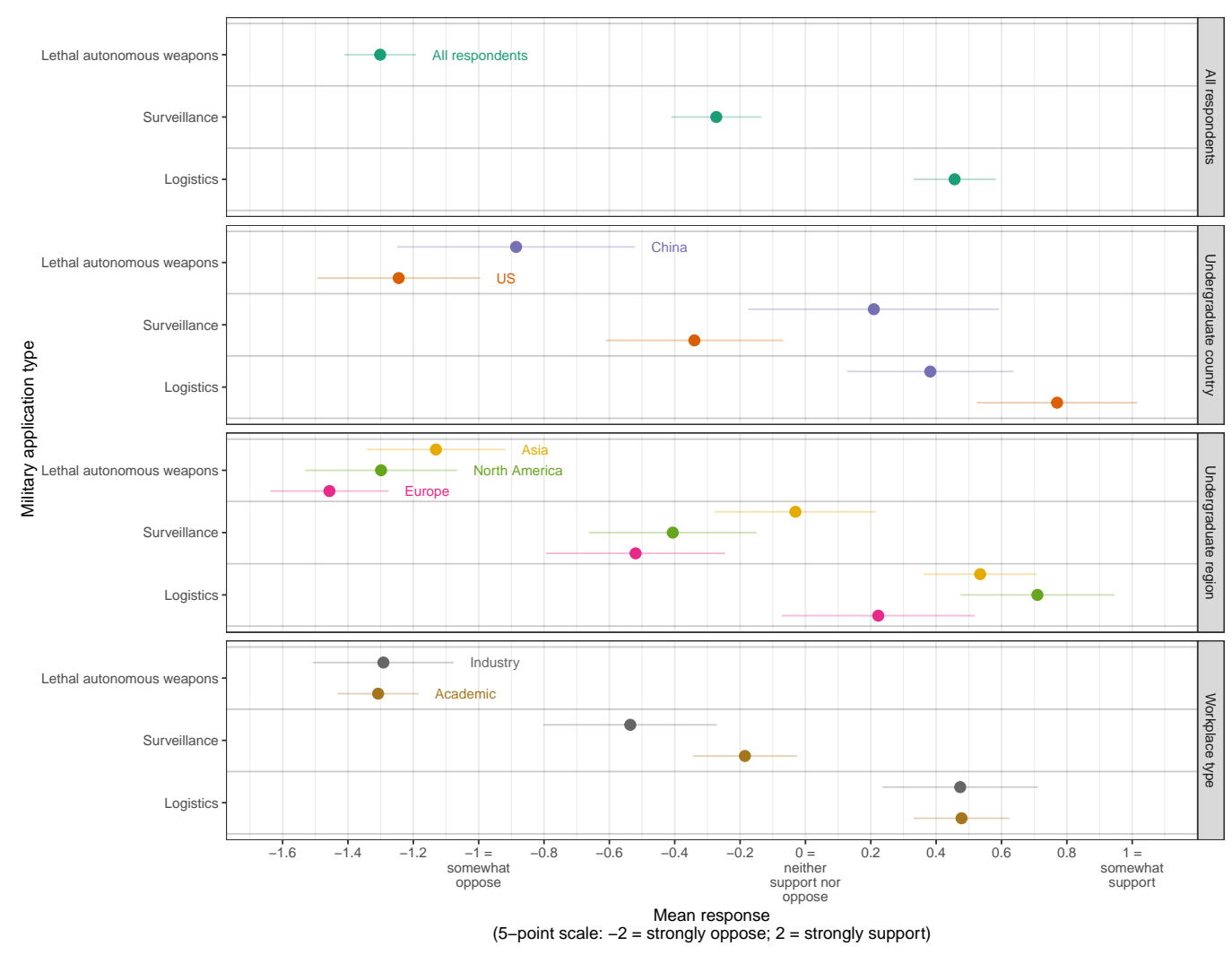

Figure 4: Attitudes toward researchers working on military applications of AI. Respondents were presented with two applications randomly selected from the three and indicated how much they support or oppose other researchers working on those applications using a five-point scale: $-2=$ strongly oppose, $-1=$ somewhat oppose, $0=$ neither support nor oppose, $1=$ somewhat support, $2=$ strongly support. We present the overall means and the demographic subgroup means with their corresponding 95\% confidence intervals. For the subgroup analysis, we broke down the responses by the respondents' undergraduate country, undergraduate region, and workplace type.

How would these AI/ML researcher attitudes translate into potential action? For each application (lethal autonomous weapon systems, surveillance, and logistics), the respondents who said they strongly or somewhat opposed other researchers working on the application received a follow-up question asking if they would take action if their organization decided to work on the application. Figure S16 shows the distribution of responses for each application. A majority of researchers who said they opposed others working on each application said they would actively avoid working on the project, express their concern to a superior in their organization involved in the decision, or sign a petition against the decision. $75 \%$ of researchers who said they opposed others working on lethal autonomous weapons said they would avoid working on lethal autonomous weapons themselves, and $42 \%$ of those respondents said they would resign or threaten to resign from their jobs. In absolute terms, $31 \%$ of researchers indicated that they would resign or threaten to resign from their jobs, and $25 \%$ indicated that they would speak out publicly to the media or online if their organization decided to work on lethal autonomous weapons. Of those who say they oppose other researchers working on lethal autonomous weapons, less than $1 \%$ said they would 
do nothing. The percentages for surveillance and logistical software are $3.5 \%$ and $7.5 \%$, respectively (for further results see Figure S16).

A major conflict between the AI/ML community and a national military involved Google engineers protesting their company's participation in Project Maven in the US. In 2018, some 3,000 Google employees signed a petition, voicing ethical concerns regarding the project (Deahl, 2018). Employees expressed concern that the project could be used for military targeting. As a result, Google decided not to renew its Project Maven contract with the US Department of Defense.

Given the controversy over Google's participation in Project Maven, we asked respondents if they supported or opposed Google's decision not to renew its contract using a five-point Likert scale with -2 meaning "strongly oppose" to 2 meaning "strongly support." Figure S17 details broad support within our AI/ML research respondents for Google's decision to withdraw from Project Maven. 38\% strongly support and 21\% support Google's decision to pull out of Project Maven while only 9\% strongly or somewhat oppose the decision.

The results are broadly consistent across demographic subgroups, as seen in Figure 4 above. Generally, across subgroups, respondents are the most opposed to working on lethal autonomous weapons and least opposed to working on military logistics.

\section{Conclusion}

It is important to recognize some of the limits to our findings referenced above, including the focus on important AI/ML conferences and demographic biases in our sample. Future surveys could address these issues and also expand the sample frame to include related researchers, such as AI ethics experts and social scientists who study the societal impact of AI. ${ }^{14}$ Nevertheless, the unique scope of the sample gives us the ability to speak to AI/ML research attitudes about AI governance in unique ways compared to previous literature.

As institutions, regulations, and norms of AI governance are forming, this survey of AI/ML researchers provides insight into how this emerging epistemic community views the ethical and governance issues related to the technology. The respondents place relatively high levels of trust in international organizations to manage the development and use of AI in the public interest. Researchers' trust some tech companies substantially more than others to develop and use AI in the public interest, a fact of potentially great relevance given the epistemic authority of AI researchers and the competition for AI talent. Compared with the US public who place high levels of trust in the US military, AI/ML researchers are relatively distrustful of the military. Furthermore, the AI/ML researchers we surveyed are opposed to working on lethal autonomous weapon systems in particular. Given their responses about publication norms, the respondents are also aware of the potential adverse impacts of their research. Finally, a majority of respondents think that AI safety research should be prioritized more and researchers should conduct pre-publication reviews to assess the potential harms their research could cause. This line of research could help guide policymakers, tech companies, civil society, and the AI/ML community in building and deploying safe and ethical AI systems.

14. This might also help address the gender bias in our sample. 


\section{Acknowledgments}

We want to thank Charlie Giattino, Emmie Hine, Tegan McCaslin, Kwan Yee Ng, and Catherine Peng for their research assistance. For helpful feedback and input, we want to thank: Catherine Aiken, Carolyn Ashurst, Miles Brundage, Rosie Campbell, Alexis Carlier, Jeff Ding, Owain Evans, Ben Garfinkel, Katja Grace, Ross Gruetzemacher, Jade Leung, Alex Lintz, Max Negele, Toby Shevlane, Brian Tse, Eva Vivalt, Waqar Zaidi, Remco Zwetsloot, our colleagues at our respective institutions, and our anonymous reviewers. We are also grateful for research support from the Center for Security and Emerging Technology at Georgetown University and the Berkeley Existential Risk Initiative.

Funding: This research was supported by: the Ethics and Governance of AI Fund, the Open Philanthropy Project grant for "Oxford University - Research on the Global Politics of AI," the Minerva Research Initiative under Grant \#FA9550-18-1-0194, and the CIFAR Azrieli Global Scholars Program. The research reported here should solely be attributed to the authors; all errors are the responsibilities of the authors.

Authors contributions: A.D., B.Z., M.A., and M.H. (in alphabetical order) designed the research and provided the conceptual framing of the work. B.Z. and M.A. handled the data acquisition. B.Z. and N.D. analyzed the data. A.D., B.Z., L.K., M.A., M.H., and N.D. wrote the paper.

Competing interests: The authors declare no competing interests.

Data and materials availability: Due to the data privacy promised to respondents and that our IRB applications noted that we would not share individual-level results, we cannot release the data in full. We made this decision because the population we are sampling from is a relatively small group of individuals, which increases the likelihood of respondents being identifiable from individual-level data. Instead, we have opted to report detailed breakdowns of the data by key demographics in the Appendix.

\section{Appendix A: Supplementary Materials}

The Appendix contains the following:

The Text of the Survey

The Demographics of the Survey Respondents

Figures S1 - S19

Tables S1 - S31

\section{Text of the Survey}

Unless specified, the order of the items or scales presented here is the order presented to respondents in the survey.

\section{AI GOVERNANCE CHALLENGES}

In the next 10 years, how important is it for tech companies and governments to carefully manage the following issues?

[Respondents were shown five randomly selected items.] 
- Ensure fairness and transparency in AI used in hiring

- Ensure fairness and transparency in AI used in criminal justice

- Make AI used for medical diagnosis accurate and transparent

- Protect data privacy

- Ensure that autonomous vehicles are safe

- Prevent AI from being used to spread fake and harmful content online

- Prevent AI cyber attacks against governments, companies, organizations, and individuals

- Prevent AI-assisted surveillance from violating privacy and civil liberties

- Reducing risks from US-China competition over AI

- Make sure AI systems are safe, trustworthy, and aligned with human values

- Develop treaties to prevent the misuse of lethal autonomous weapons

- Guarantee a good standard of living for those who lose their jobs to automation

- Prevent critical AI systems failures, such as a multi-day regional power outage or a trillion dollar market crash from automated algorithms

Answer choices: Slider that you can choose in between whole numbers (to 1 decimal point), marked

- 3 = Very important

- 2 = Somewhat important

- 1 = Not too important

- $0=$ Not at all important

- I don't know

\section{TRUST IN ACTORS}

Suppose that the following organizations were in a position to strongly shape the development and use of advanced AI. How much trust do you have in each of these organizations to do so in the best interests of the public?

[Respondents were shown five randomly selected actors.]

Included if the person does not work in the US:

- The government of $<$ COUNTRY WHERE THEY DO RESEARCH $>{ }^{15}$

15. Earlier in the survey, respondents were asked the following question: "In which country do you spend the most time doing research?". Respondents input the country from a drop-down menu. Those who did not input a country were assigned "the country where you do research" in questions that piped in the country where the respondent spent most of their time doing research. 
- The military of $<$ COUNTRY WHERE THEY DO RESEARCH $>$

Included if the person works in the US or China:

- The US military

- The Chinese military

To everyone else:

- The US government

- The Chinese government

- The United Nations (UN)

- The European Union (EU)

- An intergovernmental AI research organization (similar to CERN)

- Google

- Facebook

- Apple

- Microsoft

- Amazon

- OpenAI

- DeepMind

- Tencent

- Baidu

- Alibaba

- Non-governmental scientific organizations (e.g., AAAI)

- Partnership on AI, a consortium of tech companies, academics, and civil society groups Answer choices:

- A great deal of trust (3)

- A fair amount of trust (2)

- Not too much trust (1)

- No trust at all (0)

- I don't know 
AI SAFETY

AI SAFETY INTRODUCTION

AI safety research focuses on making AI systems more robust, more trustworthy, and better at behaving in accordance with the operator's intentions.

Examples of such AI safety research include:

- Making AI algorithms interpretable to humans

- Making sure that an AI system is robust to distributional shifts or adversarial inputs

- Making sure that an AI system's behavior aligns with the operator's true intentions

FAMiliarity With AI SAFETy RESEARCH

How familiar are you with AI safety research?

Use the slider to indicate your familiarity.

- 0 means not familiar at all (e.g., this is the first time you're hearing about the concept)

- 4 means very familiar (e.g., you have worked on the topic)

\section{PRIORITIZING AI SAFETY RESEARCH}

How much should AI safety research be prioritized - by, for instance, the tech industry, the academic field, and governments - relative to today?

Answer choices:

- Much less (-2)

- $\operatorname{Less}(-1)$

- About the same (0)

- More (1)

- Much more (2)

- I don't know

AtTitudes toward MiLitary APplications of AI

SUPPORT FOR OTHERS AND THEMSELVES RESEARCHING MILITARY TECHNOLOGY

[Respondents were shown two out of the three applications below; the order that the two questions were shown appear were randomized.]

Do you support or oppose researchers in <COUNTRY WHERE THEY DO RESEARCH> working on the development of lethal autonomous weapons to be used by the military of $<$ COUNTRY WHERE THEY DO RESEARCH $>$ ? 
Lethal autonomous weapons are systems that, once activated by a human, are capable of targeting and firing on their own.

Do you support or oppose researchers in <COUNTRY WHERE THEY DO RESEARCH > working on the development of surveillance technologies to be used by intelligence agencies of $<$ COUNTRY WHERE THEY DO RESEARCH $>$ ?

Intelligence agencies could use AI to expand their capacity to analyze image, video, sound, and text data.

Do you support or oppose researchers in <COUNTRY WHERE THEY DO RESEARCH > working on the development of logistics algorithms to optimize storage and transportation for the military of <COUNTRY WHERE THEY DO RESEARCH $>$ ?

The military could use machine learning algorithms to improve their logistics, such as the storage, purchasing and transportation of weapons and food.

Answer choices:

- Strongly support (2)

- Somewhat support (1)

- Neither support nor oppose (0)

- Somewhat oppose $(-1)$

- Strongly oppose $(-2)$

- I don't know

[For each of the questions above, if they selected "somewhat oppose" or "strongly oppose" above, the respondents were shown the respective question below.]

Suppose your organization has decided to research lethal autonomous weapons to be used by the military of <COUNTRY WHERE THEY DO RESEARCH $>$. Which, if any, of the following actions would you take?

Suppose your organization has decided to research surveillance technologies to be used by intelligence agencies of <COUNTRY WHERE THEY DO RESEARCH $>$. Which, if any, of the following actions would you take?

Suppose your organization has decided to research logistics algorithms to optimize storage and transportation for the military of <COUNTRY WHERE THEY DO RESEARCH $>$. Which, if any, of the following actions would you take?

- Nothing 
- Actively avoid working on the project

- Expressing your concern to a superior in your organization involved in the decision

- Sign a petition against the decision

- Participate in a public protest

- Speak out against the decision anonymously to the media or online

- Speak out against the decision publicly to the media or online

- Resign or threaten to resign from your job

- Other: [short textbox]

Project MAVEN

Google had a contract to work on Project Maven, a US Department of Defense project that develops and integrates computer vision algorithms to support military operations. Some Google employees voiced ethical concerns regarding the project. Google decided not to renew its Project Maven contract with the US Department of Defense.

Do you support or oppose this decision by Google not to renew its contract?

Answer choices:

- Strongly support (2)

- Somewhat support (1)

- Neither support nor oppose (0)

- Somewhat oppose $(-1)$

- Strongly oppose $(-2)$

- I don't know

[Optional question]: Would you like to elaborate on the reasoning behind your previous answer? [Text box]

Publication NORMS

Pre-PUblicATiOn REVIEW

Define "pre-publication review" as follows: For work that has some chance of adverse impacts, having a strong norm or policy to have discussions about the ethical implications of publication that are

- Informed: the discussion includes the lead and senior authors

- Substantive: the discussion lasts for at least an hour 
- Serious: the discussion can lead to real-world decisions (e.g., not to publish parts of the research in question)

Taking into account the cost (e.g., in terms of researcher time) to what extent do you agree or disagree with the following statement?

Machine learning research institutions (including firms, governments, and universities) should practice pre-publication review.

- Strongly agree (2)

- Somewhat agree (1)

- Somewhat disagree $(-1)$

- Strongly disagree $(-2)$

- I don't know

SHARING VARIOUS ASPECTS OF RESEARCH

What is your view toward publicly sharing the following aspects of research, such as at conferences, in academic journals, or online?

[Respondents were shown three aspects of research.]

- High-level description of methods

- Detailed description of methods

- Results

- Code

- Training data

- Trained model

- Algorithm(s)

Answer choices:

- It must be shared every time (5)

- Researchers need a very strong reason not to share (4)

- Researchers are encouraged to share (3)

- It's preferred that researchers share but it's not paramount that they do (2)

- It's completely up to the researchers to share or not to share (1)

- It doesn’t matter (0) 


\section{Demographics of Survey Respondents}

Table S1: Summary statistics of the non-respondents and respondents: binary differences. We collected demographic information for all our respondents and a random sample of 446 non-respondents using information publicly available online. The table presents the proportion of individuals in each demographic category for gender, region of undergraduate and PhD, region where the respondent works, and the type of workplace for both non-respondents and respondents. The mean undergraduate graduation year and log citations are also shown. For each the difference between the nonrespondents' and respondents' proportions is presented alongside the corresponding standard error. The Holm method was used to control the family-wise error rate.

\begin{tabular}{|c|c|c|c|c|}
\hline Variable & Non-respondent & Respondent & Difference $(S E)$ & Percent missing \\
\hline Prop. male & 0.89 & 0.91 & $0.01(0.02)$ & 0.01 \\
\hline $\begin{array}{l}\text { Mean undergrad gradu- } \\
\text { ation year }\end{array}$ & 2007.62 & 2008.95 & $1.33(0.47)$ & 0.21 \\
\hline $\begin{array}{l}\text { Prop. undergrad re- } \\
\text { gion: North America }\end{array}$ & 0.25 & 0.27 & $0.02(0.03)$ & 0.15 \\
\hline $\begin{array}{l}\text { Prop. undergrad re- } \\
\text { gion: Europe }\end{array}$ & 0.26 & 0.29 & $0.02(0.03)$ & 0.15 \\
\hline $\begin{array}{l}\text { Prop. undergrad re- } \\
\text { gion: Asia }\end{array}$ & 0.43 & 0.39 & $-0.04(0.03)$ & 0.15 \\
\hline $\begin{array}{l}\text { Prop. undergrad re- } \\
\text { gion: Other }\end{array}$ & 0.04 & 0.05 & $0.01(0.01)$ & 0.15 \\
\hline $\begin{array}{lrl}\text { Prop. PhD } & \text { region: } \\
\text { North America } & \end{array}$ & 0.28 & 0.33 & $0.06(0.03)$ & 0.08 \\
\hline $\begin{array}{l}\text { Prop. PhD region: Eu- } \\
\text { rope }\end{array}$ & 0.59 & 0.53 & $-0.07(0.03)$ & 0.08 \\
\hline Prop. PhD region: Asia & 0.11 & 0.09 & $-0.01(0.02)$ & 0.08 \\
\hline $\begin{array}{l}\text { Prop. } \\
\text { Other }\end{array}$ & 0.02 & 0.02 & $0.01(0.01)$ & 0.08 \\
\hline $\begin{array}{l}\text { Prop. currently en- } \\
\text { rolled in PhD }\end{array}$ & 0.20 & 0.33 & $0.12(0.03)^{* * *}$ & 0.05 \\
\hline Mean log citations (all) & 6.75 & 6.26 & $-0.49(0.12)^{* * *}$ & 0.17 \\
\hline Mean h-index (all) & 19.68 & 14.42 & $-5.26(1.12)^{* * *}$ & 0.17 \\
\hline $\begin{array}{l}\text { Prop. work region: Eu- } \\
\text { rope }\end{array}$ & 0.28 & 0.33 & $0.05(0.03)$ & 0.01 \\
\hline $\begin{array}{lr}\text { Prop. work region: } \\
\text { North America }\end{array}$ & 0.59 & 0.54 & $-0.05(0.03)$ & 0.01 \\
\hline $\begin{array}{l}\text { Prop. work region: } \\
\text { Asia }\end{array}$ & 0.12 & 0.12 & ¡0.01(0.02) & 0.01 \\
\hline $\begin{array}{l}\text { Prop. work region: } \\
\text { Other }\end{array}$ & 0.01 & 0.02 & $0.01(0.01)$ & 0.01 \\
\hline Prop. work in academia & 0.68 & 0.80 & $0.12(0.03)^{* * *}$ & 0.00 \\
\hline Prop. work in industry & 0.36 & 0.35 & $-0.01(0.03)$ & 0.00 \\
\hline
\end{tabular}


Table S2: Association between demographic characteristics and survey response: results from multiple regression model. We collected demographic information for all our respondents and a random sample of 446 non-respondents using information publicly available online. Here we use multiple linear regression to predict the response to the survey using the demographic variables that we collected. The (arbitrarily chosen) reference categories, the ones that are excluded from the list of coefficients, are female/other for gender, North America for undergraduate, PhD, and work region, and industry for type of workplace. The F-test of overall significance rejects the null hypothesis that respondents do not differ in whether they responded to the survey depending on demographic characteristics. The Holm method was used to control the family-wise error rate.

\begin{tabular}{|c|c|}
\hline & Coefficient $(S E)$ \\
\hline (Intercept) & $\begin{array}{l}0.540^{* * *} \\
(0.016)\end{array}$ \\
\hline Male & $\begin{array}{l}0.022 \\
(0.016)\end{array}$ \\
\hline Undergrad graduation year & $\begin{array}{l}0.002 \\
(0.021)\end{array}$ \\
\hline Undergrad region: Europe & $\begin{array}{l}-0.030 \\
(0.022)\end{array}$ \\
\hline Undergrad region: Asia & $\begin{array}{l}-0.037 \\
(0.020)\end{array}$ \\
\hline Undergrad region: Other & $\begin{array}{l}-0.013 \\
(0.018)\end{array}$ \\
\hline PhD region: Europe & $\begin{array}{l}0.039 \\
(0.026)\end{array}$ \\
\hline PhD region: Asia & $\begin{array}{c}-0.019 \\
(0.023)\end{array}$ \\
\hline $\mathrm{PhD}$ region: Other & $\begin{array}{l}0.009 \\
(0.021)\end{array}$ \\
\hline Currently enrolled in $\mathrm{PhD}$ & $\begin{array}{l}0.033 \\
(0.019)\end{array}$ \\
\hline Log all citations & $\begin{array}{l}0.022 \\
(0.028)\end{array}$ \\
\hline All h-index & $\begin{array}{c}-0.083^{*} \\
(0.026)\end{array}$ \\
\hline Work region: Europe & $\begin{array}{l}0.017 \\
(0.026)\end{array}$ \\
\hline Work region: Asia & $\begin{array}{l}0.034 \\
(0.024)\end{array}$ \\
\hline Work region: Other & $\begin{array}{l}0.014 \\
(0.021)\end{array}$ \\
\hline Work in academia & $\begin{array}{l}0.069^{* * *} \\
(0.017)\end{array}$ \\
\hline Missing: undergrad year & $\begin{array}{l}0.001 \\
(0.028)\end{array}$ \\
\hline Missing: undergrad region & -0.044 \\
\hline
\end{tabular}


Missing: all citations $\quad 0.009$

$(0.016)$

\begin{tabular}{l}
\hline$N$ \\
${ }^{*} p<0.05,{ }^{* *} p<0.01,{ }^{* * *} p<0.001$ \\
$F(18,951)=4.196 ; p$-value: $<0.001$
\end{tabular}

\section{Additional Figures}

\section{Evaluation of AI GOVERNANCE CHALLENGES}

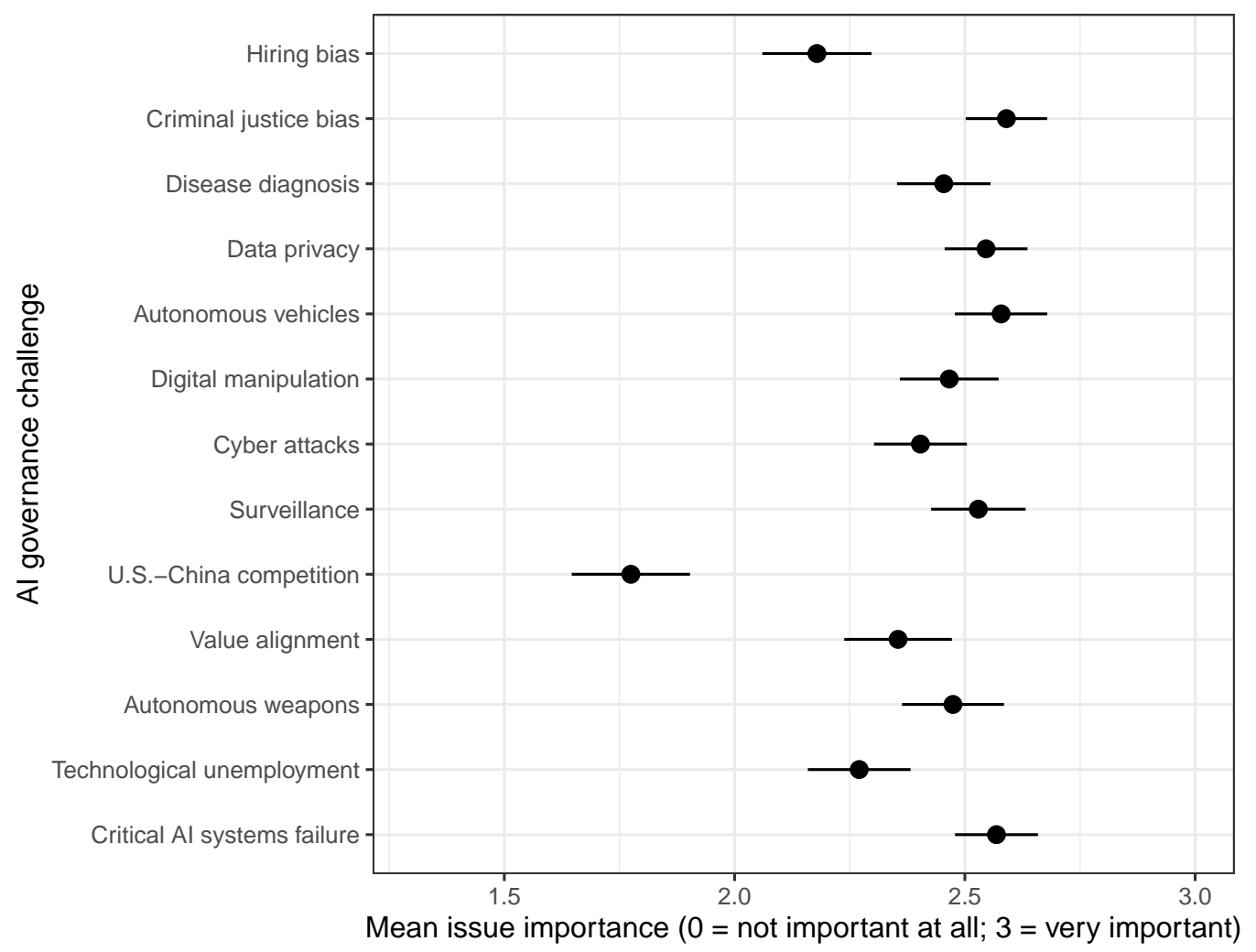

Figure S1: Perceived issue importance of AI governance challenges: all responses from the AI/ML researcher survey. Each respondent was presented with five AI governance challenges randomly selected from a list of 13. Respondents were asked to evaluate the importance of each governance challenge using a four-point scale (the slider scale allows respondents to input values to the tenth decimal point): $0=$ not important, 1 = not too important, $2=$ somewhat important, $3=$ very important. We present the mean response for each governance challenge along with the corresponding 95\% confidence intervals. 


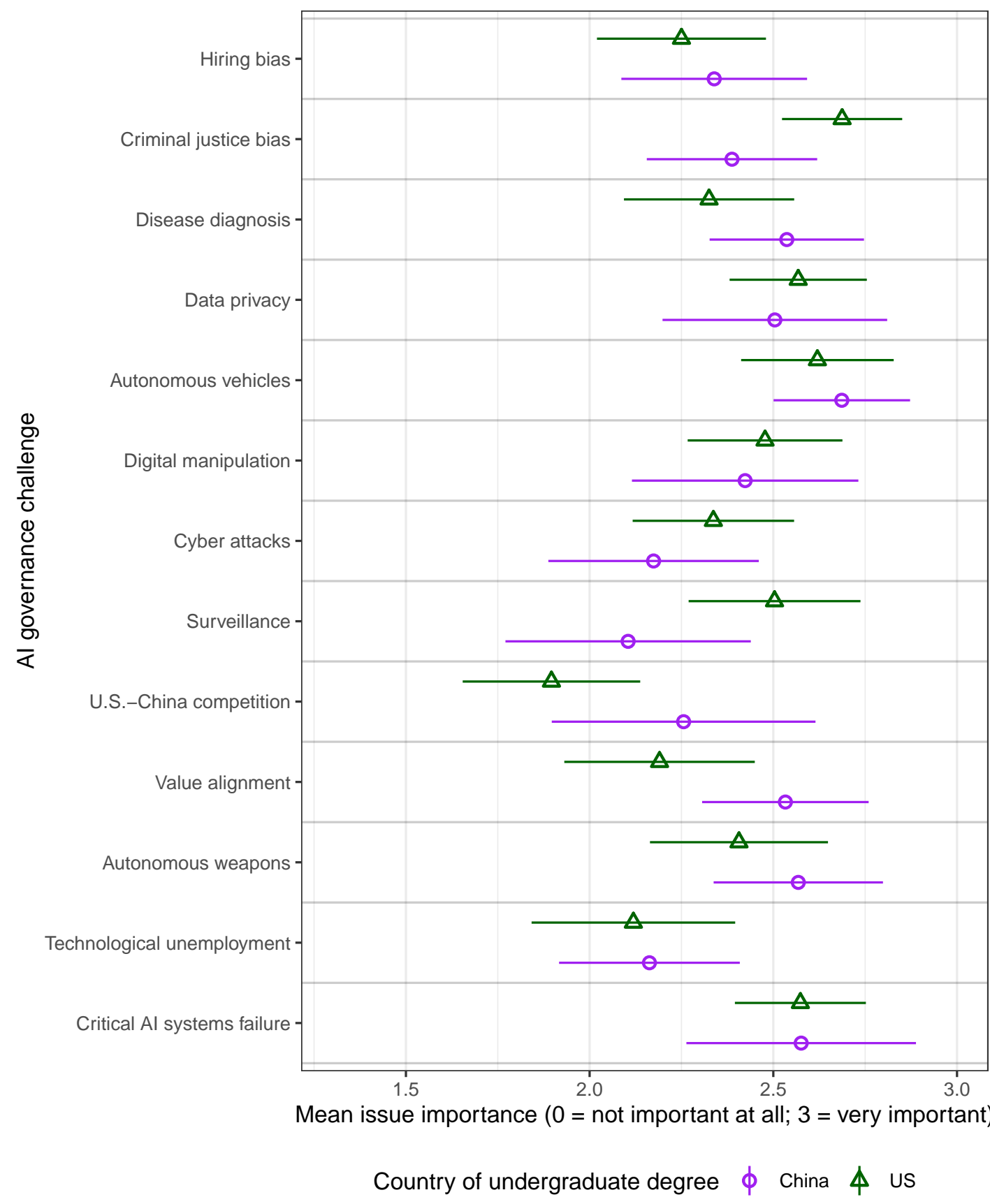

Figure S2: Perceived issue importance of AI governance challenges: by country of undergraduate degree (China and the US). Each respondent was presented with five AI governance challenges randomly selected from a list of 13. Respondents were asked to evaluate the importance of each governance challenge using a four-point scale (the slider scale allows respondents to input values to the tenth decimal point): $0=$ not important, $1=$ not too important, $2=$ somewhat important, 3 = very important. We identified the country of respondents' undergraduate degrees using publicly available information on the internet. We present the mean response for each governance challenge (by country of undergraduate degree) along with the corresponding $95 \%$ confidence intervals. 
Zhang, Anderluung, Kahn, Dreksler, Horowitz \& Dafoe

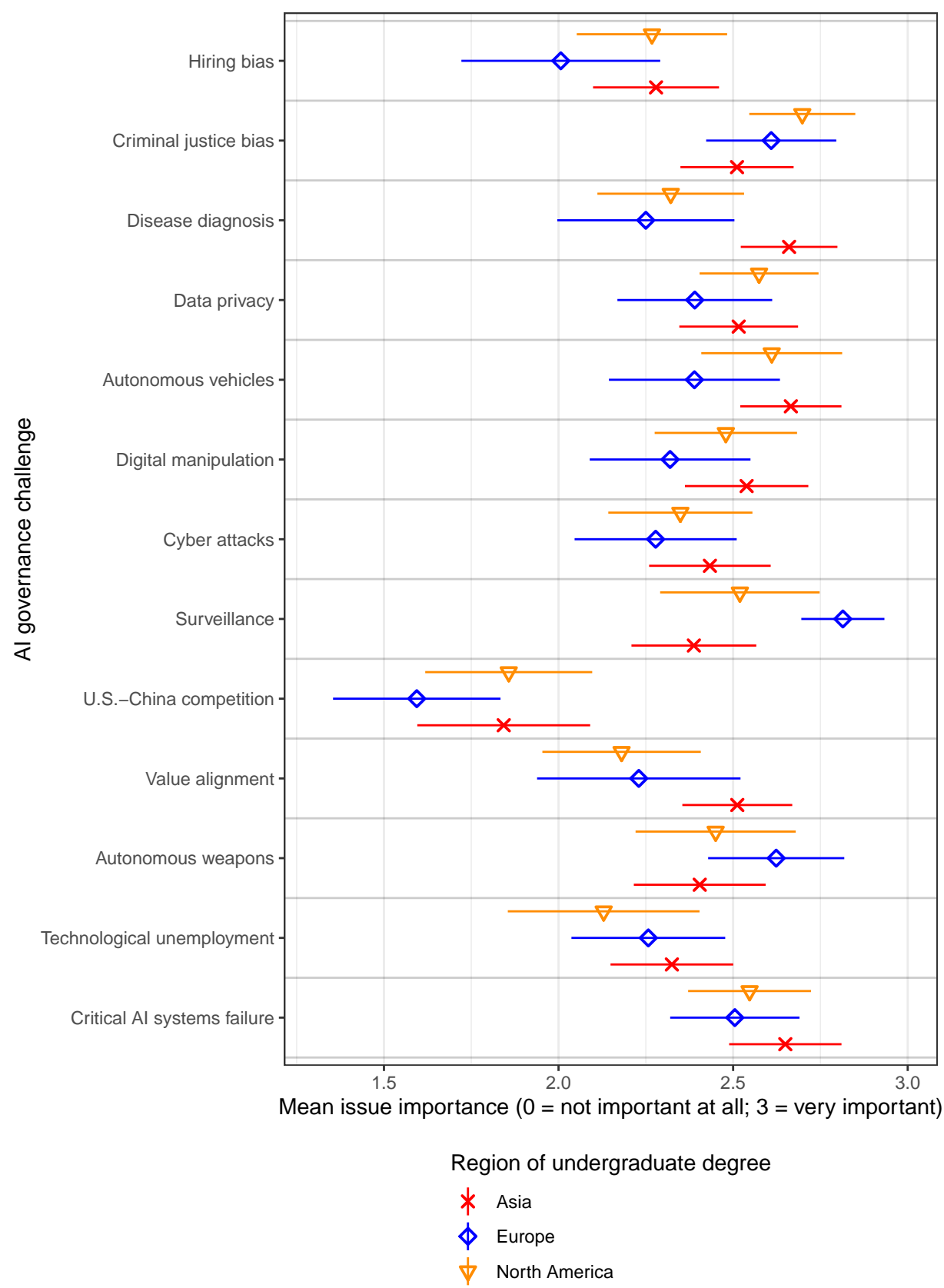

Figure S3: Perceived issue importance of AI governance challenges: by region of undergraduate degree (Asia, Europe, and North America). Each respondent was presented with five AI governance challenges randomly selected from a list of 13. Respondents were asked to evaluate the importance of each governance challenge using a four-point scale (the slider scale allows respondents to input values to the tenth decimal point): $0=$ not important, $1=$ not too important, 2 = somewhat important, 3 = very important. We present the mean response for each governance challenge (by region of undergraduate degree) along with the corresponding $95 \%$ confidence intervals. 
Ethics and Governance of Artificial Intelligence

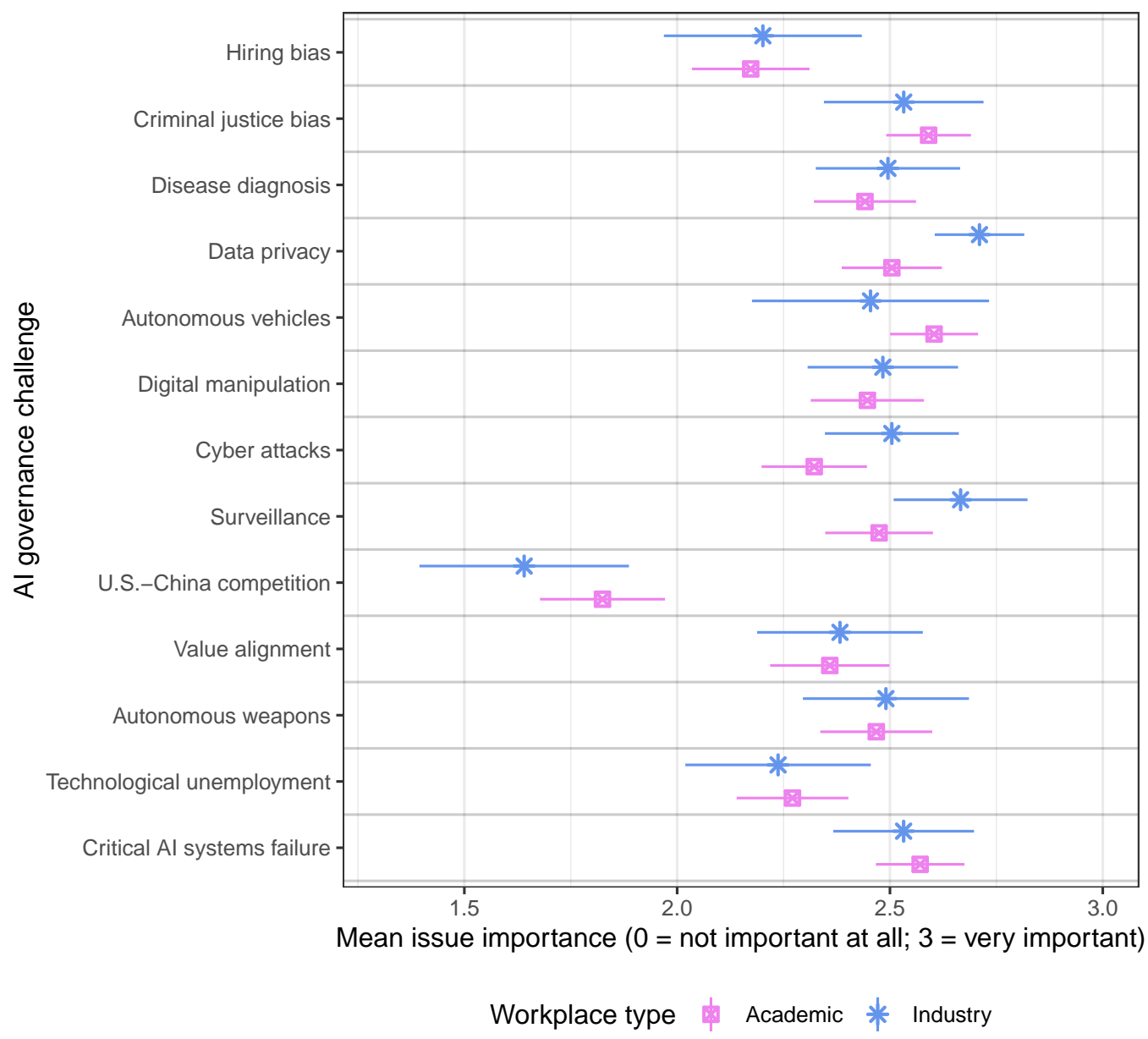

Figure S4: Perceived issue importance of AI governance challenges: by workplace type (academic and industry). Each respondent was presented with five AI governance challenges randomly selected from a list of 13. Respondents were asked to evaluate the importance of each governance challenge using a four-point scale (the slider scale allows respondents to input values to the tenth decimal point): $0=$ not important, 1 = not too important, 2 = somewhat important, $3=$ very important. We identified the respondents' workplace types using publicly available information on the internet. Note that a single respondent can work both in academia and industry. We present the mean response for each governance challenge (by workplace type) along with the corresponding $95 \%$ confidence intervals. 
Trust in aCtors to Shape the DeVelopment and use of AI in the Public INTEREST

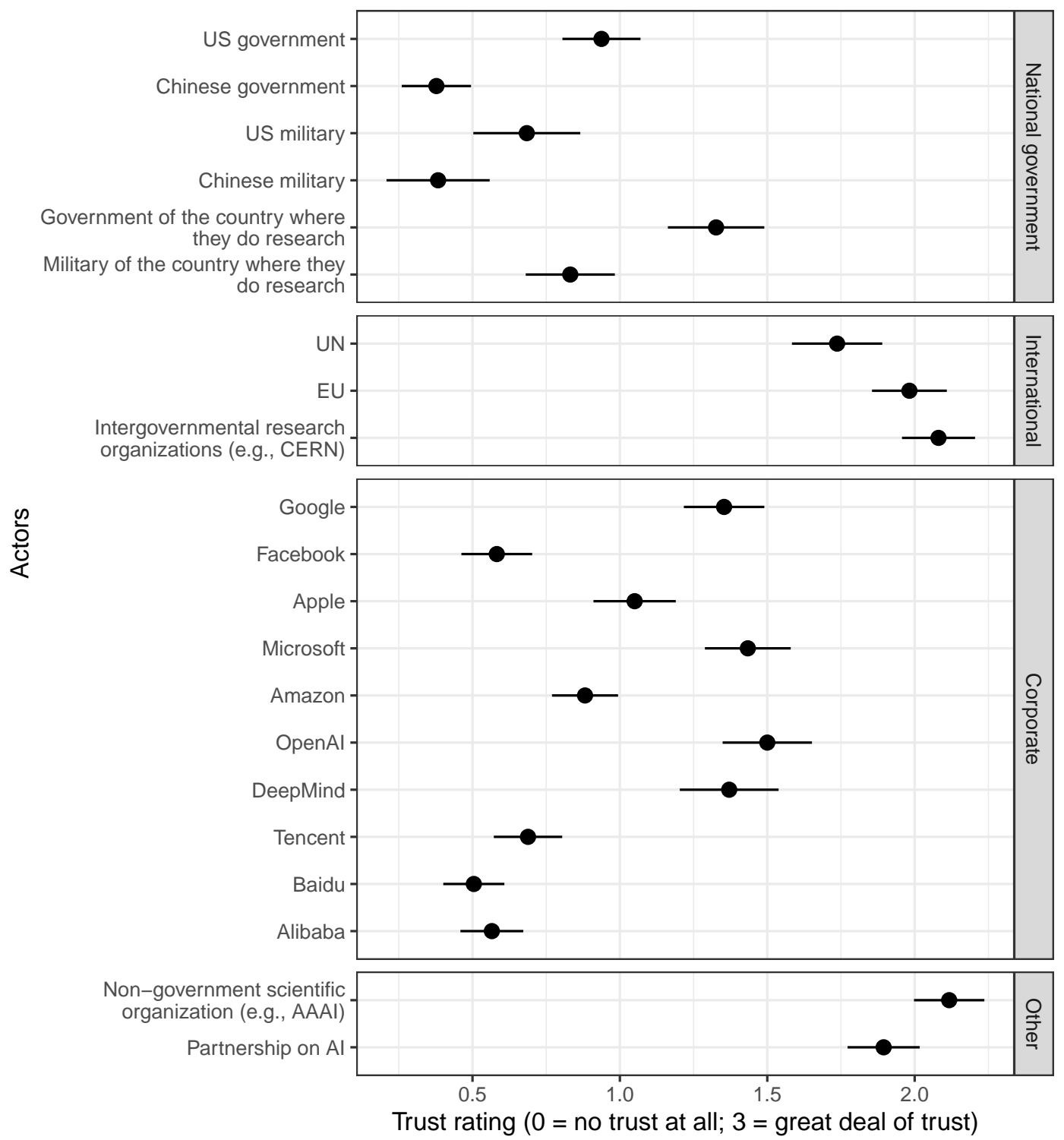

Figure S5: Trust in actors to shape the development and use of AI in the public interest: all responses from the AI/ML researcher survey. Respondents were shown five randomly selected actors and asked to evaluate how much they trust the actors using a four-point scale: $0=$ no trust at all, $1=$ not too much trust, $2=$ a fair amount of trust, $3=$ a great deal of trust. The US military and the Chinese military were shown only to respondents who do research in the US or China; these respondents had equal probability of being shown the US military or the Chinese military. Of the 60 responses to the US military, 56 came from those who do research in the US. Of the 66 responses to the Chinese military, 60 came from those who do research in the US. We present the mean response for each actor along with the corresponding $95 \%$ confidence intervals. 
Ethics and Governance of Artificial Intelligence

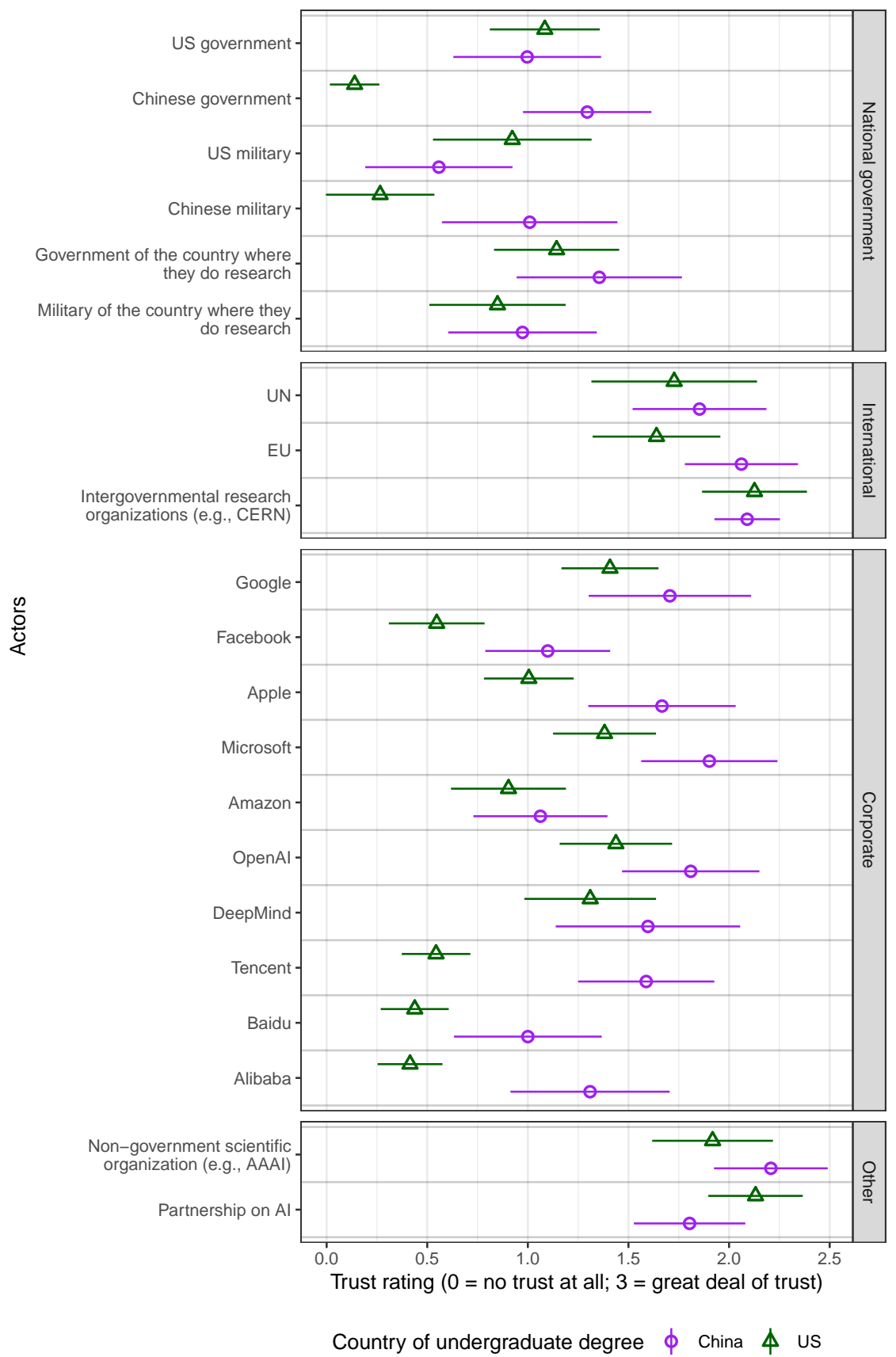

Figure S6: Trust in actors to shape the development and use of AI in the public interest: by country of undergraduate degree (China and the US). Respondents were shown five randomly selected actors and asked to evaluate how much they trust the actors using a four-point scale: $0=$ no trust at all, 1 = not too much trust, $2=$ a fair amount of trust, $3=a$ great deal of trust. The US military and the Chinese military were shown only to respondents who do research in the US or China; these respondents had equal probability of being shown the US military or the Chinese military. We present the mean response for each actor (by country of undergraduate degree) along with the corresponding $95 \%$ confidence intervals. 


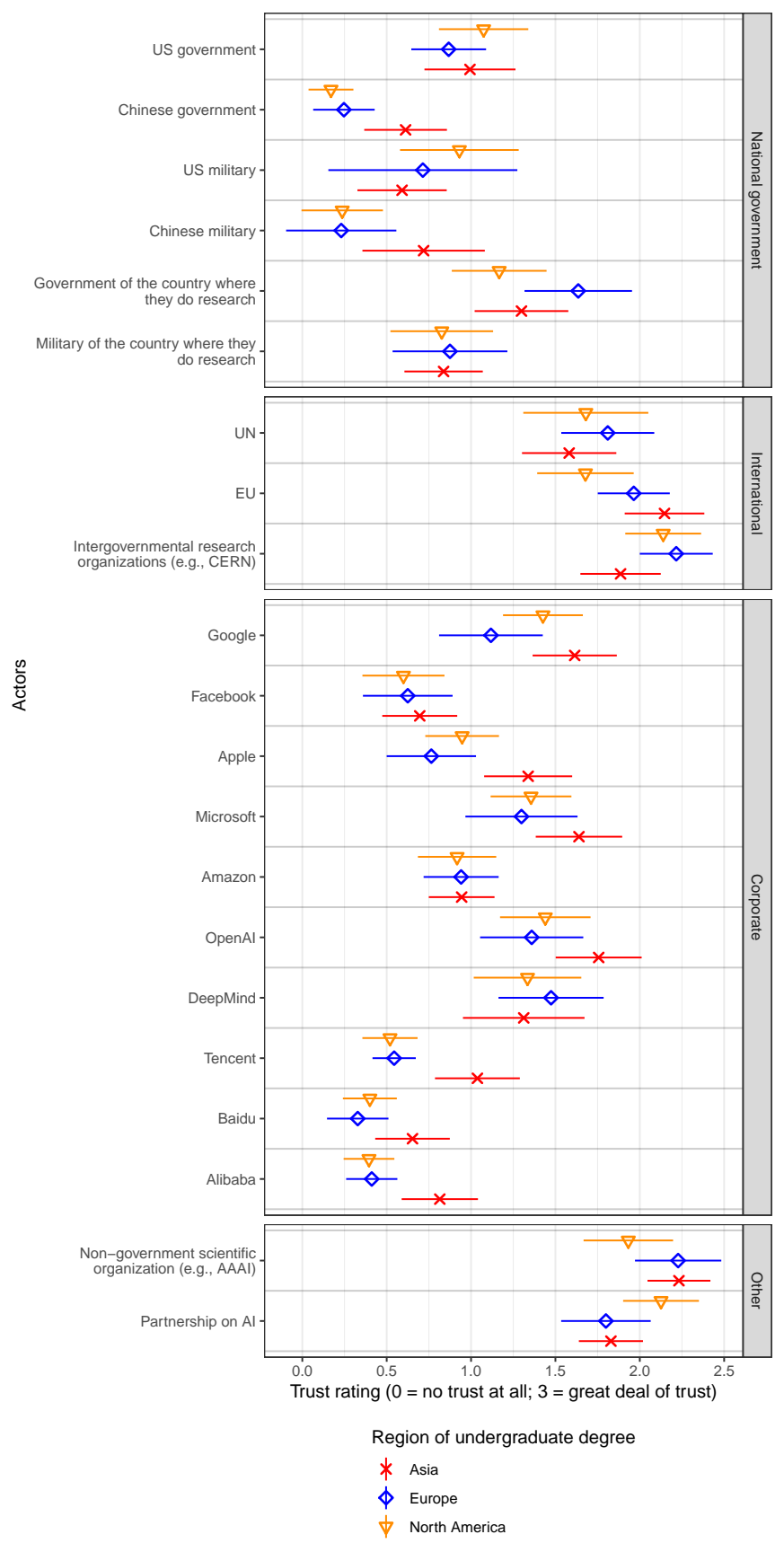

Figure S7: Trust in actors to shape the development and use of AI in the public interest: by region of undergraduate degree (Asia, Europe, and North America). Respondents were shown five randomly selected actors and asked to evaluate how much they trust the actors using a four-point scale: $0=$ no trust at all, $1=$ not too much trust, 2 = a fair amount of trust, $3=$ a great deal of trust. The US military and the Chinese military were shown only to respondents who do research in the US or China; these respondents had equal probability of being shown the US military or the Chinese military. We present the mean response for each actor (by region of undergraduate degree) along with the corresponding $95 \%$ confidence intervals. 
Ethics and Governance of Artificial Intelligence

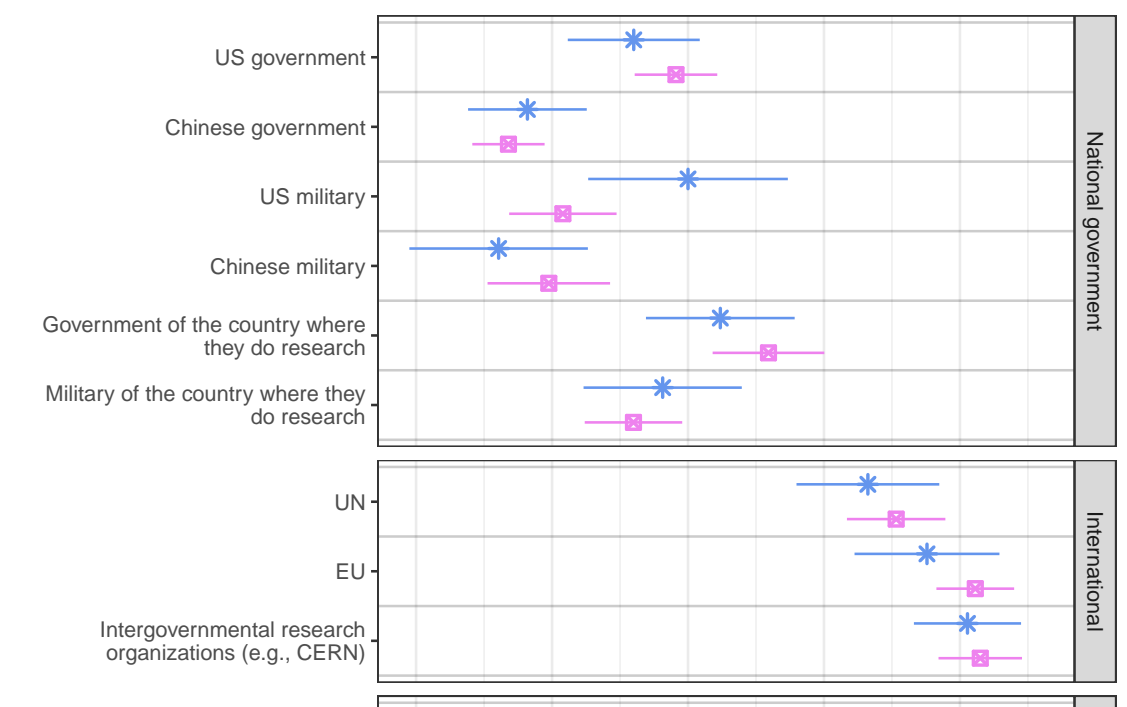

$\frac{0}{0}$

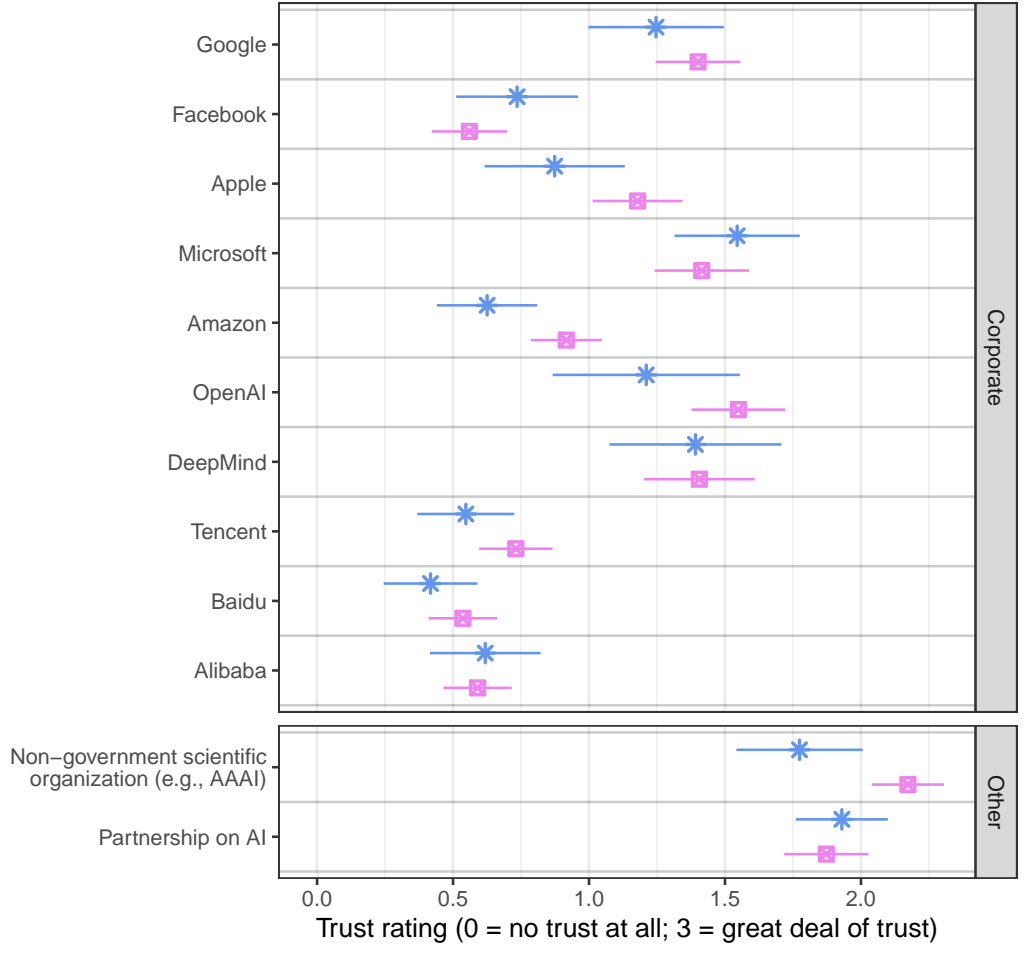

Workplace type Academic * Industry

Figure S8: Trust in actors to shape the development and use of AI in the public interest: by workplace type (academic and industry). Respondents were shown five randomly selected actors and asked to evaluate how much they trust the actors using a four-point scale: $0=$ no trust at all, $1=$ not too much trust, 2 = a fair amount of trust, $3=$ a great deal of trust. The US military and the Chinese military were shown only to respondents who do research in the US or China; these respondents had equal probability of being shown the US military or the Chinese military. We present the mean response for each actor (by their workplace type) along with the corresponding 95\% confidence intervals. 


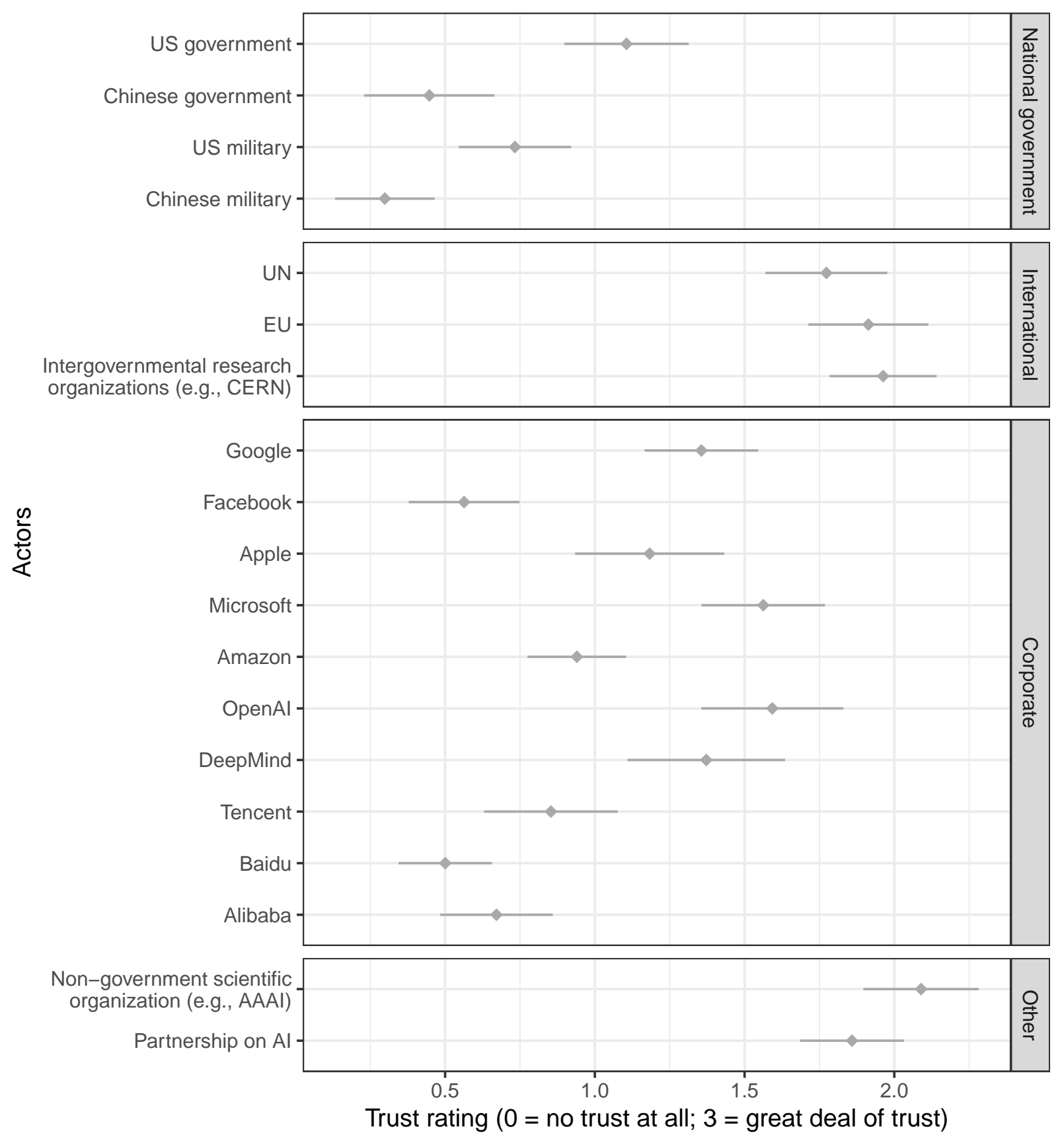

Figure S9: Trust in actors to shape the development and use of AI in the public interest: those who report spending most of their time doing research in the US. Respondents were shown five randomly selected actors and asked to evaluate how much they trust the actors using a four-point scale: $0=$ no trust at all, $1=$ not too much trust, 2 = a fair amount of trust, $3=$ a great deal of trust. The US military and the Chinese military were shown only to respondents who do research in the US or China; these respondents had equal probability of being shown the US military or the Chinese military. The country where each respondent spends the most time working or studying is selfreported in the survey. We present the mean responses for each actor along with the corresponding $95 \%$ confidence intervals. 
Ethics and Governance of Artificial Intelligence

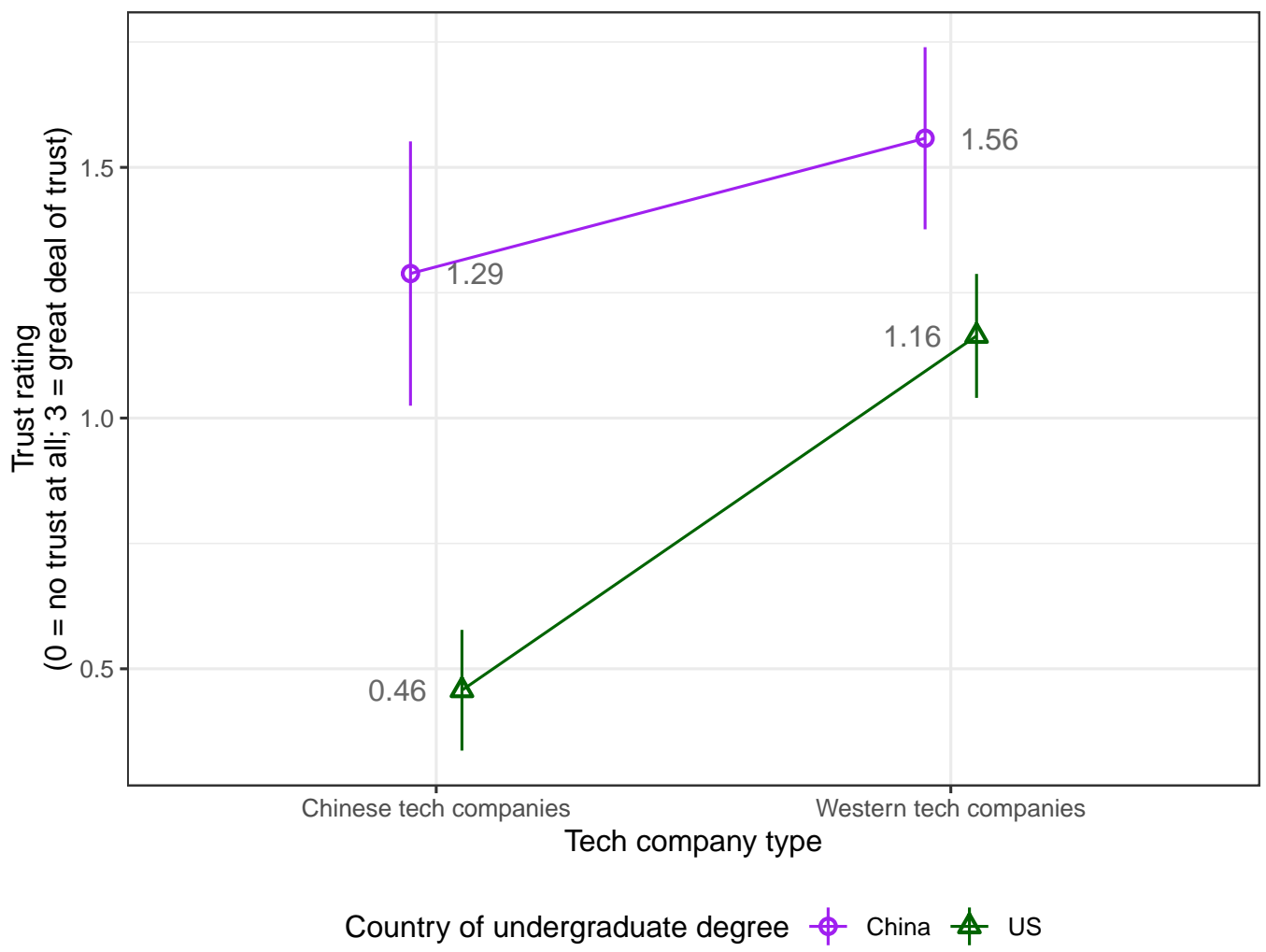

Figure S10: Interaction plot: how respondents who attended university in China versus the US rate trust in Chinese versus Western tech companies. Respondents were asked to evaluate how much they trust the companies using a four-point scale: $0=$ no trust at all, $1=$ not too much trust, $2=$ a fair amount of trust, $3=$ a great deal of trust. The figure is generated from a linear regression with a two-way interaction between Chinese versus Western tech companies and having an undergraduate degree from the US versus China. Only respondents who received undergraduate degrees from the US and China are included in this analysis. See Table S18 for the regression output table. 
AI SAFETY

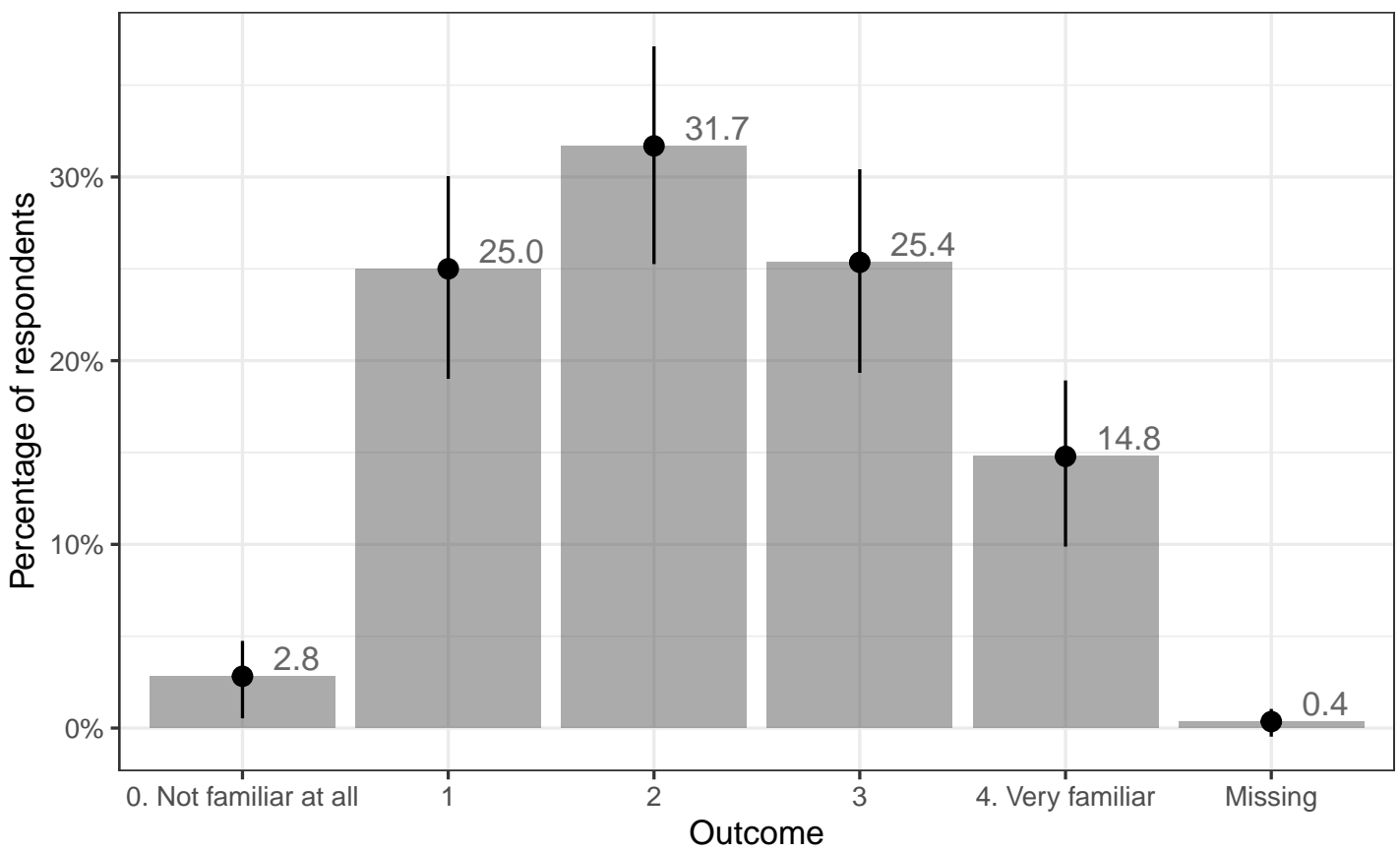

Figure S11: Familiarity with AI safety: distribution of responses. After reading a definition of AI safety (see the Text of the Survey section for the definition), respondents input their familiarity with AI safety using a five-point slider $(0=$ not familiar at all; $4=$ very familiar $)$. We present the mean response at each level of familiarity with AI safety and for missing responses, along with the corresponding $95 \%$ confidence intervals. 
Ethics and Governance of Artificial Intelligence
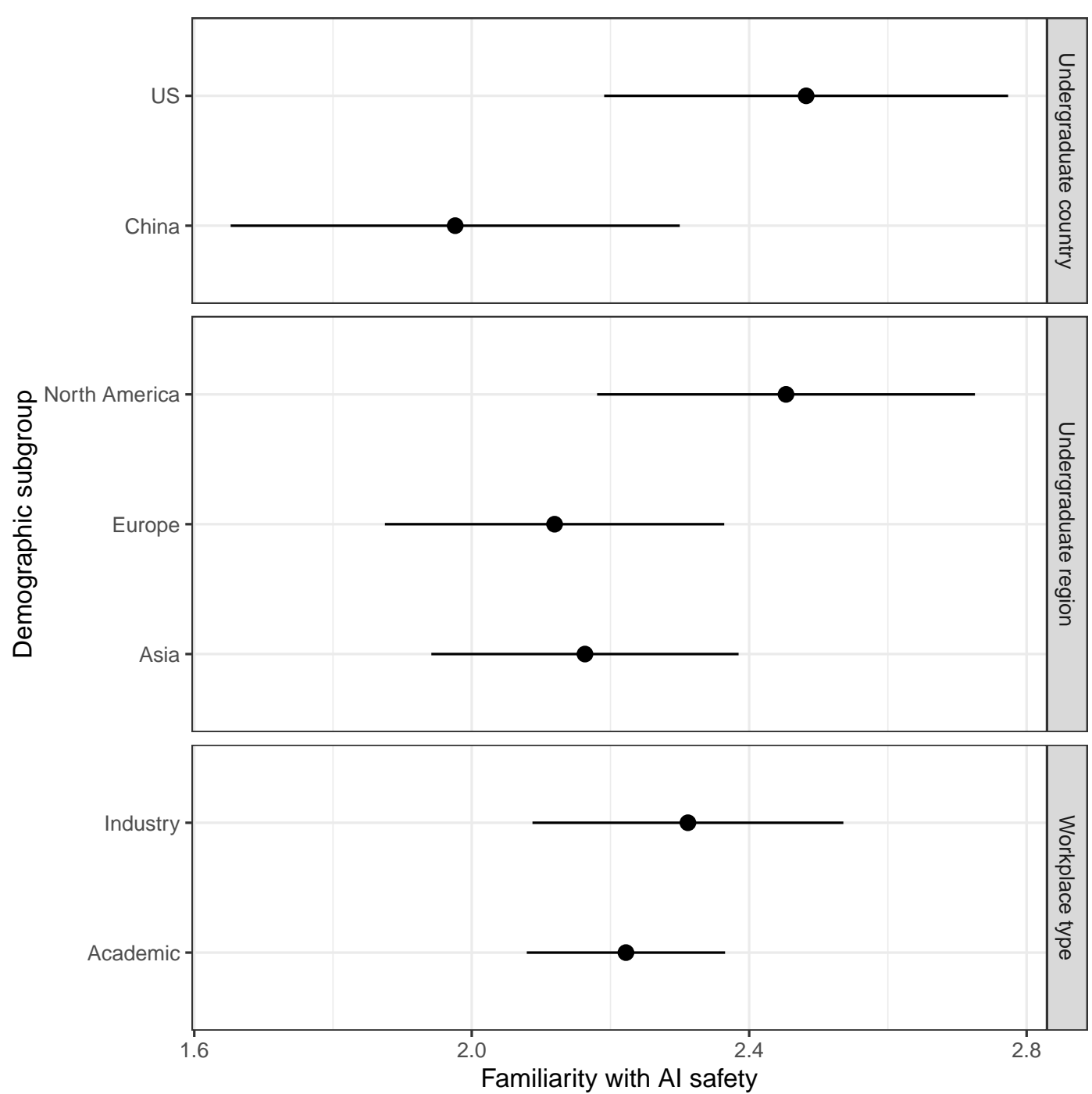

Figure S12: Familiarity with AI safety: mean response by demographic subgroups. After reading a definition of AI safety (see the Text of the Survey section for the definition), respondents input their familiarity with AI safety using a five-point slider $(0=$ not familiar at all; $4=$ very familiar $)$. We present the mean AI safety familiarity response by undergraduate country (US and China), undergraduate region (North America, Europe, and Asia), and workplace type (industry and academic), along with the corresponding $95 \%$ confidence intervals. 


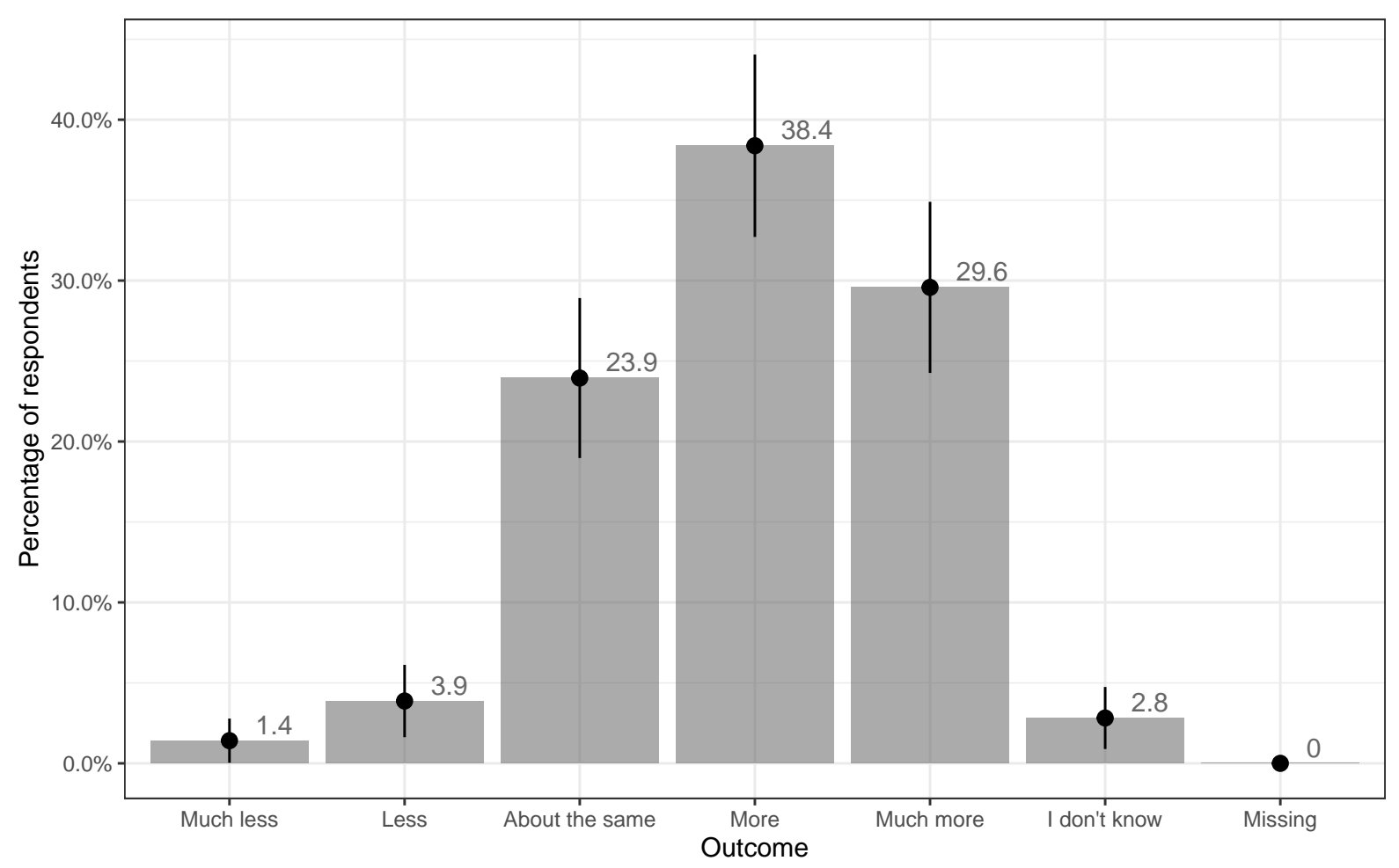

Figure S13: How much should AI safety be prioritized: distribution of responses. This question appears after the familiarity with AI safety question. Respondents were asked how much AI safety research should be prioritized relative to today. The answer choices are a Likert scale from -2 to 2: -2 = much less; $-1=$ less; $0=$ about the same; 1 = more; $2=$ much more. There was also an "I don't know" option. We present the mean response for each option along with the corresponding 95\% confidence intervals. 
Ethics and Governance of Artificial Intelligence
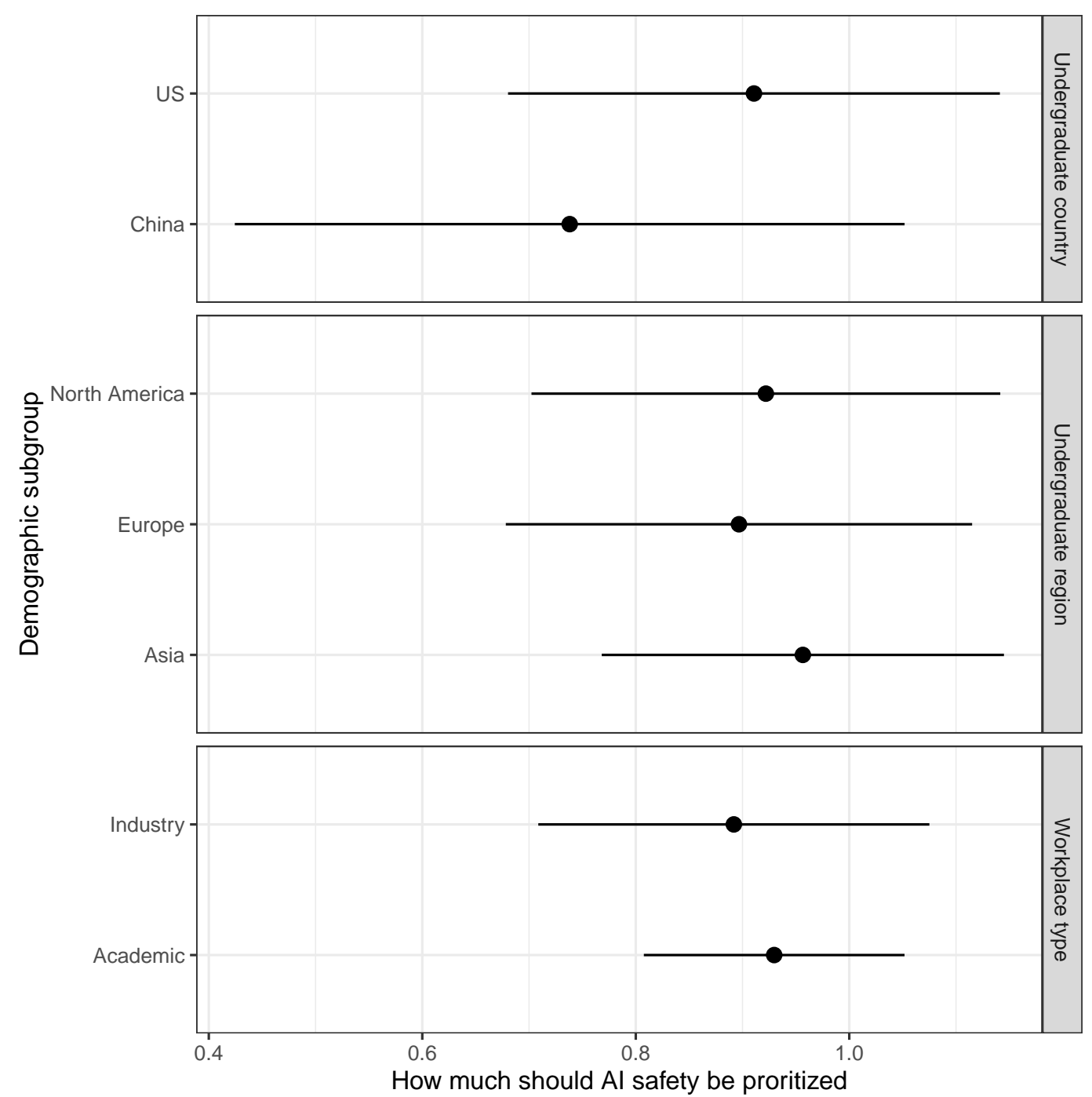

Figure S14: How much should AI safety be prioritized: mean response by demographic subgroups. Respondents were asked how much AI safety research should be prioritized relative to today. The answer choices are a Likert scale from -2 to 2: -2 = much less; $-1=$ less; $0=$ about the same; $1=$ more; 2 = much more. There was also an "I don't know" option. We present the mean response by undergraduate country (US and China), undergraduate region (North America, Europe, and Asia), and workplace type (industry and academic), along with the corresponding $95 \%$ confidence intervals. 


\section{Attitudes TOWARD MILITARY APPLiCATIONS OF AI}

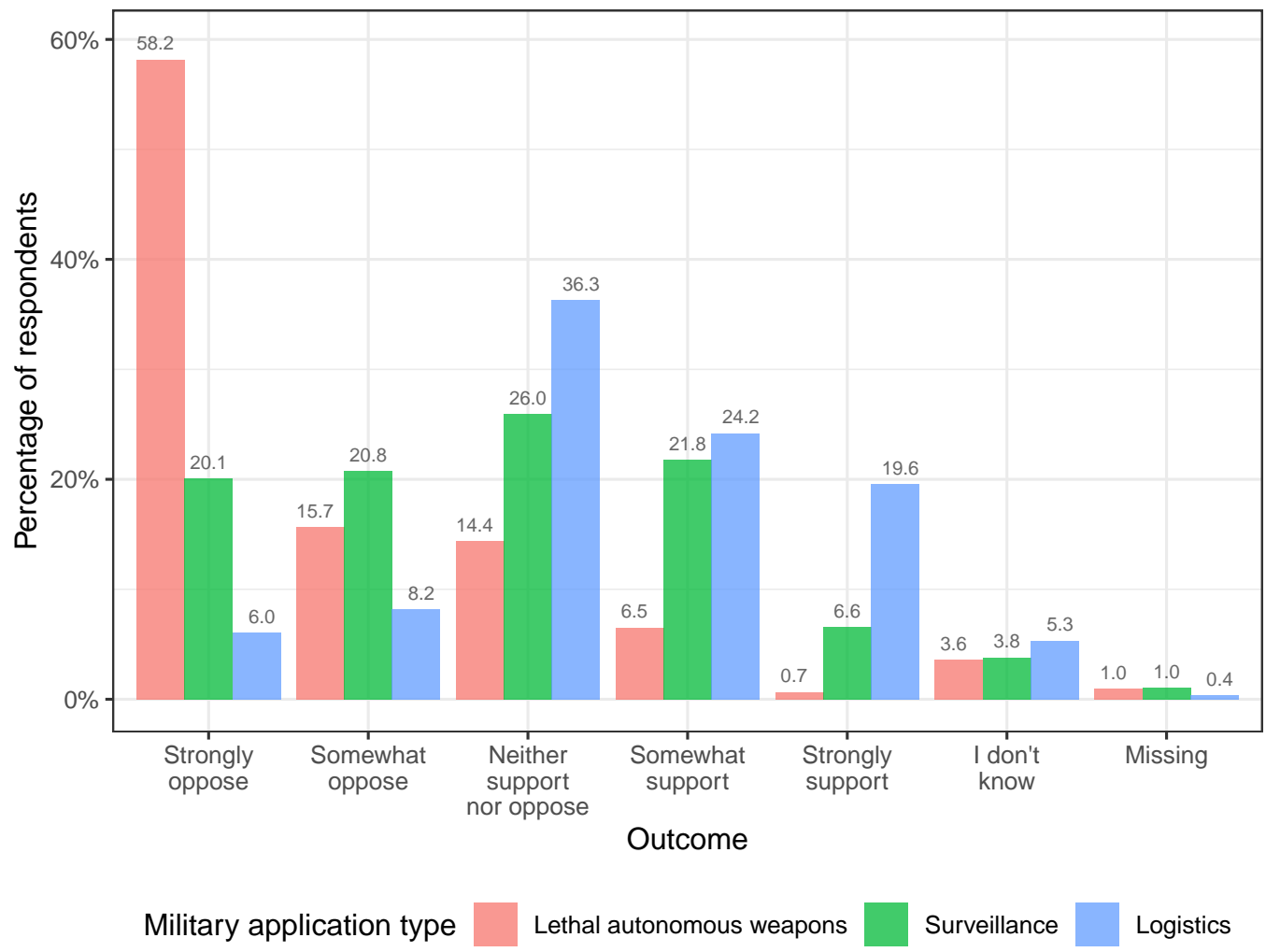

Figure S15: Attitudes toward researchers working on military applications of AI: distribution of responses. Respondents were asked to indicate their level of support for two of the three randomly presented military applications (lethal autonomous weapons, surveillance, and logistics) on a fivepoint scale from -2 to 2: -2 = strongly oppose, $-1=$ somewhat oppose, $0=$ neither support nor oppose, 1 = somewhat support, 2 = strongly support. There was also an "I don't know" option. Each military application was defined when it was presented (see the Text of the Survey section for the definition). We present the percentage of respondents who chose each response as well as those who did not respond to the question, along with the corresponding $95 \%$ confidence intervals. 
Ethics and Governance of Artificial Intelligence
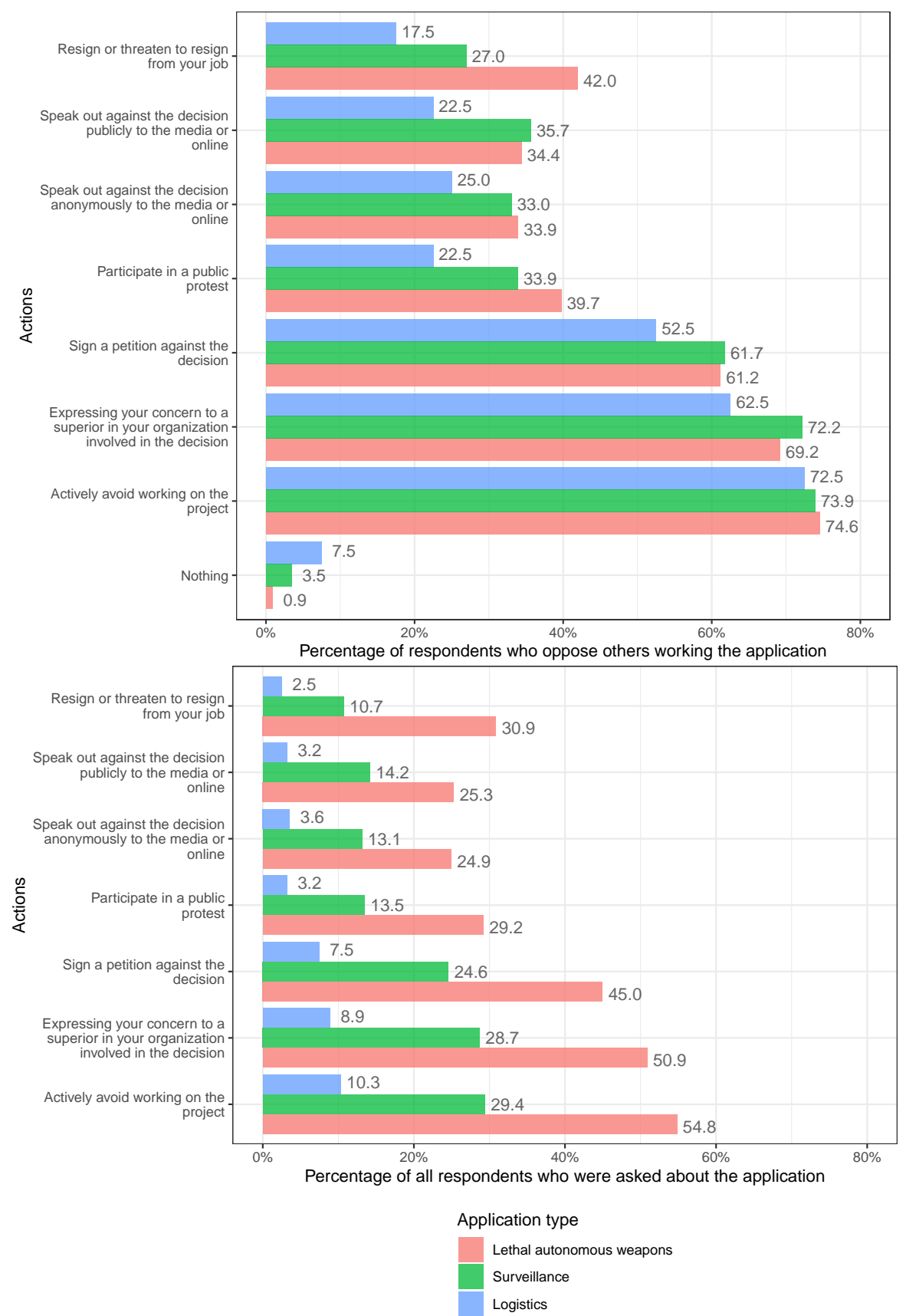

Figure S16: Support for collective action against research into military applications of AI: distribution of responses. Respondents were asked which actions, if any, they would take if their organization decided to research two randomly chosen applications from the following three: lethal autonomous weapons, surveillance, or logistics. The question text also highlighted that this was specific to where the respondent worked or studied. In the top panel, the x-axis is the percentage of respondents who were asked about the application and indicated they "oppose" or "strongly oppose" researchers working on the application. In the bottom panel, the x-axis is the percentage of all respondents who were asked about the application. Recall that each respondent was asked about two applications randomly selected from the three. 


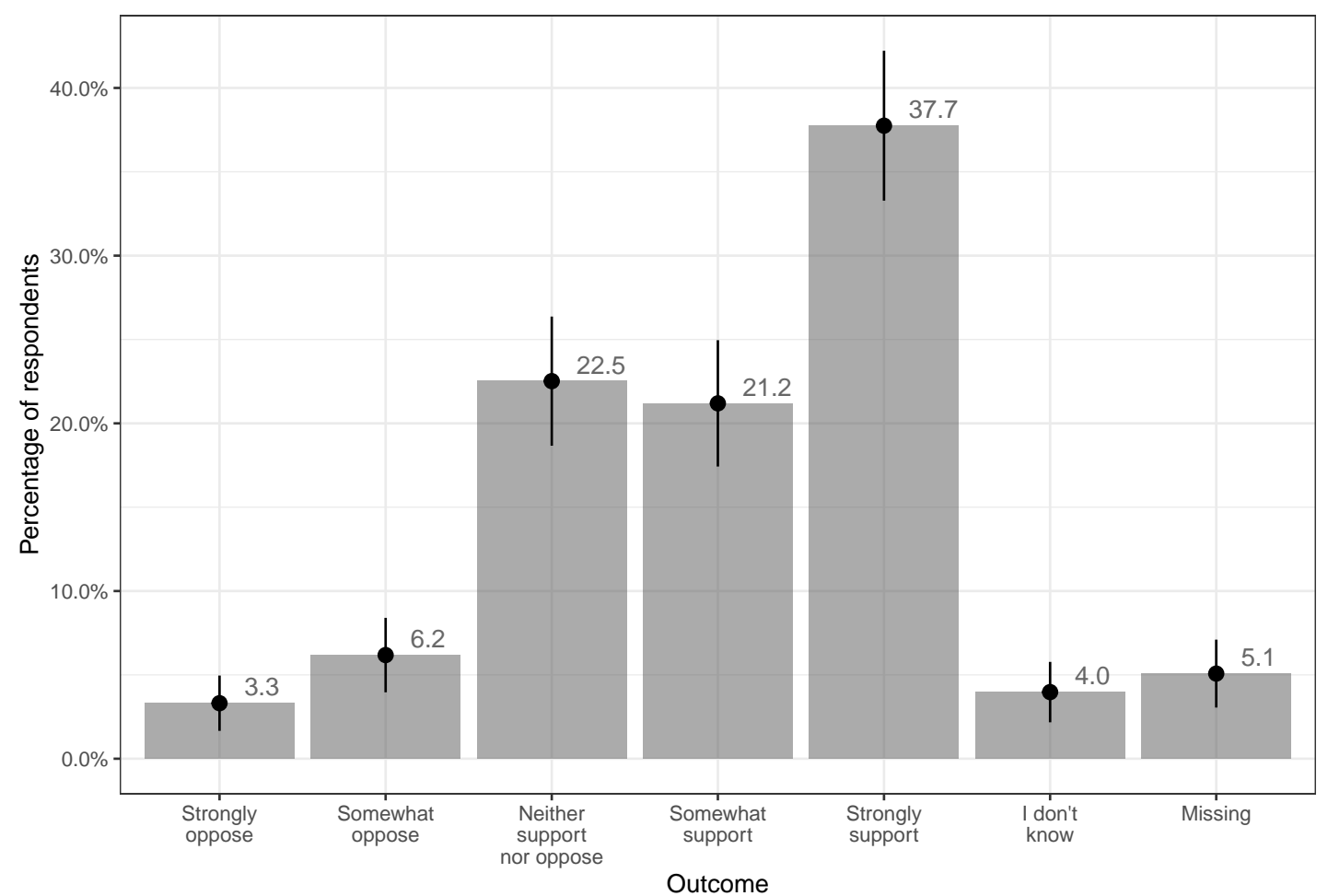

Figure S17: Attitudes toward Google not renewing its Project Maven contract: distribution of responses. Respondents were presented with a short description of the employees' reactions to Google's Project Maven and the following non-renewal of the contract (see the Text of the Survey section for the description) and were asked to indicate their support for the non-renewal decision on a five-point scale from -2 to 2: -2 = strongly oppose, $-1=$ somewhat oppose, $0=$ neither support nor oppose, 1 = somewhat support, 2 = strongly support. There was also an "I don't know" option. We present the percentage of respondents choosing each option and who did not respond to the question, along with the corresponding $95 \%$ confidence intervals. 


\section{PUBLICATION NORMS}

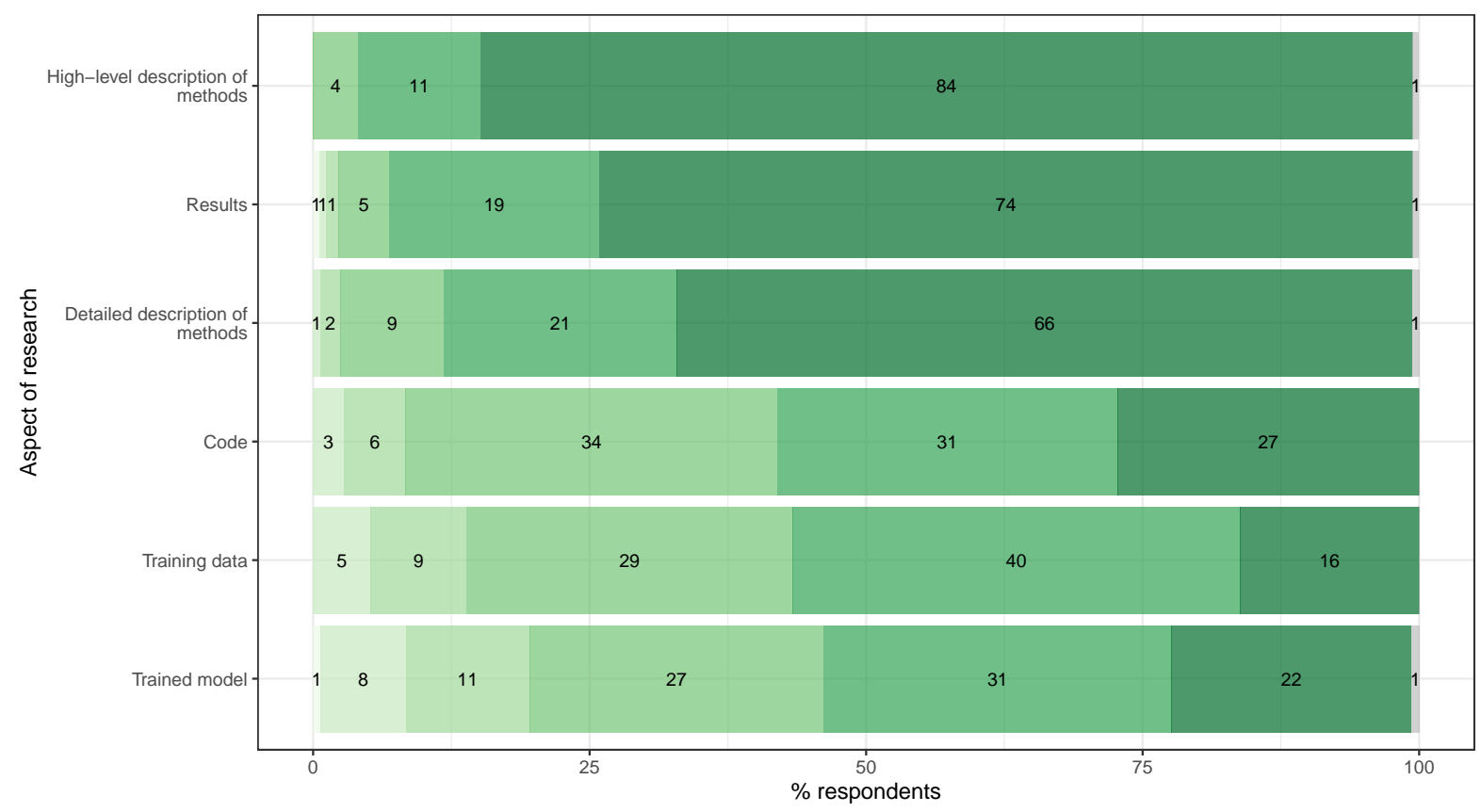

Response

It doesn't matter

It's completely up to the researchers

to share or not to share

ers share

but it's not paramount that they do

Researchers are encouraged to share

Figure S18: Sharing aspects of research: distribution of responses. Respondents were presented with three aspects of research randomly chosen from a list of six. For each aspect of research, they selected from six levels of openness ( $0=i t$ doesn't matter; $1=i t$ 's completely up to the researchers to share or not to share; $2=i t$ 's preferred that researchers share but it's not paramount that they do; $3=$ researchers are encouraged to share; $4=$ researchers need a very strong reason not to share; $5=i t$ must be shared every time). We present the mean response for each level of openness for the different aspects of research, along with the corresponding $95 \%$ confidence intervals. 
Zhang, Anderluung, Kahn, Dreksler, Horowitz \& Dafoe

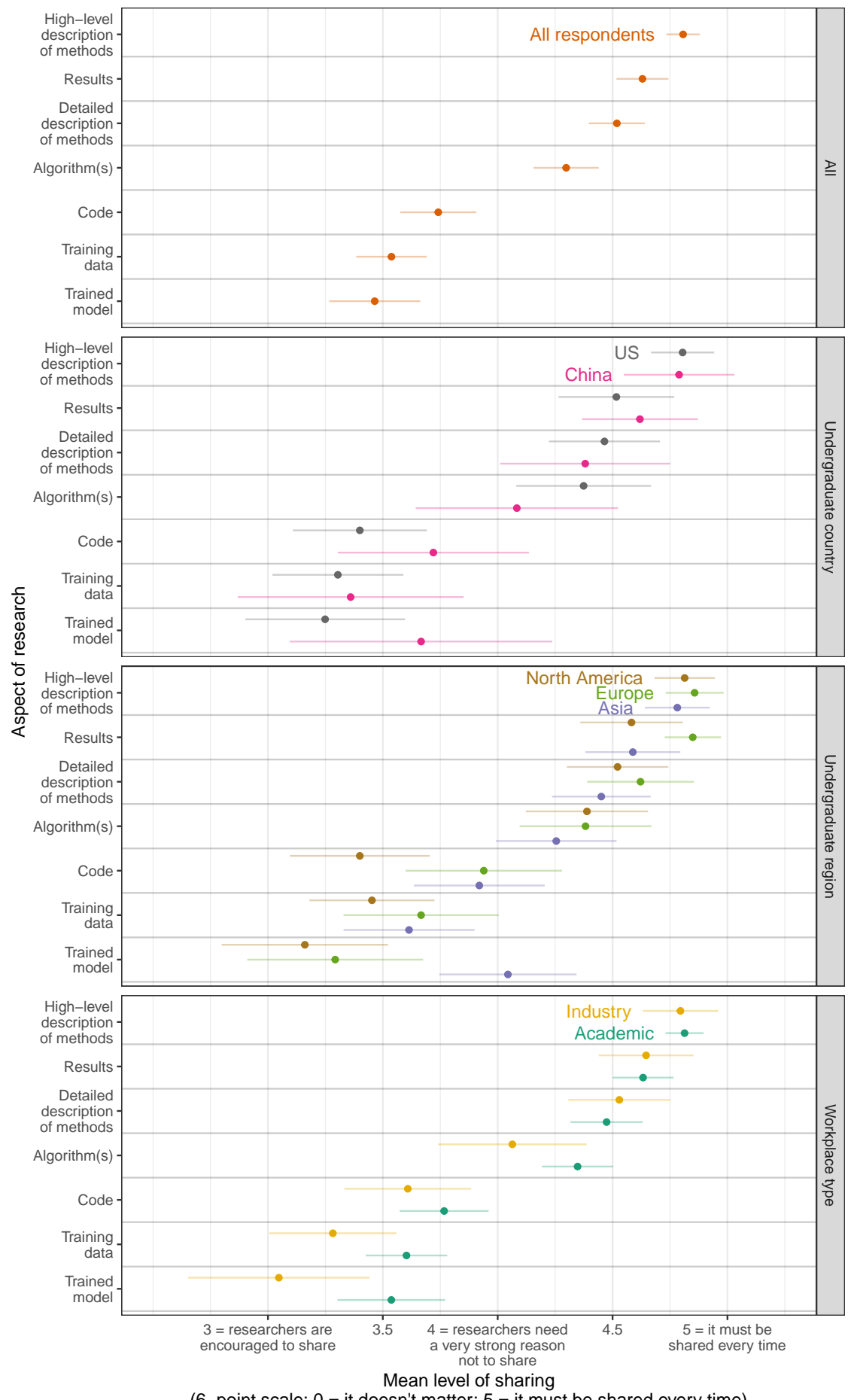

Figure S19: Sharing aspects of research: mean level of openness response for each aspect of research, by demographic subgroups. We present the mean openness response for each aspect of research for all respondents as well as by undergraduate country (US and China), undergraduate region (North America, Europe, and Asia), and workplace type (industry and academic). The corresponding 95\% confidence intervals are shown. 


\section{Additional Tables}

Evaluation of AI governance CHALlEnges

Table S3: Perceived issue importance of AI governance challenges (comparing AI/ML researchers' and the US public's responses). The table presents the mean perceived importance of each of the AI governance challenges and the associated standard error and sample size for each type of respondent (AI/ML researcher and US public).

\begin{tabular}{|l|l|l|l|l|}
\hline Governance challenge & Mean & $S E$ & $N$ & Respondent type \\
\hline Hiring bias & 2.18 & 0.06 & 170 & AI/ML researchers \\
\hline Criminal justice bias & 2.59 & 0.05 & 167 & AI/ML researchers \\
\hline Disease diagnosis & 2.45 & 0.05 & 147 & AI/ML researchers \\
\hline Data privacy & 2.55 & 0.05 & 177 & AI/ML researchers \\
\hline Autonomous vehicles & 2.58 & 0.05 & 165 & AI/ML researchers \\
\hline Digital manipulation & 2.47 & 0.05 & 157 & AI/ML researchers \\
\hline Cyber attacks & 2.40 & 0.05 & 176 & AI/ML researchers \\
\hline Surveillance & 2.53 & 0.05 & 172 & AI/ML researchers \\
\hline US-China competition & 1.77 & 0.07 & 159 & AI/ML researchers \\
\hline Value alignment & 2.35 & 0.06 & 156 & AI/ML researchers \\
\hline Autonomous weapons & 2.47 & 0.06 & 157 & AI/ML researchers \\
\hline Technological unemployment & 2.27 & 0.06 & 168 & AI/ML researchers \\
\hline Critical AI systems failure & 2.57 & 0.05 & 179 & AI/ML researchers \\
\hline Hiring bias & 2.54 & 0.03 & 760 & US Public \\
\hline Criminal justice bias & 2.53 & 0.03 & 778 & US Public \\
\hline Disease diagnosis & 2.52 & 0.03 & 767 & US Public \\
\hline Data privacy & 2.62 & 0.03 & 807 & US Public \\
\hline Autonomous vehicles & 2.56 & 0.02 & 796 & US Public \\
\hline Digital manipulation & 2.53 & 0.03 & 741 & US Public \\
\hline Cyber attacks & 2.59 & 0.02 & 745 & US Public \\
\hline Surveillance & 2.56 & 0.03 & 784 & US Public \\
\hline US-China competition & 2.52 & 0.03 & 766 & US Public \\
\hline Value alignment & 2.55 & 0.03 & 783 & US Public \\
\hline Autonomous weapons & 2.58 & 0.02 & 757 & US Public \\
\hline Technological unemployment & 2.50 & 0.03 & 738 & US Public \\
\hline Critical AI systems failure & 2.47 & 0.03 & 778 & US Public \\
\hline
\end{tabular}


Table S4: Top five most important AI governance challenges (AI/ML researchers versus US public). The table presents the five highest mean responses of perceived importance of the AI governance challenges ranked in descending order for AI/ML researchers and the US public.

\begin{tabular}{|l|l|l|}
\hline Ranking & AI/ML researchers & US Public \\
\hline 1 & Criminal justice bias & Data privacy \\
\hline 2 & Autonomous vehicles & Cyber attacks \\
\hline 3 & Critical AI systems failure & Autonomous weapons \\
\hline 4 & Data privacy & Surveillance \\
\hline 5 & Surveillance & Autonomous vehicles \\
\hline
\end{tabular}

Table S5: Rating issue importance of AI governance challenges (by undergraduate country). The table presents AI/ML researchers' mean perceived importance of each of the AI governance challenges and the associated standard error and sample size by country where the respondent completed their undergraduate degree (US and China).

\begin{tabular}{|l|l|l|l|l|}
\hline Governance challenge & Mean & $S E$ & $N$ & Undergraduate country \\
\hline Hiring bias & 2.25 & 0.12 & 36 & US \\
\hline Criminal justice bias & 2.69 & 0.08 & 47 & US \\
\hline Disease diagnosis & 2.33 & 0.12 & 34 & US \\
\hline Data privacy & 2.57 & 0.10 & 42 & US \\
\hline Autonomous vehicles & 2.62 & 0.11 & 35 & US \\
\hline Digital manipulation & 2.48 & 0.11 & 37 & US \\
\hline Cyber attacks & 2.34 & 0.11 & 38 & US \\
\hline Surveillance & 2.50 & 0.12 & 30 & US \\
\hline US-China competition & 1.90 & 0.12 & 39 & US \\
\hline Value alignment & 2.19 & 0.13 & 31 & US \\
\hline Autonomous weapons & 2.41 & 0.12 & 38 & US \\
\hline Technological unemployment & 2.12 & 0.14 & 35 & US \\
\hline Critical AI systems failure & 2.57 & 0.09 & 43 & US \\
\hline Hiring bias & 2.34 & 0.13 & 23 & China \\
\hline Criminal justice bias & 2.39 & 0.12 & 24 & China \\
\hline Disease diagnosis & 2.54 & 0.11 & 26 & China \\
\hline Data privacy & 2.50 & 0.16 & 24 & China \\
\hline Autonomous vehicles & 2.69 & 0.09 & 31 & China \\
\hline Digital manipulation & 2.42 & 0.16 & 20 & China \\
\hline Cyber attacks & 2.17 & 0.15 & 23 & China \\
\hline Surveillance & 2.10 & 0.17 & 27 & China \\
\hline US-China competition & 2.26 & 0.18 & 17 & China \\
\hline Value alignment & 2.53 & 0.12 & 23 & China \\
\hline Autonomous weapons & 2.57 & 0.12 & 25 & China \\
\hline Technological unemployment & 2.16 & 0.13 & 25 & China \\
\hline Critical AI systems failure & 2.58 & 0.16 & 22 & China \\
\hline & & & & \\
\hline
\end{tabular}


Table S6: Rating issue importance of AI governance challenges (by undergraduate region). The table presents AI/ML researchers' mean perceived importance of each of the AI governance challenges and the associated standard error and sample size by region where the respondent completed their undergraduate degree (Europe, North America, and Asia).

\begin{tabular}{|l|l|l|l|l|}
\hline Governance challenge & Mean & $S E$ & $N$ & Undergraduate region \\
\hline Hiring bias & 2.01 & 0.15 & 43 & Europe \\
\hline Criminal justice bias & 2.61 & 0.10 & 43 & Europe \\
\hline Disease diagnosis & 2.25 & 0.13 & 30 & Europe \\
\hline Data privacy & 2.39 & 0.11 & 41 & Europe \\
\hline Autonomous vehicles & 2.39 & 0.12 & 37 & Europe \\
\hline Digital manipulation & 2.32 & 0.12 & 41 & Europe \\
\hline Cyber attacks & 2.28 & 0.12 & 41 & Europe \\
\hline Surveillance & 2.81 & 0.06 & 42 & Europe \\
\hline US-China competition & 1.59 & 0.12 & 42 & Europe \\
\hline Value alignment & 2.23 & 0.15 & 42 & Europe \\
\hline Autonomous weapons & 2.62 & 0.10 & 32 & Europe \\
\hline Technological unemployment & 2.26 & 0.11 & 35 & Europe \\
\hline Critical AI systems failure & 2.50 & 0.09 & 41 & Europe \\
\hline Hiring bias & 2.27 & 0.11 & 40 & North America \\
\hline Criminal justice bias & 2.70 & 0.08 & 52 & North America \\
\hline Disease diagnosis & 2.32 & 0.11 & 40 & North America \\
\hline Data privacy & 2.57 & 0.09 & 47 & North America \\
\hline Autonomous vehicles & 2.61 & 0.10 & 38 & North America \\
\hline Digital manipulation & 2.48 & 0.10 & 40 & North America \\
\hline Cyber attacks & 2.35 & 0.11 & 45 & North America \\
\hline Surveillance & 2.52 & 0.12 & 31 & North America \\
\hline US-China competition & 1.86 & 0.12 & 44 & North America \\
\hline Value alignment & 2.18 & 0.12 & 36 & North America \\
\hline Autonomous weapons & 2.45 & 0.12 & 41 & North America \\
\hline Technological unemployment & 2.13 & 0.14 & 40 & North America \\
\hline Critical AI systems failure & 2.55 & 0.09 & 46 & North America \\
\hline Hiring bias & 2.28 & 0.09 & 55 & Asia \\
\hline Criminal justice bias & 2.51 & 0.08 & 44 & Asia \\
\hline Disease diagnosis & 2.66 & 0.07 & 49 & Asia \\
\hline Data privacy & 2.52 & 0.09 & 53 & Asia \\
\hline Autonomous vehicles & 2.67 & 0.07 & 67 & Asia \\
\hline Digital manipulation & 2.54 & 0.09 & 56 & Asia \\
\hline Cyber attacks & 2.43 & 0.09 & 60 & Asia \\
\hline Surveillance & 2.39 & 0.09 & 63 & Asia \\
\hline US-China competition & 1.84 & 0.13 & 47 & Asia \\
\hline Value alignment & 2.51 & 0.08 & 55 & Asia \\
\hline Autonomous weapons & 2.40 & 0.10 & 57 & Asia \\
\hline Technological unemployment & 2.32 & 0.09 & 68 & Asia \\
\hline & & & & \\
\hline
\end{tabular}




\begin{tabular}{|l|l|l|l|l|}
\hline Critical AI systems failure & 2.65 & 0.08 & 56 & Asia \\
\hline
\end{tabular}

Table S7: Rating issue importance of AI governance challenges (by workplace type). The table presents AI/ML researchers' mean perceived importance of each of the AI governance challenges and the associated standard error and sample size by workplace type (academic and industry).

\begin{tabular}{|l|l|l|l|l|}
\hline Governance challenge & Mean & $S E$ & $N$ & Workplace type \\
\hline Hiring bias & 2.17 & 0.07 & 131 & Academic \\
\hline Criminal justice bias & 2.59 & 0.05 & 124 & Academic \\
\hline Disease diagnosis & 2.44 & 0.06 & 113 & Academic \\
\hline Data privacy & 2.50 & 0.06 & 125 & Academic \\
\hline Autonomous vehicles & 2.60 & 0.05 & 131 & Academic \\
\hline Digital manipulation & 2.45 & 0.07 & 113 & Academic \\
\hline Cyber attacks & 2.32 & 0.06 & 132 & Academic \\
\hline Surveillance & 2.47 & 0.06 & 127 & Academic \\
\hline US-China competition & 1.82 & 0.07 & 123 & Academic \\
\hline Value alignment & 2.36 & 0.07 & 111 & Academic \\
\hline Autonomous weapons & 2.47 & 0.07 & 117 & Academic \\
\hline Technological unemployment & 2.27 & 0.07 & 128 & Academic \\
\hline Critical AI systems failure & 2.57 & 0.05 & 135 & Academic \\
\hline Hiring bias & 2.20 & 0.12 & 42 & Industry \\
\hline Criminal justice bias & 2.53 & 0.10 & 43 & Industry \\
\hline Disease diagnosis & 2.50 & 0.09 & 42 & Industry \\
\hline Data privacy & 2.71 & 0.05 & 53 & Industry \\
\hline Autonomous vehicles & 2.45 & 0.14 & 35 & Industry \\
\hline Digital manipulation & 2.48 & 0.09 & 46 & Industry \\
\hline Cyber attacks & 2.50 & 0.08 & 48 & Industry \\
\hline Surveillance & 2.67 & 0.08 & 52 & Industry \\
\hline US-China competition & 1.64 & 0.13 & 40 & Industry \\
\hline Value alignment & 2.38 & 0.10 & 51 & Industry \\
\hline Autonomous weapons & 2.49 & 0.10 & 42 & Industry \\
\hline Technological unemployment & 2.24 & 0.11 & 45 & Industry \\
\hline Critical AI systems failure & 2.53 & 0.08 & 51 & Industry \\
\hline
\end{tabular}


Table S8: Association between perceived issue importance and different AI governance challenges. Output from the multiple linear regression used to compare differences in perceived issue importance between AI governance challenges. We regress perceived issue importance on all of the AI governance challenges. The (arbitrarily chosen) reference category, the one that is excluded from the list of coefficients, is critical AI system failure. We clustered the standard errors by survey respondent because each respondent was presented with five AI governance challenges randomly chosen from the list of 13. The F-test of overall significance rejects the null hypothesis that respondents perceive all the governance challenges to have equal issue importance. The Holm method was used to control the family-wise error rate.

\begin{tabular}{|c|c|}
\hline & Coefficient $(S E)$ \\
\hline \multirow[t]{2}{*}{ (Intercept) } & $2.579^{* * *}$ \\
\hline & $(0.051)$ \\
\hline \multirow[t]{2}{*}{ Autonomous weapons } & -0.104 \\
\hline & $(0.077)$ \\
\hline \multirow[t]{2}{*}{ Criminal justice bias } & 0.012 \\
\hline & $(0.067)$ \\
\hline \multirow[t]{2}{*}{ Critical AI systems failure } & -0.010 \\
\hline & $(0.065)$ \\
\hline \multirow[t]{2}{*}{ Cyber attacks } & -0.175 \\
\hline & $(0.071)$ \\
\hline \multirow[t]{2}{*}{ Data privacy } & -0.033 \\
\hline & $(0.066)$ \\
\hline \multirow[t]{2}{*}{ Digital manipulation } & -0.113 \\
\hline & $(0.072)$ \\
\hline \multirow[t]{2}{*}{ Disease diagnosis } & -0.124 \\
\hline & $(0.070)$ \\
\hline \multirow[t]{2}{*}{ Hiring bias } & $-0.400^{* * *}$ \\
\hline & $(0.077)$ \\
\hline \multirow[t]{2}{*}{ Surveillance } & -0.049 \\
\hline & $(0.071)$ \\
\hline \multirow[t]{2}{*}{ Technological unemployment } & $-0.308^{* * *}$ \\
\hline & $(0.076)$ \\
\hline \multirow[t]{2}{*}{ US-China competition } & $-0.804^{* * *}$ \\
\hline & $(0.082)$ \\
\hline \multirow[t]{2}{*}{ Value alignment } & $-0.224^{*}$ \\
\hline & $(0.075)$ \\
\hline $\bar{N}$ & 2,150 responses; 430 unique respondents \\
\hline$F$-Statistic & $13.93^{* * *}(d f=12 ; 429)$ \\
\hline
\end{tabular}


Table S9: Association between perceived issue importance and demographic variables controlling for issues. The table presents the output from the multiple linear regression used to compare differences in perceived issue importance between demographic subgroups whilst controlling for the different types of AI governance issues. We regressed perceived issue importance on the categorical variables of gender (female/other, male, and prefer not to say or missing response), location of undergraduate education (Europe, US, China, other, and missing response), location of work/study (Europe, US, China, and other), and type of workplace (industry and academic). The (arbitrarily chosen) reference categories, the ones that are excluded from the list of coefficients, are female/other for gender, and China for the location of undergraduate education and place of work/study. The F-test of overall significance rejects the null hypothesis that respondents do not differ in their perceived importance of AI governance challenges (when controlling for issue) depending on demographic subgroups. We cluster the standard errors by respondents because each respondent was presented with five AI governance challenges. The Holm method was used to control the family-wise error rate.

\begin{tabular}{ll}
\hline & Coefficient $(S E)$ \\
\hline (Intercept) & $3.058^{* * *}$ \\
& $(0.135)$ \\
Gender: male & $-0.283^{* * *}$ \\
& $(0.055)$ \\
Gender: prefer not to say/NA & -0.311 \\
& $(0.172)$ \\
Place of undergraduate degree: Europe & -0.005 \\
& $(0.091)$ \\
Place of undergraduate degree: missing & 0.105 \\
& $(0.089)$ \\
Place of undergraduate degree: other & 0.155 \\
& $(0.079)$ \\
Place of undergraduate degree: US & 0.032 \\
& $(0.079)$ \\
Place of work: Europe & -0.230 \\
Place of work: other & $(0.106)$ \\
& -0.269 \\
Place of work: US & $(0.114)$ \\
Job: industry & -0.201 \\
& $(0.094)$ \\
Job: academic & -0.021 \\
& $(0.071)$ \\
$F$-Statistic & -0.074 \\
\hline & $(0.072)$ \\
\hline & 2,150 responses, 430 unique respondents \\
& $8.935^{* * *}(d f=23 ; 429)$ \\
\hline
\end{tabular}

${ }^{*} \mathrm{p}<.05 ;{ }^{* *} \mathrm{p}<.01 ;{ }^{* * *} \mathrm{p}<.001$ 
Trust in aCtors to Shape the DeVelopment and use of AI in the Public INTEREST

Table S10: Trust in actors to shape the development and use of AI in the public interest: comparing $A I / M L$ researchers' and the US public's responses. This table contains the data used to generate Figure 2. AI/ML researchers were shown five randomly selected actors and asked to evaluate how much they trust the actors using a four-point scale: $0=$ no trust at all, $1=$ not too much trust, 2 $=$ a fair amount of trust, $3=$ a great deal of trust. For the AI/ML researchers survey, the "Tech companies" result is the mean response across all corporate actors presented to respondents. The AI/ML researchers' responses to the US military and the Chinese military are denoted with $*$ because those two actors were shown only to those who do research in the US or China. These respondents had an equal probability of being shown the US military or the Chinese military. In the public opinion survey, respondents were asked about their confidence in the actors to develop AI (question type A) or manage the development and use of AI (question type B) in the best interest of the public using a similar four-point scale. For question type $C$, both questions were asked; we averaged the responses to these two questions for each of these actors for clarity. For "US intelligence agencies," we averaged across responses to the NSA, the FBI, and the CIA. Table S11 contains the detailed breakdowns by actor and respondent type.

\begin{tabular}{|c|c|c|c|c|c|c|}
\hline Actor & $\begin{array}{l}\text { Question } \\
\text { type }\end{array}$ & Mean & $S E$ & $N$ & Subgroup & Actor type \\
\hline $\begin{array}{l}\text { Government of the } \\
\text { country where they do } \\
\text { research }\end{array}$ & & 1.33 & 0.08 & 100 & $\begin{array}{l}\mathrm{AI} / \mathrm{ML} \text { re- } \\
\text { searchers }\end{array}$ & National \\
\hline $\begin{array}{l}\text { Military of the country } \\
\text { where they do research }\end{array}$ & & 0.83 & 0.08 & 106 & $\begin{array}{l}\mathrm{AI} / \mathrm{ML} \text { re- } \\
\text { searchers }\end{array}$ & National \\
\hline US government & & 0.94 & 0.07 & 113 & $\begin{array}{l}\mathrm{AI} / \mathrm{ML} \text { re- } \\
\text { searchers }\end{array}$ & National \\
\hline Chinese government & & 0.38 & 0.06 & 115 & $\begin{array}{l}\mathrm{AI} / \mathrm{ML} \text { re- } \\
\text { searchers }\end{array}$ & National \\
\hline US military* & & 0.73 & 0.10 & 56 & $\begin{array}{l}\text { AI/ML } \\
\text { researchers } \\
\text { (does re- } \\
\text { search in } \\
\text { the US } \\
\text { only) }\end{array}$ & National \\
\hline Chinese military* & & 0.30 & 0.08 & 60 & 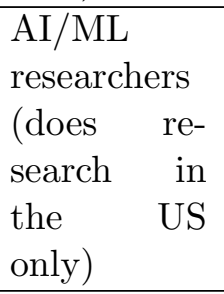 & National \\
\hline $\mathrm{UN}$ & & 1.74 & 0.08 & 122 & $\begin{array}{l}\mathrm{AI} / \mathrm{ML} \text { re- } \\
\text { searchers }\end{array}$ & International \\
\hline $\mathrm{EU}$ & & 1.98 & 0.06 & 114 & $\begin{array}{l}\mathrm{AI} / \mathrm{ML} \text { re- } \\
\text { searchers }\end{array}$ & International \\
\hline
\end{tabular}




\begin{tabular}{|c|c|c|c|c|c|c|}
\hline $\begin{array}{l}\text { Intergovernmental re- } \\
\text { search organizations } \\
\text { (e.g., CERN) }\end{array}$ & & 2.08 & 0.06 & 114 & $\begin{array}{l}\mathrm{AI} / \mathrm{ML} \text { re- } \\
\text { searchers }\end{array}$ & International \\
\hline Tech companies & & 0.98 & 0.03 & 1171 & $\begin{array}{l}\mathrm{AI} / \mathrm{ML} \text { re- } \\
\text { searchers }\end{array}$ & Corporate \\
\hline Google & & 1.35 & 0.07 & 131 & $\begin{array}{l}\text { AI/ML re- } \\
\text { searchers }\end{array}$ & Corporate \\
\hline Facebook & & 0.58 & 0.06 & 104 & $\begin{array}{l}\text { AI/ML re- } \\
\text { searchers }\end{array}$ & Corporate \\
\hline Apple & & 1.05 & 0.07 & 117 & $\begin{array}{l}\mathrm{AI} / \mathrm{ML} \text { re- } \\
\text { searchers }\end{array}$ & Corporate \\
\hline Microsoft & & 1.43 & 0.07 & 118 & $\begin{array}{l}\text { AI/ML re- } \\
\text { searchers }\end{array}$ & Corporate \\
\hline Amazon & & 0.88 & 0.06 & 108 & $\begin{array}{l}\text { AI/ML re- } \\
\text { searchers }\end{array}$ & Corporate \\
\hline OpenAI & & 1.50 & 0.08 & 113 & $\begin{array}{l}\mathrm{AI} / \mathrm{ML} \text { re- } \\
\text { searchers }\end{array}$ & Corporate \\
\hline DeepMind & & 1.37 & 0.09 & 99 & $\begin{array}{l}\text { AI/ML re- } \\
\text { searchers }\end{array}$ & Corporate \\
\hline Tencent & & 0.69 & 0.06 & 116 & $\begin{array}{l}\text { AI/ML re- } \\
\text { searchers }\end{array}$ & Corporate \\
\hline Baidu & & 0.50 & 0.05 & 134 & $\begin{array}{l}\mathrm{AI} / \mathrm{ML} \text { re- } \\
\text { searchers }\end{array}$ & Corporate \\
\hline Alibaba & & 0.57 & 0.05 & 131 & $\begin{array}{l}\mathrm{AI} / \mathrm{ML} \text { re- } \\
\text { searchers }\end{array}$ & Corporate \\
\hline $\begin{array}{l}\text { Non-government scien- } \\
\text { tific organization (e.g., } \\
\text { AAAI) }\end{array}$ & & 2.12 & 0.06 & 104 & $\begin{array}{l}\mathrm{AI} / \mathrm{ML} \text { re- } \\
\text { searchers }\end{array}$ & Other \\
\hline Partnership on AI & & 1.89 & 0.06 & 103 & $\begin{array}{l}\mathrm{AI} / \mathrm{ML} \text { re- } \\
\text { searchers }\end{array}$ & Other \\
\hline US government & $\mathrm{B}$ & 1.05 & 0.04 & 743 & US public & National \\
\hline US military* $^{*}$ & $\mathrm{~A}$ & 1.56 & 0.04 & 638 & US public & National \\
\hline US intelligence agencies & $\mathrm{A}$ & 1.16 & 0.03 & 2096 & US public & National \\
\hline UN & $\mathrm{B}$ & 1.06 & 0.03 & 802 & US public & International \\
\hline $\begin{array}{l}\text { Intergovernmental re- } \\
\text { search organizations } \\
\text { (e.g., CERN) }\end{array}$ & $\mathrm{C}$ & 1.30 & 0.03 & 1392 & US public & International \\
\hline NATO & $\mathrm{A}$ & 1.17 & 0.03 & 695 & US public & International \\
\hline $\begin{array}{l}\text { International organiza- } \\
\text { tions }\end{array}$ & $\mathrm{B}$ & 1.10 & 0.03 & 827 & US public & International \\
\hline Tech companies & $\mathrm{C}$ & 1.33 & 0.03 & 1432 & US public & Corporate \\
\hline Google & $\mathrm{C}$ & 1.20 & 0.03 & 1412 & US public & Corporate \\
\hline Facebook & $\mathrm{C}$ & 0.78 & 0.03 & 1373 & US public & Corporate \\
\hline
\end{tabular}




\begin{tabular}{|l|l|l|l|l|l|l|}
\hline Apple & C & 1.19 & 0.03 & 1367 & US public & Corporate \\
\hline Microsoft & C & 1.26 & 0.03 & 1368 & US public & Corporate \\
\hline Amazon & C & 1.22 & 0.03 & 1469 & US public & Corporate \\
\hline $\begin{array}{l}\text { Non-government scien- } \\
\text { tific organization (e.g., } \\
\text { AAAI) }\end{array}$ & B & 1.35 & 0.03 & 792 & US public & Other \\
\hline Partnership on AI & B & 1.35 & 0.03 & 780 & US public & Other \\
\hline University researchers & A & 1.56 & 0.03 & 666 & US public & Other \\
\hline
\end{tabular}

Table S11: Trust in actors to shape the development and use of AI in the public interest: by respondent type. The table presents the mean trust in different actors and the associated standard error and sample size by type of actor (national government, international, corporate, and other) and type of respondent (AI/ML researchers and US public).

\begin{tabular}{|l|l|l|l|l|l|}
\hline Actor & Mean & $S E$ & $N$ & Actor type & Respondent type \\
\hline US government & 0.94 & 0.07 & 113 & National & AI/ML researchers \\
\hline Chinese government & 0.38 & 0.06 & 115 & National & AI/ML researchers \\
\hline $\begin{array}{l}\text { Government of the country where } \\
\text { they do research }\end{array}$ & 1.33 & 0.08 & 100 & National & AI/ML researchers \\
\hline $\begin{array}{l}\text { Military of the country where they } \\
\text { do research }\end{array}$ & 0.83 & 0.08 & 106 & National & AI/ML researchers \\
\hline US military & 0.68 & 0.09 & 60 & National & AI/ML researchers \\
\hline Chinese military & 0.38 & 0.09 & 66 & National & AI/ML researchers \\
\hline UN & 1.74 & 0.08 & 122 & International & AI/ML researchers \\
\hline EU & 1.98 & 0.06 & 114 & International & AI/ML researchers \\
\hline $\begin{array}{l}\text { Intergovernmental research organi- } \\
\text { zations (e.g., CERN) }\end{array}$ & 2.08 & 0.06 & 114 & International & AI/ML researchers \\
\hline Google & 1.35 & 0.07 & 131 & Corporate & AI/ML researchers \\
\hline Facebook & 0.58 & 0.06 & 104 & Corporate & AI/ML researchers \\
\hline Apple & 1.05 & 0.07 & 117 & Corporate & AI/ML researchers \\
\hline Microsoft & 1.43 & 0.07 & 118 & Corporate & AI/ML researchers \\
\hline Amazon & 0.88 & 0.06 & 108 & Corporate & AI/ML researchers \\
\hline OpenAI & 1.50 & 0.08 & 113 & Corporate & AI/ML researchers \\
\hline DeepMind & 1.37 & 0.09 & 99 & Corporate & AI/ML researchers \\
\hline Tencent & 0.69 & 0.06 & 116 & Corporate & AI/ML researchers \\
\hline Baidu & 0.50 & 0.05 & 134 & Corporate & AI/ML researchers \\
\hline Alibaba & 0.57 & 0.05 & 131 & Corporate & AI/ML researchers \\
\hline $\begin{array}{l}\text { Non-government scientific organiza- } \\
\text { tion (e.g., AAAI) }\end{array}$ & 2.12 & 0.06 & 104 & Other & AI/ML researchers \\
\hline Partnership on AI & 1.89 & 0.06 & 103 & Other & AI/ML researchers \\
\hline Amazon & 1.33 & 0.04 & 685 & Corporate & Public \\
\hline Apple & 1.29 & 0.04 & 697 & Corporate & Public \\
\hline CIA & 1.21 & 0.04 & 730 & National & Public \\
\hline
\end{tabular}




\begin{tabular}{|l|l|l|l|l|l|}
\hline Facebook & 0.85 & 0.04 & 632 & Corporate & Public \\
\hline FBI & 1.21 & 0.04 & 656 & National & Public \\
\hline Google & 1.34 & 0.04 & 645 & Corporate & Public \\
\hline $\begin{array}{l}\text { Intergovernmental research organi- } \\
\text { zations (e.g., CERN) }\end{array}$ & 1.42 & 0.04 & 645 & International & Public \\
\hline Microsoft & 1.40 & 0.04 & 597 & Corporate & Public \\
\hline NATO & 1.17 & 0.03 & 695 & International & Public \\
\hline Non-profit (e.g., OpenAI) & 1.44 & 0.03 & 659 & Other & Public \\
\hline NSA & 1.28 & 0.04 & 710 & National & Public \\
\hline Tech companies & 1.44 & 0.03 & 674 & Corporate & Public \\
\hline US civilian government & 1.16 & 0.03 & 671 & National & Public \\
\hline US military & 1.56 & 0.04 & 638 & National & Public \\
\hline University researchers & 1.56 & 0.03 & 666 & Other & Public \\
\hline Amazon & 1.24 & 0.03 & 784 & Corporate & Public \\
\hline Apple & 1.20 & 0.03 & 775 & Corporate & Public \\
\hline Facebook & 0.91 & 0.03 & 741 & Corporate & Public \\
\hline Google & 1.20 & 0.03 & 767 & Corporate & Public \\
\hline $\begin{array}{l}\text { Intergovernmental research organi- } \\
\text { zations (e.g., CERN) }\end{array}$ & 1.27 & 0.03 & 747 & International & Public \\
\hline International organizations & 1.10 & 0.03 & 827 & International & Public \\
\hline Microsoft & 1.24 & 0.03 & 771 & Corporate & Public \\
\hline $\begin{array}{l}\text { Non-government scientific organiza- } \\
\text { tion (e.g., AAAI) }\end{array}$ & 1.35 & 0.03 & 792 & Other & Public \\
\hline Partnership on AI & 1.35 & 0.03 & 780 & Other & Public \\
\hline Tech companies & 1.33 & 0.03 & 758 & Corporate & Public \\
\hline US federal government & 1.05 & 0.04 & 743 & National & Public \\
\hline US state governments & 1.05 & 0.03 & 713 & National & Public \\
\hline UN & 1.06 & 0.03 & 802 & International & Public \\
\hline
\end{tabular}

Table S12: Trust in actors to shape the development and use of AI in the public interest (by undergraduate country). The table presents the mean trust in different actors and the associated standard error and sample size by country of undergraduate education (US and China) and type of actor (national government, international, corporate, and other).

\begin{tabular}{|l|l|l|l|l|l|}
\hline Actor & Mean & $S E$ & $N$ & Undergraduate country & Actor type \\
\hline US government & 1.08 & 0.14 & 23 & US & National \\
\hline Chinese government & 0.14 & 0.06 & 27 & US & National \\
\hline $\begin{array}{l}\text { Government of the country where } \\
\text { they do research }\end{array}$ & 1.14 & 0.16 & 21 & US & National \\
\hline $\begin{array}{l}\text { Military of the country where they } \\
\text { do research }\end{array}$ & 0.85 & 0.17 & 21 & US & National \\
\hline US military & 0.92 & 0.20 & 17 & US & National \\
\hline Chinese military & 0.27 & 0.14 & 24 & US & National \\
\hline
\end{tabular}




\begin{tabular}{|c|c|c|c|c|c|}
\hline $\mathrm{UN}$ & 1.73 & 0.21 & 22 & US & International \\
\hline $\mathrm{EU}$ & 1.64 & 0.16 & 25 & US & International \\
\hline $\begin{array}{l}\text { Intergovernmental research organi- } \\
\text { zations (e.g., CERN) }\end{array}$ & 2.13 & 0.13 & 25 & US & International \\
\hline Google & 1.41 & 0.12 & 32 & US & Corporate \\
\hline Facebook & 0.55 & 0.12 & 23 & US & Corporate \\
\hline Apple & 1.00 & 0.11 & 31 & US & Corporate \\
\hline Microsoft & 1.38 & 0.13 & 30 & US & Corporate \\
\hline Amazon & 0.90 & 0.15 & 22 & US & Corporate \\
\hline OpenAI & 1.44 & 0.14 & 24 & US & Corporate \\
\hline DeepMind & 1.31 & 0.17 & 27 & US & Corporate \\
\hline Tencent & 0.54 & 0.09 & 23 & US & Corporate \\
\hline Baidu & 0.44 & 0.09 & 32 & US & Corporate \\
\hline Alibaba & 0.41 & 0.08 & 32 & US & Corporate \\
\hline $\begin{array}{l}\text { Non-government scientific organiza- } \\
\text { tion (e.g., AAAI) }\end{array}$ & 1.92 & 0.15 & 23 & US & Other \\
\hline Partnership on AI & 2.13 & 0.12 & 22 & US & Other \\
\hline US government & 1.00 & 0.19 & 19 & China & National \\
\hline Chinese government & 1.30 & 0.16 & 14 & China & National \\
\hline $\begin{array}{l}\text { Government of the country where } \\
\text { they do research }\end{array}$ & 1.36 & 0.21 & 15 & China & National \\
\hline $\begin{array}{l}\text { Military of the country where they } \\
\text { do research }\end{array}$ & 0.97 & 0.19 & 19 & China & National \\
\hline US military & 0.56 & 0.19 & 15 & China & National \\
\hline Chinese military & 1.01 & 0.22 & 16 & China & National \\
\hline $\mathrm{UN}$ & 1.85 & 0.17 & 19 & China & International \\
\hline $\mathrm{EU}$ & 2.06 & 0.14 & 16 & China & International \\
\hline $\begin{array}{l}\text { Intergovernmental research organi- } \\
\text { zations (e.g., CERN) }\end{array}$ & 2.09 & 0.08 & 12 & China & International \\
\hline Google & 1.71 & 0.21 & 17 & China & Corporate \\
\hline Facebook & 1.10 & 0.16 & 16 & China & Corporate \\
\hline Apple & 1.67 & 0.19 & 15 & China & Corporate \\
\hline Microsoft & 1.90 & 0.17 & 16 & China & Corporate \\
\hline Amazon & 1.06 & 0.17 & 16 & China & Corporate \\
\hline OpenAI & 1.81 & 0.17 & 21 & China & Corporate \\
\hline DeepMind & 1.60 & 0.23 & 9 & China & Corporate \\
\hline Tencent & 1.59 & 0.17 & 17 & China & Corporate \\
\hline Baidu & 1.00 & 0.19 & 19 & China & Corporate \\
\hline Alibaba & 1.31 & 0.20 & 18 & China & Corporate \\
\hline $\begin{array}{l}\text { Non-government scientific organiza- } \\
\text { tion (e.g., AAAI) }\end{array}$ & 2.21 & 0.14 & 15 & China & Other \\
\hline Partnership on AI & 1.80 & 0.14 & 22 & China & Other \\
\hline
\end{tabular}


Table S13: Trust in actors to shape the development and use of AI in the public interest (by undergraduate region). The table presents the mean trust in different actors and the associated standard error and sample size by region of undergraduate education (Europe, North America, and Asia) and type of actor (national government, international, corporate, and other).

\begin{tabular}{|c|c|c|c|c|c|}
\hline Actor & Mean & $S E$ & $N$ & Undergraduate region & Actor type \\
\hline US government & 0.87 & 0.11 & 33 & Europe & National \\
\hline Chinese government & 0.25 & 0.09 & 31 & Europe & National \\
\hline $\begin{array}{l}\text { Government of the } \\
\text { country where they do } \\
\text { research }\end{array}$ & 1.64 & 0.16 & 22 & Europe & National \\
\hline $\begin{array}{l}\text { Military of the country } \\
\text { where they do research }\end{array}$ & 0.88 & 0.17 & 24 & Europe & National \\
\hline US military & 0.71 & 0.29 & 7 & Europe & National \\
\hline Chinese military & 0.23 & 0.17 & 6 & Europe & National \\
\hline UN & 1.81 & 0.14 & 33 & Europe & International \\
\hline EU & 1.96 & 0.11 & 28 & Europe & International \\
\hline $\begin{array}{l}\text { Intergovernmental re- } \\
\text { search organizations } \\
\text { (e.g., CERN) }\end{array}$ & 2.22 & 0.11 & 30 & Europe & International \\
\hline Google & 1.12 & 0.16 & 29 & Europe & Corporate \\
\hline Facebook & 0.62 & 0.14 & 22 & Europe & Corporate \\
\hline Apple & 0.76 & 0.14 & 24 & Europe & Corporate \\
\hline Microsoft & 1.30 & 0.17 & 24 & Europe & Corporate \\
\hline Amazon & 0.94 & 0.11 & 27 & Europe & Corporate \\
\hline OpenAI & 1.36 & 0.16 & 32 & Europe & Corporate \\
\hline DeepMind & 1.47 & 0.16 & 25 & Europe & Corporate \\
\hline Tencent & 0.54 & 0.07 & 30 & Europe & Corporate \\
\hline Baidu & 0.33 & 0.09 & 29 & Europe & Corporate \\
\hline Alibaba & 0.41 & 0.08 & 37 & Europe & Corporate \\
\hline $\begin{array}{l}\text { Non-government scien- } \\
\text { tific organization (e.g., } \\
\text { AAAI) }\end{array}$ & 2.23 & 0.13 & 22 & Europe & Other \\
\hline Partnership on AI & 1.80 & 0.14 & 16 & Europe & Other \\
\hline US government & 1.07 & 0.14 & 26 & North America & National \\
\hline Chinese government & 0.17 & 0.07 & 28 & North America & National \\
\hline $\begin{array}{l}\text { Government of the } \\
\text { country where they do } \\
\text { research }\end{array}$ & 1.17 & 0.14 & 24 & North America & National \\
\hline $\begin{array}{l}\text { Military of the country } \\
\text { where they do research }\end{array}$ & 0.83 & 0.16 & 24 & North America & National \\
\hline US military & 0.93 & 0.18 & 19 & North America & National \\
\hline Chinese military & 0.24 & 0.12 & 27 & North America & National \\
\hline UN & 1.68 & 0.19 & 25 & North America & International \\
\hline
\end{tabular}




\begin{tabular}{|c|c|c|c|c|c|}
\hline $\mathrm{EU}$ & 1.68 & 0.15 & 28 & North America & International \\
\hline $\begin{array}{l}\text { Intergovernmental re- } \\
\text { search organizations } \\
\text { (e.g., CERN) }\end{array}$ & 2.14 & 0.11 & 30 & North America & International \\
\hline Google & 1.43 & 0.12 & 33 & North America & Corporate \\
\hline Facebook & 0.60 & 0.12 & 26 & North America & Corporate \\
\hline Apple & 0.95 & 0.11 & 34 & North America & Corporate \\
\hline Microsoft & 1.36 & 0.12 & 35 & North America & Corporate \\
\hline Amazon & 0.92 & 0.12 & 27 & North America & Corporate \\
\hline OpenAI & 1.44 & 0.14 & 25 & North America & Corporate \\
\hline DeepMind & 1.33 & 0.16 & 28 & North America & Corporate \\
\hline Tencent & 0.52 & 0.08 & 26 & North America & Corporate \\
\hline Baidu & 0.40 & 0.08 & 35 & North America & Corporate \\
\hline Alibaba & 0.40 & 0.08 & 35 & North America & Corporate \\
\hline $\begin{array}{l}\text { Non-government scien- } \\
\text { tific organization (e.g., } \\
\text { AAAI) }\end{array}$ & 1.93 & 0.14 & 26 & North America & Other \\
\hline Partnership on AI & 2.13 & 0.11 & 23 & North America & Other \\
\hline US government & 0.99 & 0.14 & 39 & Asia & National \\
\hline Chinese government & 0.61 & 0.12 & 37 & Asia & National \\
\hline $\begin{array}{l}\text { Government of the } \\
\text { country where they do } \\
\text { research }\end{array}$ & 1.30 & 0.14 & 39 & Asia & National \\
\hline $\begin{array}{l}\text { Military of the country } \\
\text { where they do research }\end{array}$ & 0.84 & 0.12 & 41 & Asia & National \\
\hline US military & 0.59 & 0.14 & 26 & Asia & National \\
\hline Chinese military & 0.72 & 0.19 & 23 & Asia & National \\
\hline UN & 1.58 & 0.14 & 42 & Asia & International \\
\hline $\mathrm{EU}$ & 2.15 & 0.12 & 34 & Asia & International \\
\hline $\begin{array}{l}\text { Intergovernmental re- } \\
\text { search organizations } \\
\text { (e.g., CERN) }\end{array}$ & 1.89 & 0.12 & 33 & Asia & International \\
\hline Google & 1.61 & 0.13 & 43 & Asia & Corporate \\
\hline Facebook & 0.70 & 0.11 & 37 & Asia & Corporate \\
\hline Apple & 1.34 & 0.13 & 39 & Asia & Corporate \\
\hline Microsoft & 1.64 & 0.13 & 38 & Asia & Corporate \\
\hline Amazon & 0.94 & 0.10 & 38 & Asia & Corporate \\
\hline OpenAI & 1.76 & 0.13 & 39 & Asia & Corporate \\
\hline DeepMind & 1.31 & 0.18 & 28 & Asia & Corporate \\
\hline Tencent & 1.04 & 0.13 & 40 & Asia & Corporate \\
\hline Baidu & 0.65 & 0.11 & 46 & Asia & Corporate \\
\hline Alibaba & 0.81 & 0.12 & 42 & Asia & Corporate \\
\hline
\end{tabular}




\begin{tabular}{|l|l|l|l|l|l|}
\hline $\begin{array}{l}\text { Non-government scien- } \\
\text { tific organization (e.g., } \\
\text { AAAI) }\end{array}$ & 2.23 & 0.10 & 37 & Asia & Other \\
\hline Partnership on AI & 1.83 & 0.10 & 44 & Asia & Other \\
\hline
\end{tabular}

Table S14: Trust in actors to shape the development and use of AI in the public interest (by workplace and actor). The table presents the mean trust in different actors and the associated standard error and sample size by type of workplace (academic and industry) and type of actor (national government, international, corporate, and other).

\begin{tabular}{|l|l|l|l|l|l|}
\hline Actor & Mean & $S E$ & $N$ & Workplace type & Actor type \\
\hline US government & 0.96 & 0.08 & 89 & Academic & National \\
\hline Chinese government & 0.34 & 0.07 & 84 & Academic & National \\
\hline $\begin{array}{l}\text { Government of the country where } \\
\text { they do research }\end{array}$ & 1.30 & 0.10 & 72 & Academic & National \\
\hline $\begin{array}{l}\text { Military of the country where they } \\
\text { do research }\end{array}$ & 0.80 & 0.09 & 74 & Academic & National \\
\hline US military & 0.54 & 0.10 & 39 & Academic & National \\
\hline Chinese military & 0.49 & 0.11 & 49 & Academic & National \\
\hline UN & 1.77 & 0.09 & 92 & Academic & International \\
\hline EU & 2.06 & 0.07 & 88 & Academic & International \\
\hline $\begin{array}{l}\text { Intergovernmental research organi- } \\
\text { zations (e.g., CERN) }\end{array}$ & 2.07 & 0.08 & 82 & Academic & International \\
\hline Google & 1.40 & 0.08 & 97 & Academic & Corporate \\
\hline Facebook & 0.56 & 0.07 & 80 & Academic & Corporate \\
\hline Apple & 1.18 & 0.08 & 82 & Academic & Corporate \\
\hline Microsoft & 1.41 & 0.09 & 89 & Academic & Corporate \\
\hline Amazon & 0.92 & 0.07 & 81 & Academic & Corporate \\
\hline OpenAI & 1.55 & 0.09 & 92 & Academic & Corporate \\
\hline DeepMind & 1.41 & 0.10 & 68 & Academic & Corporate \\
\hline Tencent & 0.73 & 0.07 & 94 & Academic & Corporate \\
\hline Baidu & 0.54 & 0.06 & 99 & Academic & Corporate \\
\hline Alibaba & 0.59 & 0.06 & 98 & Academic & Corporate \\
\hline $\begin{array}{l}\text { Non-government scientific organiza- } \\
\text { tion (e.g., AAAI) }\end{array}$ & 2.17 & 0.07 & 80 & Academic & Other \\
\hline Partnership on AI & 1.87 & 0.08 & 74 & Academic & Other \\
\hline US government & 0.80 & 0.12 & 26 & Industry & National \\
\hline Chinese government & 0.41 & 0.11 & 33 & Industry & National \\
\hline $\begin{array}{l}\text { Government of the country where } \\
\text { they do research }\end{array}$ & 1.12 & 0.14 & 28 & Industry & National \\
\hline $\begin{array}{l}\text { Military of the country where they } \\
\text { do research }\end{array}$ & 0.91 & 0.15 & 34 & Industry & National \\
\hline US military & 1.00 & 0.19 & 19 & Industry & National \\
\hline
\end{tabular}




\begin{tabular}{|l|l|l|l|l|l|}
\hline Chinese military & 0.30 & 0.17 & 19 & Industry & National \\
\hline UN & 1.66 & 0.13 & 37 & Industry & International \\
\hline EU & 1.88 & 0.14 & 33 & Industry & International \\
\hline $\begin{array}{l}\text { Intergovernmental research organi- } \\
\text { zations (e.g., CERN) }\end{array}$ & 2.03 & 0.10 & 39 & Industry & International \\
\hline Google & 1.25 & 0.13 & 37 & Industry & Corporate \\
\hline Facebook & 0.74 & 0.11 & 29 & Industry & Corporate \\
\hline Apple & 0.87 & 0.13 & 38 & Industry & Corporate \\
\hline Microsoft & 1.54 & 0.12 & 32 & Industry & Corporate \\
\hline Amazon & 0.63 & 0.09 & 27 & Industry & Corporate \\
\hline OpenAI & 1.21 & 0.18 & 19 & Industry & Corporate \\
\hline DeepMind & 1.39 & 0.16 & 30 & Industry & Corporate \\
\hline Tencent & 0.55 & 0.09 & 24 & Industry & Corporate \\
\hline Baidu & 0.42 & 0.09 & 36 & Industry & Corporate \\
\hline Alibaba & 0.62 & 0.10 & 36 & Industry & Corporate \\
\hline $\begin{array}{l}\text { Non-government scientific organiza- } \\
\text { tion (e.g., AAAI) }\end{array}$ & 1.77 & 0.12 & 25 & Industry & Other \\
\hline Partnership on AI & & & & & Other \\
\hline
\end{tabular}

Table S15: Trust in actors to shape the development and use of AI in the public interest (respondents who spend most of their time doing research in the US). The table presents the mean trust in different actors and the associated standard error and sample size by type of actor (national government, international, corporate, and other) for respondents who work in the US.

\begin{tabular}{|l|l|l|l|l|l|}
\hline Actor & Mean & $S E$ & $N$ & $\begin{array}{l}\text { Country where } \\
\text { they do research }\end{array}$ & Actor type \\
\hline US government & 1.11 & 0.11 & 55 & US & National \\
\hline Chinese government & 0.45 & 0.11 & 45 & US & National \\
\hline US military & 0.73 & 0.10 & 56 & US & National \\
\hline Chinese military & 0.30 & 0.08 & 60 & US & National \\
\hline UN & 1.77 & 0.10 & 52 & US & International \\
\hline EU & 1.91 & 0.10 & 58 & US & International \\
\hline $\begin{array}{l}\text { Intergovernmental research organi- } \\
\text { zations (e.g., CERN) }\end{array}$ & 1.96 & 0.09 & 47 & US & International \\
\hline Google & 1.36 & 0.10 & 62 & US & Corporate \\
\hline Facebook & 0.56 & 0.09 & 50 & US & Corporate \\
\hline Apple & 1.18 & 0.13 & 44 & US & Corporate \\
\hline Microsoft & 1.56 & 0.11 & 63 & US & Corporate \\
\hline Amazon & 0.94 & 0.08 & 52 & US & Corporate \\
\hline OpenAI & 1.59 & 0.12 & 54 & US & Corporate \\
\hline DeepMind & 1.37 & 0.13 & 44 & US & Corporate \\
\hline Tencent & 0.85 & 0.11 & 49 & US & Corporate \\
\hline Baidu & 0.50 & 0.08 & 62 & US & Corporate \\
\hline
\end{tabular}




\begin{tabular}{|l|l|l|l|l|l|}
\hline Alibaba & 0.67 & 0.10 & 61 & US & Corporate \\
\hline $\begin{array}{l}\text { Non-government scientific organiza- } \\
\text { tion (e.g., AAAI) }\end{array}$ & 2.09 & 0.10 & 50 & US & Other \\
\hline Partnership on AI & 1.86 & 0.09 & 51 & US & Other \\
\hline
\end{tabular}

Table S16: Association between trust and all of the different actors. The table presents the output from the multiple linear regression used to compare differences in rated trust between all actors. We regressed trust on all actors. The (arbitrarily chosen) reference category, the one that is excluded from the list of coefficients, is Alibaba. The F-test of overall significance rejects the null hypothesis that trust does not differ between the actors. The Holm method was used to control the family-wise error rate.

\begin{tabular}{ll}
\hline & Coefficient $(S E)$ \\
\hline (Intercept) & $0.566^{* * *}$ \\
& $(0.054)$ \\
Amazon & $0.316^{* * *}$ \\
& $(0.078)$ \\
Apple & $0.484^{* * *}$ \\
& $(0.078)$ \\
Baidu & -0.061 \\
& $(0.065)$ \\
Chinese government & -0.188 \\
& $(0.075)$ \\
Chinese military & -0.182 \\
& $(0.102)$ \\
DeepMind & $0.805^{* * *}$ \\
& $(0.102)$ \\
EU & $1.416^{* * *}$ \\
& $(0.084)$ \\
Facebook & 0.017 \\
Google & $(0.076)$ \\
& $0.788^{* * *}$ \\
Government of the country where they do & $(0.086)$ \\
research & $0.761^{* * *}$ \\
Intergovernmental research organizations & $(0.100)$ \\
(e.g., CERN) & $1.515^{* * *}$ \\
Microsoft & $(0.084)$ \\
Military of the country where they do re- & $0.266^{*}$ \\
search & \\
& $0.868^{* * *}$ \\
& $(0.087)$ \\
& \\
& \\
&
\end{tabular}


Non-government scientific organization $1.551^{* * *}$ (e.g., AAAI)

OpenAI

\section{OpenAI}

Partnership on AI

Pencent

Tencent

US government

0.123

$(0.064)$

US military

$0.372^{* * *}$

$(0.086)$

$\mathrm{UN}$

(0.092)

\begin{tabular}{ll}
\hline$N$ & 2,288 responses, 434 unique respondents \\
$F$-Statistic & $70.07^{* * *}(d f=20 ; 433)$ \\
\hline
\end{tabular}

${ }^{*} \mathrm{p}<.05 ;{ }^{* *} \mathrm{p}<.01 ;{ }^{* * *} \mathrm{p}<.001$

Table S1\%: Association between trust in actors and demographic variables controlling for actors. The table presents the output from the multiple linear regression used to compare differences in trust in actors between demographic subgroups whilst controlling for the different individual actors. We regressed trust in actors on the categorical variables of gender (female/other, male, and prefer not to say or missing response), location of undergraduate education (Europe, the US, China, other, and missing response), location of work/study (Europe, the US, China, and other), and type of workplace (industry, academic, and other). The (arbitrarily chosen) reference categories, the ones that are excluded from the list of coefficients, are female/other for gender, other for workplace type, and China for the location of undergraduate education and place of work/study. The F-test of overall significance rejects the null hypothesis that respondents do not differ in their trust of actors (when controlling for individual actors) between demographic subgroups. The Holm method was used to control the family-wise error rate.

\begin{tabular}{ll}
\hline & Coefficient $(S E)$ \\
\hline Intercept) & $0.765^{* * *}$ \\
& $(0.155)$ \\
Gender: male & 0.122 \\
& $(0.081)$ \\
Gender: prefer not to say/NA & 0.033 \\
& $(0.113)$ \\
Place of undergraduate degree: Europe & $-0.321^{*}$ \\
& $(0.095)$ \\
Place of undergraduate degree: missing & $-0.342^{*}$ \\
& $(0.103)$ \\
Place of undergraduate degree: other & $-0.402^{* * *}$ \\
& $(0.087)$ \\
Place of undergraduate degree: US & $-0.359^{* * *}$
\end{tabular}


$\begin{array}{ll}\text { Place of work: Europe } & (0.083) \\ & -0.046 \\ \text { Place of work: other } & (0.134) \\ & 0.054\end{array}$

$(0.137)$

Place of work: US $\quad 0.005$

$(0.125)$

Job: industry $\quad-0.047$

$(0.076)$

Job: academic $\quad 0.023$

$(0.079)$

$N \quad 2,288$ responses, 434 unique respondents

$F$-Statistic $55.41^{* * *}(d f=31 ; 433)$

${ }^{*} \mathrm{p}<.05 ;{ }^{* *} \mathrm{p}<.01 ;{ }^{* * *} \mathrm{p}<.001$

Table S18: Interaction between country of undergraduate degree and trust of Western versus Chinese tech companies. For this regression analysis, we focus only on respondents who received their undergraduate degrees in the US or China and trust in tech companies. We regress trust on whether the tech company is Western or Chinese, the country of the respondent's undergraduate degree, and the interaction between the two. Google, Facebook, Apple, Microsoft, Amazon, OpenAI, and DeepMind are coded as Western tech companies. Tencent, Baidu, and Alibaba are coded as Chinese tech companies. The arbitrary reference group for tech company type is Chinese tech companies; the arbitrary reference group for country of undergraduate degree is the US. We cluster standard errors by respondent because each respondent evaluated multiple tech companies. The Holm method was used to control the family-wise error rate.

\begin{tabular}{ll}
\hline & Coefficient $(S E)$ \\
\hline (Intercept) & $0.457^{* * *}$ \\
& $(0.061)$ \\
Western tech companies & $0.707^{* * *}$ \\
& $(0.075)$ \\
Place of undergraduate degree: China & $0.831^{* * *}$ \\
& $(0.148)$ \\
Western tech companies:Place of under- & $-0.437^{* *}$ \\
graduate degree: China & $(0.154)$ \\
\hline$N$ & 440 responses; 159 unique respondents \\
$F$-Statistic & $47.00^{* * *}(d f=3 ; 158)$ \\
\hline${ }^{*} \mathrm{p}<.05 ;{ }^{* *} \mathrm{p}<.01 ;{ }^{* * *} \mathrm{p}<.001$ &
\end{tabular}




\section{AI SAFETY}

Table S19: Familiarity with AI safety. The table presents the raw frequency and proportion of respondents who indicated different levels of familiarity with the issue of AI safety. The standard errors of the proportions are also presented. After reading a definition of AI safety (see the Text of the Survey section for the definition), respondents input their familiarity with AI safety using a five-point slider ( $0=$ not familiar at all; $4=$ very familiar $)$.

\begin{tabular}{|l|l|l|l|}
\hline AI safety familiarity level & Proportion & $S E$ & Frequency \\
\hline Missing & $<0.001$ & 0.00 & 1 \\
\hline 0 - Not familiar at all & 0.03 & 0.01 & 8 \\
\hline 1 & 0.25 & 0.03 & 71 \\
\hline 2 & 0.32 & 0.03 & 90 \\
\hline 3 & 0.25 & 0.03 & 72 \\
\hline 4 - Very familiar & 0.15 & 0.02 & 42 \\
\hline
\end{tabular}

Table S20: Familiarity with AI safety (mean response by demographic subgroups). The table presents the AI/ML researchers' mean familiarity with AI safety and the associated standard error and sample size, by demographic subgroup. After reading a definition of AI safety (see the Text of the Survey section for the definition), respondents input their familiarity with AI safety using a five-point slider $(0=$ not familiar at all; $4=$ very familiar $)$.

\begin{tabular}{|l|l|l|l|l|}
\hline Demographic subgroup & Demographic subgroup type & Mean & $S E$ & $N$ \\
\hline US & Undergraduate country & 2.48 & 0.15 & 56 \\
\hline China & Undergraduate country & 1.98 & 0.17 & 42 \\
\hline Europe & Undergraduate region & 2.12 & 0.12 & 69 \\
\hline North America & Undergraduate region & 2.45 & 0.14 & 64 \\
\hline Asia & Undergraduate region & 2.16 & 0.11 & 98 \\
\hline Academic & Workplace type & 2.22 & 0.07 & 217 \\
\hline Industry & Workplace type & 2.31 & 0.11 & 77 \\
\hline
\end{tabular}

Table S21: How much should AI safety be prioritized? Respondents were asked how much AI safety research should be prioritized relative to today. The answer choices are a Likert scale from -2 to 2: $-2=$ much less; $-1=$ less; $0=$ about the same; 1 = more; $2=$ much more. There was also an "I don't know" option. We present the proportion of respondents who chose each option or have a missing response, along with the associated standard error and raw frequency.

\begin{tabular}{|l|l|l|l|}
\hline AI safety prioritization & Proportion & $S E$ & Frequency \\
\hline -2: Much less & 0.01 & 0.01 & 4 \\
\hline -1: Less & 0.04 & 0.01 & 11 \\
\hline 0: About the same & 0.24 & 0.03 & 68 \\
\hline 1: More & 0.38 & 0.03 & 109 \\
\hline 2: Much more & 0.30 & 0.03 & 84 \\
\hline Missing & 0.00 & 0.00 & 0 \\
\hline I don't know & 0.03 & 0.01 & 8 \\
\hline
\end{tabular}


Table S22: Correlation between respondents' familiarity with AI safety and how much they think AI safety research should be prioritized. For both models, the outcome variable is how much the respondents think AI safety research should be prioritized. Model 1 looks at the bivariate relationship between these two variables. Model 2 includes demographic variables as controls, including gender (female/other, male, and prefer not to say or missing response), location of undergraduate education (Europe, US, Asia, other, and missing response), location of work (Europe, US, Asia, and other), and type of workplace (industry, academic, and other). The (arbitrarily chosen) reference categories, the ones that are excluded from the list of coefficients, are female/other for gender, other for workplace type, and Asia for location of undergraduate education and place of work/study. The Holm method was used to control the family-wise error rate.

\begin{tabular}{lll}
\hline & & Coefficient $(S E)$ \\
& $(1)$ & $(2)$ \\
\hline Intercept) & $0.709^{* * *}$ & 1.157 \\
& $(0.125)$ & $(0.397)$ \\
Familiarity with AI safety & 0.100 & 0.086 \\
& $(0.049)$ & $(0.047)$ \\
Gender: male & & $-0.484^{*}$ \\
& & $(0.156)$ \\
Gender: prefer not to say/NA & -0.479 \\
Place of undergraduate degree: Europe & & $(0.395)$ \\
& & 0.134 \\
Place of undergraduate degree: missing & & $(0.218)$ \\
& & 0.206 \\
Place of undergraduate degree: other & & $(0.224)$ \\
Place of undergraduate degree: US & & 0.421 \\
& & $(0.205)$ \\
Place of work: Europe & & 0.086 \\
& & $(0.203)$ \\
Place of work: other & 0.004 \\
Place of work: US & & $(0.340)$ \\
Job: industry & -0.229 \\
Job: academic & & $(0.374)$ \\
& & 0.066 \\
& & $(0.335)$ \\
& & -0.162 \\
& & $(0.148)$ \\
& & -0.154 \\
& & $(0.165)$ \\
& & 284 \\
& & $1.928(d f=12 ; 271)$ \\
\hline
\end{tabular}

${ }^{*} \mathrm{p}<.05 ;{ }^{* *} \mathrm{p}<.01 ;{ }^{* * *} \mathrm{p}<.001$ 


\section{AtTitudes toward MiLitary APplications of AI}

Table S23: Attitudes toward researchers working on military applications of AI: distribution of responses. Respondents were asked to indicate their level of support for two of the three randomly presented military applications (lethal autonomous weapons, surveillance, and logistics) on a fivepoint scale from -2 to 2. Each military application was defined when it was presented (see the Text of the Survey section for the definition). The table presents the proportion of respondents that indicated each level of response or answered "I don't know", along with the associated standard error and raw frequency, by military application type. The proportion of missing responses is also presented.

\begin{tabular}{|l|l|l|l|l|}
\hline Military application type & Response & Proportion & $S E$ & Frequency \\
\hline Lethal autonomous weapons & -2: Strongly oppose & 0.58 & 0.03 & 178 \\
\hline Lethal autonomous weapons & -1: Somewhat oppose & 0.16 & 0.02 & 48 \\
\hline Lethal autonomous weapons & 0: Neither support nor oppose & 0.14 & 0.02 & 44 \\
\hline Lethal autonomous weapons & 1: Somewhat support & 0.07 & 0.01 & 20 \\
\hline Lethal autonomous weapons & 2: Strongly support & 0.01 & 0.00 & 2 \\
\hline Lethal autonomous weapons & Missing & 0.01 & 0.01 & 3 \\
\hline Lethal autonomous weapons & I don't know & 0.04 & 0.01 & 11 \\
\hline Surveillance & -2: Strongly oppose & 0.20 & 0.02 & 58 \\
\hline Surveillance & -1: Somewhat oppose & 0.21 & 0.02 & 60 \\
\hline Surveillance & 0: Neither support nor oppose & 0.26 & 0.03 & 75 \\
\hline Surveillance & 1: Somewhat support & 0.22 & 0.02 & 63 \\
\hline Surveillance & 2: Strongly support & 0.07 & 0.01 & 19 \\
\hline Surveillance & Missing & 0.01 & 0.01 & 3 \\
\hline Surveillance & I don't know & 0.04 & 0.01 & 11 \\
\hline Logistics & -2: Strongly oppose & 0.06 & 0.01 & 17 \\
\hline Logistics & -1: Somewhat oppose & 0.08 & 0.02 & 23 \\
\hline Logistics & 0: Neither support nor oppose & 0.36 & 0.03 & 102 \\
\hline Logistics & 1: Somewhat support & 0.24 & 0.03 & 68 \\
\hline Logistics & 2: Strongly support & 0.20 & 0.02 & 55 \\
\hline Logistics & Missing & 0.00 & 0.00 & 1 \\
\hline Logistics & I don't know & 0.05 & 0.01 & 15 \\
\hline
\end{tabular}


Table S24: Attitudes toward researchers working on military applications of AI (mean response by demographic subgroup). Respondents were asked to indicate their level of support for two of the three randomly presented military applications (lethal autonomous weapons, surveillance, and logistics) on a five-point scale from -2 to 2: -2 = strongly oppose, $-1=$ somewhat oppose, 0 = neither support nor oppose, 1 = somewhat support, 2 = strongly support. There was also an "I don't know" option. Each military application was defined when it was presented (see the Text of the Survey section for the definition). The table presents the proportion of respondents that indicated each level of response or answered "I don't know", along with the associated standard error and raw frequency, by military application and demographic subgroup. The proportion of missing responses is also presented.

\begin{tabular}{|c|c|c|c|c|c|}
\hline Military application type & Mean & $S E$ & $N$ & $\begin{array}{l}\text { Demographic } \\
\text { subgroup }\end{array}$ & $\begin{array}{l}\text { Demographic } \\
\text { subgroup type }\end{array}$ \\
\hline Lethal autonomous weapons & -1.30 & 0.06 & 306 & $\begin{array}{ll}\text { All } & \text { respon- } \\
\text { dents } & \end{array}$ & $\begin{array}{ll}\text { All respon- } \\
\text { dents }\end{array}$ \\
\hline Surveillance & -0.27 & 0.07 & 289 & $\begin{array}{ll}\text { All respon- } \\
\text { dents }\end{array}$ & $\begin{array}{ll}\text { All respon- } \\
\text { dents }\end{array}$ \\
\hline Logistics & 0.46 & 0.06 & 281 & $\begin{array}{ll}\text { All respon- } \\
\text { dents }\end{array}$ & $\begin{array}{ll}\text { All respon- } \\
\text { dents }\end{array}$ \\
\hline Lethal autonomous weapons & -1.24 & 0.13 & 65 & US & $\begin{array}{l}\text { Undergraduate } \\
\text { country }\end{array}$ \\
\hline Survei & $\begin{array}{c}-0.34 \\
\end{array}$ & 0.14 & 65 & US & $\begin{array}{l}\text { Undergraduate } \\
\text { country }\end{array}$ \\
\hline Logistics & 0.77 & 0.13 & 68 & US & $\begin{array}{l}\text { Undergraduate } \\
\text { country }\end{array}$ \\
\hline Lethal autonomous r & -0.89 & 0.19 & 41 & China & $\begin{array}{l}\text { Undergraduate } \\
\text { country }\end{array}$ \\
\hline Surve & 0.21 & 0.20 & 43 & China & $\begin{array}{l}\text { Undergraduate } \\
\text { country }\end{array}$ \\
\hline Logistics & 0.38 & 0.13 & 40 & China & $\begin{array}{l}\text { Undergraduate } \\
\text { country }\end{array}$ \\
\hline Lethal & -1.46 & 0.09 & 83 & Europe & $\begin{array}{l}\text { Undergraduate } \\
\text { region }\end{array}$ \\
\hline Surveillanc & -0.52 & 0.14 & 67 & Europe & $\begin{array}{l}\text { Undergraduate } \\
\text { region }\end{array}$ \\
\hline Logistics & 0.22 & 0.15 & 62 & Europe & $\begin{array}{l}\text { Undergraduate } \\
\text { region }\end{array}$ \\
\hline Lethal autonomous weapons & -1.30 & 0.12 & 71 & North America & $\begin{array}{l}\text { Undergraduate } \\
\text { region }\end{array}$ \\
\hline Surveillance & -0.41 & 0.13 & 73 & North America & $\begin{array}{l}\text { Undergraduate } \\
\text { region }\end{array}$ \\
\hline Logistics & 0.71 & 0.12 & 78 & North America & $\begin{array}{l}\text { Undergraduate } \\
\text { region }\end{array}$ \\
\hline Lethal a & -1.13 & 0.11 & 101 & Asia & $\begin{array}{l}\text { Undergraduate } \\
\text { region }\end{array}$ \\
\hline
\end{tabular}




\begin{tabular}{|l|l|l|l|l|l|}
\hline Surveillance & -0.03 & 0.13 & 101 & Asia & $\begin{array}{l}\text { Undergraduate } \\
\text { region }\end{array}$ \\
\hline Logistics & 0.53 & 0.09 & 92 & Asia & $\begin{array}{l}\text { Undergraduate } \\
\text { region }\end{array}$ \\
\hline Lethal autonomous weapons & -1.31 & 0.06 & 234 & Academic & $\begin{array}{l}\text { Workplace } \\
\text { type }\end{array}$ \\
\hline Surveillance & -0.19 & 0.08 & 216 & Academic & $\begin{array}{l}\text { Workplace } \\
\text { type }\end{array}$ \\
\hline Logistics & 0.48 & 0.07 & 204 & Academic & $\begin{array}{l}\text { Workplace } \\
\text { type }\end{array}$ \\
\hline Lethal autonomous weapons & -1.29 & 0.11 & 82 & Industry & $\begin{array}{l}\text { Workplace } \\
\text { type }\end{array}$ \\
\hline Surveillance & -0.54 & 0.14 & 77 & Industry & $\begin{array}{l}\text { Workplace } \\
\text { type }\end{array}$ \\
\hline Logistics & 0.47 & 0.12 & 81 & Industry & $\begin{array}{l}\text { Workplace } \\
\text { type }\end{array}$ \\
\hline
\end{tabular}

Table S25: Support for collective action against research into military applications of AI: distribution of responses. The table presents the proportion and number of respondents who oppose others working on the different military applications of AI (lethal autonomous weapons, logistics, and surveillance) and who were asked about each application in the survey, broken down by type of collective action

\begin{tabular}{|l|l|l|l|l|l|}
\hline $\begin{array}{l}\text { Military } \\
\text { application } \\
\text { type }\end{array}$ & Collective action & $\begin{array}{l}\text { Proportion } \\
\text { of respon- } \\
\text { dents who } \\
\text { oppose } \\
\text { others work- } \\
\text { ing on the } \\
\text { application }\end{array}$ & $\begin{array}{l}\text { Proportion } \\
\text { of all respon- } \\
\text { dents who } \\
\text { were asked } \\
\text { about the } \\
\text { application }\end{array}$ & $\begin{array}{l}\text { Number of } \\
\text { respondents } \\
\text { who oppose } \\
\text { others work- } \\
\text { ing on the } \\
\text { application }\end{array}$ & $\begin{array}{l}\text { Number } \\
\text { of respon- } \\
\text { dents asked } \\
\text { about the } \\
\text { application }\end{array}$ \\
\hline $\begin{array}{l}\text { Lethal } \\
\text { autonomous } \\
\text { weapons }\end{array}$ & Nothing & 0.01 & - & 225 & 306 \\
\hline $\begin{array}{l}\text { Lethal } \\
\text { autonomous } \\
\text { weapons }\end{array}$ & $\begin{array}{l}\text { Actively avoid working } \\
\text { on the project }\end{array}$ & 0.75 & 0.55 & 225 & 306 \\
\hline $\begin{array}{l}\text { Lethal } \\
\text { autonomous } \\
\text { weapons }\end{array}$ & $\begin{array}{l}\text { Expressing your con- } \\
\text { cern to a superior in } \\
\text { your organization in- } \\
\text { volved in the decision }\end{array}$ & 0.69 & 0.51 & 225 & 306 \\
\hline $\begin{array}{l}\text { Lethal } \\
\text { autonomous } \\
\text { weapons }\end{array}$ & $\begin{array}{l}\text { Sign a petition against } \\
\text { the decision }\end{array}$ & 0.61 & 0.45 & 225 & 306 \\
\hline $\begin{array}{l}\text { Lethal } \\
\text { autonomous } \\
\text { weapons }\end{array}$ & $\begin{array}{l}\text { Participate in a public } \\
\text { protest }\end{array}$ & 0.40 & 0.29 & 225 & 306 \\
\hline
\end{tabular}




\begin{tabular}{|c|c|c|c|c|c|}
\hline $\begin{array}{l}\text { Lethal } \\
\text { autonomous } \\
\text { weapons }\end{array}$ & $\begin{array}{l}\text { Speak out against the } \\
\text { decision anonymously } \\
\text { to the media or online }\end{array}$ & 0.34 & 0.25 & 225 & 306 \\
\hline $\begin{array}{l}\text { Lethal } \\
\text { autonomous } \\
\text { weapons }\end{array}$ & $\begin{array}{l}\text { Speak out against the } \\
\text { decision publicly to the } \\
\text { media or online }\end{array}$ & 0.34 & 0.25 & 225 & 306 \\
\hline $\begin{array}{l}\text { Lethal } \\
\text { autonomous } \\
\text { weapons }\end{array}$ & $\begin{array}{l}\text { Resign or threaten to } \\
\text { resign from your job }\end{array}$ & 0.42 & 0.31 & 225 & 306 \\
\hline Logistics & Nothing & 0.07 & - & 40 & 281 \\
\hline Logistics & $\begin{array}{l}\text { Actively avoid working } \\
\text { on the project }\end{array}$ & 0.72 & 0.10 & 40 & 281 \\
\hline Logistics & $\begin{array}{l}\text { Expressing your con- } \\
\text { cern to a superior in } \\
\text { your organization in- } \\
\text { volved in the decision }\end{array}$ & 0.62 & 0.09 & 40 & 281 \\
\hline Logistics & $\begin{array}{l}\text { Sign a petition against } \\
\text { the decision }\end{array}$ & 0.52 & 0.07 & 40 & 281 \\
\hline Logistics & $\begin{array}{l}\text { Participate in a public } \\
\text { protest }\end{array}$ & 0.22 & 0.03 & 40 & 281 \\
\hline Logistics & $\begin{array}{l}\text { Speak out against the } \\
\text { decision anonymously } \\
\text { to the media or online }\end{array}$ & 0.25 & 0.04 & 40 & 281 \\
\hline Logistics & $\begin{array}{l}\text { Speak out against the } \\
\text { decision publicly to the } \\
\text { media or online }\end{array}$ & 0.22 & 0.03 & 40 & 281 \\
\hline Logistics & $\begin{array}{l}\text { Resign or threaten to } \\
\text { resign from your job }\end{array}$ & 0.18 & 0.02 & 40 & 281 \\
\hline Surveillance & Nothing & 0.03 & - & 115 & 289 \\
\hline Surveillance & $\begin{array}{l}\text { Actively avoid working } \\
\text { on the project }\end{array}$ & 0.74 & 0.29 & 115 & 289 \\
\hline Surveillance & $\begin{array}{l}\text { Expressing your con- } \\
\text { cern to a superior in } \\
\text { your organization in- } \\
\text { volved in the decision }\end{array}$ & 0.72 & 0.29 & 115 & 289 \\
\hline Surveillance & $\begin{array}{l}\text { Sign a petition against } \\
\text { the decision }\end{array}$ & 0.62 & 0.25 & 115 & 289 \\
\hline Surveillance & $\begin{array}{l}\text { Participate in a public } \\
\text { protest }\end{array}$ & 0.34 & 0.13 & 115 & 289 \\
\hline Surveillance & $\begin{array}{l}\text { Speak out against the } \\
\text { decision anonymously } \\
\text { to the media or online }\end{array}$ & 0.33 & 0.13 & 115 & 289 \\
\hline Surveillance & $\begin{array}{l}\text { Speak out against the } \\
\text { decision publicly to the } \\
\text { media or online }\end{array}$ & 0.36 & 0.14 & 115 & 289 \\
\hline
\end{tabular}




\begin{tabular}{|l|l|l|l|l|l|}
\hline Surveillance & $\begin{array}{l}\text { Resign or threaten to } \\
\text { resign from your job }\end{array}$ & 0.27 & 0.11 & 115 & 289 \\
\hline
\end{tabular}

Table S26: Attitudes toward Google not renewing its Project Maven contract. Respondents were presented with a short description of the employees' reactions to Google's Project Maven and the following non-renewal of the contract (see the Text of the Survey section for the description) and were asked to indicate their support for the non-renewal decision on a five-point scale from - 2 to 2. There was also an "I don't know" option. The table presents the proportion of respondents choosing each option and who did not respond to the question, along with the associated standard error and raw frequency.

\begin{tabular}{|l|l|l|l|}
\hline Response & Proportion & $S E$ & Frequency \\
\hline -2: Strongly oppose & 0.03 & 0.01 & 15 \\
\hline 1: Somewhat oppose & 0.06 & 0.01 & 28 \\
\hline 0: Neither support nor oppose & 0.23 & 0.02 & 102 \\
\hline 1: Somewhat support & 0.21 & 0.02 & 96 \\
\hline 2: Strongly support & 0.38 & 0.02 & 171 \\
\hline Missing & 0.05 & 0.01 & 23 \\
\hline I don't know & 0.04 & 0.01 & 18 \\
\hline
\end{tabular}

Table S27: Correlation between support for researchers working on lethal autonomous weapons and support for Google not renewing its Project Maven contract. In both models, the outcome variable is support for Google not renewing its Project Maven contract. Model 1 looks at the bivariate relationship between these two variables. Model 2 includes demographic variables as controls, including gender (female/other, male, and prefer not to say or missing response), location of undergraduate education (Europe, US, Asia, other, and missing response), location of work (Europe, US, Asia, and other), and type of workplace (industry, academic, and other). The (arbitrarily chosen) reference categories, the ones that are excluded from the list of coefficients, are female/other for gender, other for workplace type, and Asia for location of undergraduate education and place of work/study. The Holm method was used to control the family-wise error rate.

\section{Coefficient $(S E)$}

$(1)$

(Intercept)

Support for researchers working on lethal autonomous weapons

Gender: male

Gender: prefer not to say/NA

Place of undergraduate degree: Europe

\section{$0.388^{* *}$}

$-0.469^{* * *}$

\subsection{4}

$(0.472)$

$-0.129$ 
Place of undergraduate degree: missing

$(0.277)$

Place of undergraduate degree: other

0.246

(0.241)

Place of undergraduate degree: US

Place of work: Europe

Place of work: Europe

0.736

(0.451)

Place of work: missing

0.393

(0.647)

Place of work: other

Place of work: US

Job: industry

Job: academic

\begin{tabular}{lll}
\hline$N$ & 306 & 306 \\
$F$-Statistic & $49.41^{* * *}(d f=1 ; 304)$ & $10.36^{* * *}(d f=13 ; 292)$ \\
\hline
\end{tabular}

${ }^{*} \mathrm{p}<.05 ;{ }^{* *} \mathrm{p}<.01 ;{ }^{* * *} \mathrm{p}<.001$

\section{PublicATion NORMS}

Table S28: Responses to statement on pre-publication review. After seeing a definition of "prepublication review" (see the Text of the Survey section for the definition), respondents were asked to indicate their level of agreement with the statement: "Machine learning research institutions (including firms, governments, and universities) should practice pre-publication review." The respondents could choose responses from a four-point scale. There was also an "I don't know" option. The table presents the proportion of respondents who indicated each option or had a missing response, along with the associated standard error and raw frequency.

\begin{tabular}{|l|l|l|l|}
\hline Response & Proportion & $S E$ & Frequency \\
\hline -2: Strongly disagree & 0.14 & 0.02 & 54 \\
\hline -1: Somewhat disagree & 0.19 & 0.02 & 72 \\
\hline 1: Somewhat agree & 0.39 & 0.03 & 147 \\
\hline 2: Strongly agree & 0.20 & 0.02 & 76 \\
\hline Missing & 0.00 & 0.00 & 0 \\
\hline I don't know & 0.06 & 0.01 & 24 \\
\hline
\end{tabular}


Table S29: Sharing aspects of research (by demographic subgroup). Respondents were presented with three aspects of research randomly chosen from a list of six. For each aspect of research, they selected from six levels of openness $(0=i t$ doesn't matter; $1=i t$ 's completely up to the researchers to share or not to share; $2=i t$ 's preferred that researchers share but it's not paramount that they do; $3=$ researchers are encouraged to share; $4=$ researchers need a very strong reason not to share; $5=i t$ must be shared every time). The table presents the mean response for each aspect of research by demographic subgroup, along with the associated standard error and sample size.

\begin{tabular}{|c|c|c|c|c|c|}
\hline Aspect of research & Mean & $S E$ & $N$ & $\begin{array}{l}\text { Demographic } \\
\text { subgroup }\end{array}$ & $\begin{array}{l}\text { Demographic } \\
\text { subgroup type }\end{array}$ \\
\hline $\begin{array}{l}\text { High-level description } \\
\text { methods }\end{array}$ & 4.81 & 0.04 & 172 & All respondents & All \\
\hline $\begin{array}{l}\text { Detailed description of meth- } \\
\text { ods }\end{array}$ & 4.52 & 0.06 & 161 & All respondents & All \\
\hline Results & 4.63 & 0.06 & 174 & All respondents & All \\
\hline Code & 3.74 & 0.08 & 143 & All respondents & All \\
\hline Training data & 3.54 & 0.08 & 173 & All respondents & All \\
\hline Trained model & 3.46 & 0.10 & 143 & All respondents & All \\
\hline Algorithm(s) & 4.30 & 0.07 & 153 & All respondents & All \\
\hline $\begin{array}{l}\text { High-level description } \\
\text { methods }\end{array}$ & 4.80 & 0.07 & 42 & US & $\begin{array}{l}\text { Undergraduate } \\
\text { country }\end{array}$ \\
\hline $\begin{array}{l}\text { Detailed description of meth- } \\
\text { ods }\end{array}$ & 4.46 & 0.12 & 42 & US & $\begin{array}{l}\text { Undergraduate } \\
\text { country }\end{array}$ \\
\hline Results & 4.52 & 0.13 & 38 & US & $\begin{array}{l}\text { Undergraduate } \\
\text { country }\end{array}$ \\
\hline Code & 3.40 & 0.15 & 35 & US & $\begin{array}{l}\text { Undergraduate } \\
\text { country }\end{array}$ \\
\hline Training data & 3.30 & 0.15 & 46 & US & $\begin{array}{l}\text { Undergraduate } \\
\text { country }\end{array}$ \\
\hline Trained model & 3.25 & 0.18 & 30 & US & $\begin{array}{l}\text { Undergraduate } \\
\text { country }\end{array}$ \\
\hline Algorithm(s) & 4.37 & 0.15 & 31 & US & $\begin{array}{l}\text { Undergraduate } \\
\text { country }\end{array}$ \\
\hline $\begin{array}{l}\text { High-level description } \\
\text { methods }\end{array}$ & 4.79 & 0.12 & 19 & China & $\begin{array}{l}\text { Undergraduate } \\
\text { country }\end{array}$ \\
\hline $\begin{array}{l}\text { Detailed description of meth- } \\
\text { ods }\end{array}$ & 4.38 & 0.19 & 21 & China & $\begin{array}{l}\text { Undergraduate } \\
\text { country }\end{array}$ \\
\hline Results & 4.62 & 0.13 & 21 & China & $\begin{array}{l}\text { Undergraduate } \\
\text { country }\end{array}$ \\
\hline Code & 3.72 & 0.21 & 25 & China & $\begin{array}{l}\text { Undergraduate } \\
\text { country }\end{array}$ \\
\hline Training data & 3.36 & 0.25 & 25 & China & $\begin{array}{l}\text { Undergraduate } \\
\text { country }\end{array}$ \\
\hline Trained model & 3.67 & 0.29 & 18 & China & $\begin{array}{l}\text { Undergraduate } \\
\text { country }\end{array}$ \\
\hline
\end{tabular}




\begin{tabular}{|c|c|c|c|c|c|}
\hline Algorithm(s) & 4.08 & 0.22 & 24 & China & $\begin{array}{l}\text { Undergraduate } \\
\text { country }\end{array}$ \\
\hline $\begin{array}{l}\text { High-level description of } \\
\text { methods }\end{array}$ & 4.86 & 0.06 & 42 & Europe & $\begin{array}{l}\text { Undergraduate } \\
\text { region }\end{array}$ \\
\hline $\begin{array}{l}\text { Detailed description of meth- } \\
\text { ods }\end{array}$ & 4.62 & 0.12 & 37 & Europe & $\begin{array}{l}\text { Undergraduate } \\
\text { region }\end{array}$ \\
\hline Results & 4.85 & 0.06 & 53 & Europe & $\begin{array}{l}\text { Undergraduate } \\
\text { region }\end{array}$ \\
\hline Code & 3.94 & 0.17 & 33 & Europe & $\begin{array}{l}\text { Undergraduate } \\
\text { region }\end{array}$ \\
\hline Training data & 3.67 & 0.17 & 33 & Europe & $\begin{array}{l}\text { Undergraduate } \\
\text { region }\end{array}$ \\
\hline Trained model & 3.29 & 0.20 & 41 & Europe & $\begin{array}{l}\text { Undergraduate } \\
\text { region }\end{array}$ \\
\hline Algorithm(s) & 4.38 & 0.15 & 34 & Europe & $\begin{array}{l}\text { Undergraduate } \\
\text { region }\end{array}$ \\
\hline $\begin{array}{l}\text { High-level description of } \\
\text { methods }\end{array}$ & 4.81 & 0.07 & 44 & North America & $\begin{array}{l}\text { Undergraduate } \\
\text { region }\end{array}$ \\
\hline $\begin{array}{l}\text { Detailed description of meth- } \\
\text { ods }\end{array}$ & 4.52 & 0.11 & 47 & North America & $\begin{array}{l}\text { Undergraduate } \\
\text { region }\end{array}$ \\
\hline Results & 4.58 & 0.11 & 44 & North America & $\begin{array}{l}\text { Undergraduate } \\
\text { region }\end{array}$ \\
\hline Code & 3.40 & 0.16 & 40 & North America & $\begin{array}{l}\text { Undergraduate } \\
\text { region }\end{array}$ \\
\hline Training data & 3.45 & 0.14 & 53 & North America & $\begin{array}{l}\text { Undergraduate } \\
\text { region }\end{array}$ \\
\hline Trained model & 3.16 & 0.18 & 34 & North America & $\begin{array}{l}\text { Undergraduate } \\
\text { region }\end{array}$ \\
\hline Algorithm(s) & 4.39 & 0.14 & 35 & North America & $\begin{array}{l}\text { Undergraduate } \\
\text { region }\end{array}$ \\
\hline $\begin{array}{l}\text { High-level description of } \\
\text { methods }\end{array}$ & 4.78 & 0.07 & 55 & Asia & $\begin{array}{l}\text { Undergraduate } \\
\text { region }\end{array}$ \\
\hline $\begin{array}{l}\text { Detailed description of meth- } \\
\text { ods }\end{array}$ & 4.45 & 0.11 & 51 & Asia & $\begin{array}{l}\text { Undergraduate } \\
\text { region }\end{array}$ \\
\hline Results & 4.59 & 0.11 & 51 & Asia & $\begin{array}{l}\text { Undergraduate } \\
\text { region }\end{array}$ \\
\hline Code & 3.92 & 0.15 & 50 & Asia & $\begin{array}{l}\text { Undergraduate } \\
\text { region }\end{array}$ \\
\hline Training data & 3.61 & 0.15 & 57 & Asia & $\begin{array}{l}\text { Undergraduate } \\
\text { region }\end{array}$ \\
\hline Trained model & 4.04 & 0.15 & 45 & Asia & $\begin{array}{l}\text { Undergraduate } \\
\text { region }\end{array}$ \\
\hline
\end{tabular}




\begin{tabular}{|l|l|l|l|l|l|}
\hline Algorithm(s) & 4.25 & 0.13 & 51 & Asia & $\begin{array}{l}\text { Undergraduate } \\
\text { region }\end{array}$ \\
\hline $\begin{array}{l}\text { High-level description of } \\
\text { methods }\end{array}$ & 4.81 & 0.04 & 135 & Academic & Workplace type \\
\hline $\begin{array}{l}\text { Detailed description of meth- } \\
\text { ods }\end{array}$ & 4.47 & 0.08 & 115 & Academic & Workplace type \\
\hline Results & 4.63 & 0.07 & 129 & Academic & Workplace type \\
\hline Code & 3.77 & 0.10 & 103 & Academic & Workplace type \\
\hline Training data & 3.60 & 0.09 & 131 & Academic & Workplace type \\
\hline Trained model & 3.54 & 0.12 & 107 & Academic & Workplace type \\
\hline Algorithm(s) & 4.35 & 0.08 & 111 & Academic & Workplace type \\
\hline $\begin{array}{l}\text { High-level description } \\
\text { methods }\end{array}$ & 4.80 & 0.08 & 44 & Industry & Workplace type \\
\hline $\begin{array}{l}\text { Detailed description of meth- } \\
\text { ods }\end{array}$ & 4.53 & 0.11 & 51 & Industry & Workplace type \\
\hline Results & 4.65 & 0.11 & 48 & Industry & Workplace type \\
\hline Code & 3.61 & 0.14 & 46 & Industry & Workplace type \\
\hline Training data & 3.28 & 0.14 & 46 & Industry & Workplace type \\
\hline Trained model & 3.05 & 0.20 & 42 & Industry & Workplace type \\
\hline Algorithm(s) & 4.06 & 0.16 & 47 & Industry & Workplace type \\
\hline
\end{tabular}

Table S30: Correlation between responses to the AI safety questions and support for pre-publication review. For all three models, the outcome variable is support for pre-publication review. Model 1 shows the bivariate relationship between familiarity with AI safety and support for pre-publication review. Model 2 shows the bivariate relationship between how much respondents thought AI safety research should be prioritized and support for pre-publication review. Model 3 includes responses to both AI safety questions as predictor variables. The Holm method was used to control the family-wise error rate.

\section{Coefficient $(S E)$}

(1)

(Intercept)

$0.403^{* * *}$

(0.083)

Familiarity with AI safety

$0.153^{* *}$

$(0.045)$

How much AI safety must be proritized

\begin{tabular}{|c|c|c|c|}
\hline & & $(0.086)$ & $(0.086)$ \\
\hline $\bar{N}$ & 257 & 257 & 257 \\
\hline$F$-Statistic & $\begin{array}{l}11.29^{* *} \\
1 ; 255)\end{array}(d f=$ & $\begin{array}{l}8.831^{* *} \\
1 ; 255)\end{array}(d f=$ & $\begin{array}{l}18.48^{* * *} \\
=2 ; 254)\end{array} \quad(d f$ \\
\hline
\end{tabular}

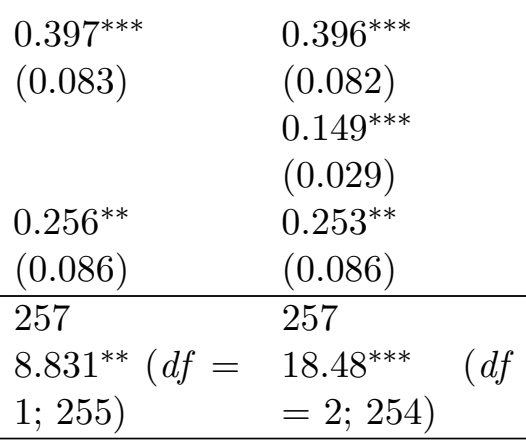

${ }^{*} \mathrm{p}<.05 ;{ }^{* *} \mathrm{p}<.01 ;{ }^{* * *} \mathrm{p}<.001$ 
Table S31: Correlation between responses to the AI safety questions and how openly respondents think aspects of research should be shared. For all three models, the outcome variable is mean level of openness averaged across the three aspects of research respondents were randomly presented with. Model 1 shows the bivariate relationship between familiarity with AI safety and how openly respondents think aspects of research should be shared. Model 2 shows the bivariate relationship between how much respondents thought AI safety research should be prioritized and how openly respondents think aspects of research should be shared. Model 3 includes responses to both AI safety questions as predictor variables. The Holm method was used to control the family-wise error rate.

Coefficient $(S E)$

(1)

(Intercept)

Familiarity with AI safety

How much AI safety must be prioritized
(2)

$4.188^{* * *}$

$(0.043)$

$-0.044$

$(0.030)$

\section{$4.187^{* * *}$}

(0.043)

0.021

(0.041)

256

$2.101(d f=$

$1 ; 254)$

256

$F$-Statistic

${ }^{*} \mathrm{p}<.05 ;{ }^{* *} \mathrm{p}<.01 ;{ }^{* * *} \mathrm{p}<.001$

\section{References}

Ada Lovelace Institute (2019). Beyond face value: public attitudes to facial recognition technology. Tech. rep., Ada Lovelace Institute.

Adler, E. (1992). The emergence of cooperation: national epistemic communities and the international evolution of the idea of nuclear arms control. International Organization, 46(1), 101-145.

Aiken, C., Dunham, J., \& Zwetsloot, R. (2020a). Immigration pathways and plans of AI talent. Tech. rep., Center for Security and Emerging Technology.

Aiken, C., Kagan, R., \& Page, M. (2020b). "Cool projects" or "expanding the efficiency of the murderous American war machine?": AI professionals' views on working with the Department of Defense. Tech. rep., Center for Security and Emerging Technology.

Amodei, D., Olah, C., Steinhardt, J., Christiano, P., Schulman, J., \& Mané, D. (2016). Concrete problems in AI safety. CoRR, abs/1606.06565.

Anderson, J., Rainie, L., \& Luchsinger, A. (2018). Artificial intelligence and the future of humans. Tech. rep., Pew Research Center.

Ashurst, C., Anderljung, M., Prunkl, C., Leike, J., Gal, Y., Shevlane, T., \& Dafoe, A. (2020). A guide to writing the NeurIPS impact statement. Centre for the Governance of AI. URL: https://perma.cc/B5R8-2B9V?type=image. Accessed: 12 Aug. 2020. 
Balaram, B., Greenham, T., \& Leonard, J. (2018). Artificial Intelligence: real public engagement. Tech. rep., RSA.

Barocas, S., Hardt, M., \& Narayanan, A. (2019). Fairness and Machine Learning. fairmlbook.org. http://www.fairmlbook.org.

Baum, S. D., Goertzel, B., \& Goertzel, T. G. (2011). How long until human-level AI? Results from an expert assessment. Technological Forecasting 85 Social Change, 78, $185-195$.

Belfield, H. (2020). Activism by the AI community: analysing recent achievements and future prospects. In Proceedings of the AAAI/ACM Conference on AI, Ethics, and Society, AIES '20, p. 15-21, New York, NY, USA. Association for Computing Machinery.

Brundage, M., Avin, S., Clark, J., Toner, H., Eckersley, P., Garfinkel, B., Dafoe, A., Scharre, P., Zeitzoff, T., Steinhardt, J., Flynn, C., Ó hÉigeartaigh, S., Beard, S., Belfield, H., Farquhar, S., Lyle, C., Crootof, R., Evans, O., Page, M., Bryson, J., Yampolskiy, R., \& Amodei, D. (2018). The malicious use of artificial intelligence: Forecasting, prevention, and mitigation. Tech. rep., Future of Humanity Institute and University of Oxford and Centre for the Study of Existential Risk and University of Cambridge and Center for a New American Security and Electronic Frontier Foundation and OpenAI.

Butcher, J., \& Beridze, I. (2019). What is the state of artificial intelligence governance globally?. The Rusi Journal, 164(5-6), 88-96.

Cave, S., Coughlan, K., \& Dihal, K. (2019). Scary robots: Examining public responses to AI. In Proceedings of the 2019 AAAI/ACM Conference on AI, Ethics, and Society, pp. 331-337. ACM.

Dafoe, A. (2018). AI Governance: A Research Agenda. Tech. rep., Centre for the Governance of AI, Future of Humanity Institute, University of Oxford.

Deahl, D. (2018). Google employees demand the company pull out of Pentagon AI project. The Verge. URL: https://www.theverge.com/2018/4/4/17199818/google-pentagonproject-maven-pull-out-letter-ceo-sundar-pichai. Accessed: 12 Nov. 2020.

Eurobarometer (2017). Special Eurobarometer 460: Attitudes towards the impact of digitisation and automation on daily life. Tech. rep., Eurobarometer.

Eurobarometer (2019). Standard Eurobarometer 92: Autumn 2019 Europeans and artificial intelligence. Tech. rep., Eurobarometer.

European Commission (2020). Open public consultation on the European White Paper on Artificial Intelligence: Summary Report on the open public consultation on the White Paper on Artificial Intelligence. Tech. rep., European Commission.

Fjeld, J., Achten, N., Hilligoss, H., Nagy, A., \& Srikumar, M. (2020). Principled artificial intelligence: Mapping consensus in ethical and rights-based approaches to principles for AI. Tech. rep., Berkman Klein Center for Internet \& Society.

G20 (2019). G20 ministerial statement on trade and digital economy. Tech. rep., G20. 
Grace, K., Salvatier, J., Dafoe, A., Zhang, B., \& Evans, O. (2018). When will AI exceed human performance? Evidence from AI experts. Journal of Artificial Intelligence Research, 62, 729-754.

Gruetzemacher, R., Paradice, D., \& Lee, K. B. (2020). Forecasting extreme labor displacement: A survey of AI practitioners. Technological Forecasting and Social Change, 161. 120323.

Haas, P. M. (1992a). Banning chlorofluorocarbons: epistemic community efforts to protect stratospheric ozone. International Organization, 46(1), 187-224.

Haas, P. (1992b). Introduction: epistemic communities and international policy coordination.. International Organization, 46(1), 1-35.

Hoff, K., \& Bashir, M. (2015). Trust in automation: Integrating empirical evidence on factors that influence trust. Human Factors The Journal of the Human Factors and Ergonomics Society, 57, 407-434.

Horowitz, M. C. (2016). Public opinion and the politics of the killer robots debate. Research 6 Politics, 3(1).

Horowitz, M. C. (2018). Artificial intelligence, international competition, and the balance of power. Texas National Security Review, $1(3)$.

Horowitz, M. C. (2019). When speed kills: Lethal autonomous weapon systems, deterrence and stability. Journal of Strategic Studies, 42(6), 764-788.

Kanaan, M. (2020). T-Minus AI: Humanity's Countdown to Artificial Intelligence and the New Pursuit of Global Power. BenBella Books, Dallas, TX.

Knowles, B., \& Richards, J. T. (2021). The sanction of authority: Promoting public trust in ai. In FAccT '21: Proceedings of the 2021 ACM Conference on Fairness, Accountability, and Transparency, pp. 262-271, New York, NY, USA. Association for Computing Machinery.

Krafft, P. M., Young, M., Katell, M., Huang, K., \& Bugingo, G. (2020). Defining AI in policy versus practice. In Proceedings of the AAAI/ACM Conference on AI, Ethics, and Society, AIES '20, p. 72-78, New York, NY, USA. Association for Computing Machinery.

Lankton, N. K., \& McKnight, D. H. (2008). Do people trust facebook as a technology or as a "person"? distinguishing technology trust from interpersonal trust. In Benbasat, I., \& Montazemi, A. R. (Eds.), Learning from the past $\&$ charting the future of the discipline. 14th Americas Conference on Information Systems, AMCIS 2008, Toronto, Ontario, Canada, August 14-17, 2008, p. 375. Association for Information Systems.

Lin, H.-T., Balcan, M.-F., Hadsell, R., \& Ranzato, M. (2020). Getting started with NeurIPS 2020. NeurIPS Blog. URL: https://perma.cc/2WSM-EJXB?type=image. Accessed: 12 Aug. 2020.

Lin, W., \& Green, D. P. (2016). Standard operating procedures: A safety net for pre-analysis plans. PS: Political Science \& Politics, 49(3), 495-500.

Mayer, R. C., Davis, J. H., \& Schoorman, F. D. (1995). An integrative model of organizational trust. The Academy of Management Review, 20(3), 709-734. 
McEvily, B., \& Tortoriello, M. (2011). Measuring trust in organisational research: Review and recommendations. Journal of Trust Research, 1(1), 23-63.

Müller, V. C., \& Bostrom, N. (2016). Future progress in artificial intelligence: A survey of expert opinion. In Müller, V. (Ed.), Fundamental Issues of Artificial Intelligence, pp. 553-571. Springer International Publishing, Cham.

Noble, S. U. (2018). Algorithms of Oppression. NYU Press, New York.

OpenAI LP (2019). OpenAI LP. OpenAI Blog. URL: https://perma.cc/LS3M-SHZ6. Accessed: 11 Mar. 2020.

PytlikZillig, L. M., Hamm, J. A., Shockley, E., Herian, M. N., Neal, T. M., Kimbrough, C. D., Tomkins, A. J., \& Bornstein, B. H. (2016). The dimensionality of trust-relevant constructs in four institutional domains: results from confirmatory factor analyses. Journal of Trust Research, 6(2), 111-150.

Rainie, L., Keeter, S., \& Perrin, A. (2019). Trust and distrust in america. Tech. rep., Pew Research Center.

Russell, S. (2019). Human Compatible: Artificial Intelligence and the Problem of Control. Penguin, New York.

Sandberg, A., \& Bostrom, N. (2011). Machine intelligence survey. Tech. rep., Future of Humanity Institute, Oxford University. Technical Report \#2011-1.

Savage, N. (2020). The race to the top among the world's leaders in artificial intelligence. Nature, 588(7837), S102-S104.

Saxena, N. A., Huang, K., DeFilippis, E., Radanovic, G., Parkes, D. C., \& Liu, Y. (2019). How do fairness definitions fare?: Examining public attitudes towards algorithmic definitions of fairness. In Proceedings of the 2019 AAAI/ACM Conference on AI, Ethics, and Society, AIES '19, pp. 99-106, New York, NY, USA. ACM, Association for Computing Machinery.

Scharre, P. (2018). Army of None: Autonomous Weapons and the Future of War. WW Norton \& Company, New York.

Smith, A. (2018). Public attitudes toward computer algorithms. Tech. rep., Pew Research Center.

Smith, A. (2019). More than half of U.S. adults trust law enforcement to use facial recognition responsibly. Tech. rep., Pew Research Center.

Smith, A., \& Anderson, M. (2016). Automation in everyday life. Tech. rep., Pew Research Center.

Solaiman, I., Clark, J., \& Brundage, M. (2019). GPT-2: 1.5B release. OpenAI Blog. URL: https://perma.cc/PFA8-KTBP. Accessed: 23 Jul. 2020.

The OECD Council on Artificial Intelligence (2019). Recommendation of the council on artificial intelligence. Tech. rep. JT03447952, Organisation for Economic Co-operation and Development.

Wakabayashi, D., \& Shane, S. (2018). Google will not renew Pentagon contract that upset employees. The New York Times. URL: https://perma.cc/KFK2-3F9A. Accessed: 29 Apr. 2020. 
Walsh, T. (2018). Expert and non-expert opinion about technological unemployment. International Journal of Automation and Computing, 15(5), 637-642.

West, D. M. (2018). Brookings survey finds worries over AI impact on jobs and personal privacy, concern U.S. will fall behind China. Tech. rep., The Brookings Institute.

Zhang, B., \& Dafoe, A. (2019). Artificial intelligence: American attitudes and trends. Tech. rep., Centre for the Governance of AI, University of Oxford.

Zhang, B., \& Dafoe, A. (2020). US public opinion on the governance of artificial intelligence. In Proceedings of the AAAI/ACM Conference on AI, Ethics, and Society, AIES '20, p. 187-193, New York, NY, USA. Association for Computing Machinery.

Zhang, D., Mishra, S., Brynjolfsson, E., Etchemendy, J., Ganguli, D., Grosz, B., Lyons, T., Manyika, J., Niebles, J. C., Sellitto, M., Yoav, S., Clark, J., \& Perrault, R. (2021). Artificial Intelligence Index Report 2021. Tech. rep., AI Index Steering Committee, Human-Centered AI Institute, Stanford University, Stanford.

Zwetsloot, R., \& Dafoe, A. (2019). Thinking about risks from AI: Accidents, misuse and structure. Lawfare. URL: https://perma.cc/4J2N-2KYV. Accessed: 23 Sep. 2020.

Zwetsloot, R., Zhang, B., Dreksler, N., Kahn, L., Anderljung, M., Dafoe, A., \& Horowitz, M. C. (2021). Skilled and mobile: Survey evidence of ai researchers' immigration preferences. In Proceedings of the 2021 AAAI/ACM Conference on AI, Ethics, and Society (AIES '21), May 19-21, 2021, Virtual Event, USA. 